\title{
An Experimental Investigation of the Load Distribution of Splined Joints under Gear Loading Conditions
}

\section{THESIS}

Presented in Partial Fulfillment of the Requirements for the Degree Master of Science in the Graduate School of The Ohio State University

\author{
By \\ Michael Alan Benatar \\ Graduate Program in Mechanical Engineering \\ The Ohio State University \\ 2016 \\ Master's Examination Committee: \\ Dr. Ahmet Kahraman, Advisor \\ Dr. Jason Dreyer
}


Copyright by

Michael Alan Benatar

2016 


\begin{abstract}
Splined joints are commonly used to transmit rotary motion from a shaft to machine elements such as gears. While computationally efficient spline load distribution models have recently been proposed, there is no validated model of a spline due to lack of highfidelity experimental data. Accordingly, this study aims to (i) establish an extensive experimental database on load distributions of splined joints subject to gear loading conditions and (ii) assess the accuracy of the spline load distribution model of Hong et al. (2014) through direct comparisons of its predictions to experimental measurements.

On the experimental side, a quasi-static, spline-specific test setup is designed, fabricated, and instrumented. A test matrix covering various loading conditions is executed in order to compile an extensive spline load distribution database. The modeling effort centers around expanding the model of Hong et al. (2014) by adding a new root stress prediction module.
\end{abstract}

The experimental data illustrates the cyclic nature of loads and resultant stresses on spline teeth caused by rotation of the spline teeth in relation to the gear mesh that loads the splined joint. A nonlinear relationship between torque applied and resultant stress is revealed, as well as the relationship between the location of maximum stress along the face width and the amount of lead crown modification applied. Through correlations to 
the experimental results, the model is shown to be accurate; it captures several unique effects of spur and helical gear loading conditions. 


\section{DEDICATION}

Dedicated to my parents and siblings. 


\section{ACKNOWLEDGMENTS}

First, I would like to thank my advisor, Dr. Kahraman, for all of his advice, assistance, and editing help throughout the completion of my thesis. I would also like to thank Dr. David Talbot, Mr. Sam Shon, and Mr. Jonny Harianto for their assistance with the programming and data analysis, design of the test setup and collection of data, incorporation of the root stress module into SplineLDP, and all other assistance they provided me throughout my time in the lab. Additionally, I would like to thank all of the other students in the lab for their support and help. Next, I would like to thank Dr. Dreyer for agreeing to serve on my thesis committee. I would also like to thank the Gear and Power Transmission Research Laboratory Consortium members and other GearLab sponsors for providing the financial support to complete this project. Last, but certainly not least, I would like to thank my family and friends for their support, not only during the completion of this project, but, also, throughout my entire life. 


\title{
VITA
}

\author{
November 16, 1992...................................Born - Columbus, Ohio \\ June 2011 ................................................ \\ Upper Arlington, Ohio \\ December 2014 .........................................S. Mechanical Engineering \\ The Ohio State University \\ January 2015 to present .............................Graduate Research Associate, GearLab \\ The Ohio State University
}

\section{FIELDS OF STUDY}

Major Field: Mechanical Engineering 


\section{TABLE OF CONTENTS}

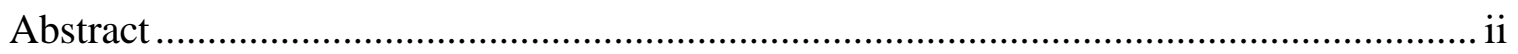

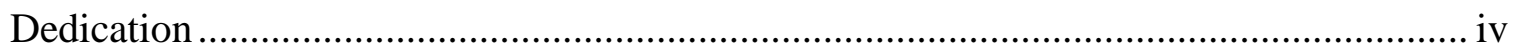

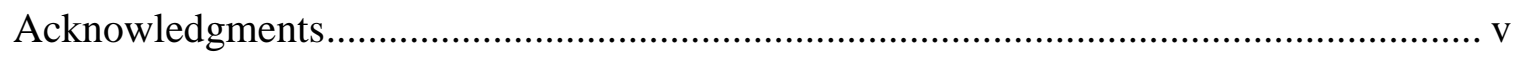

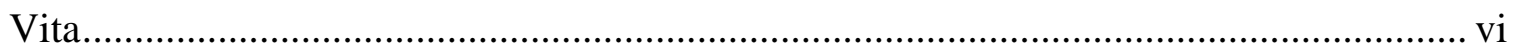

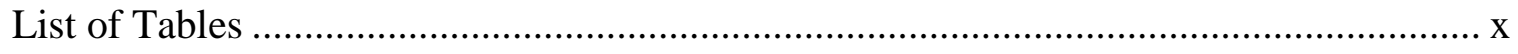

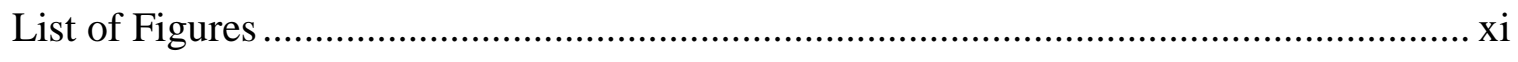

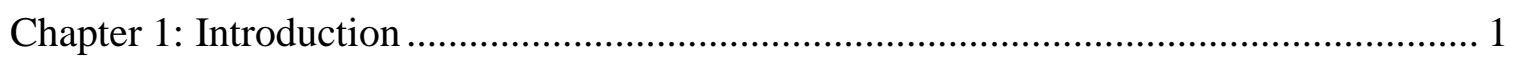

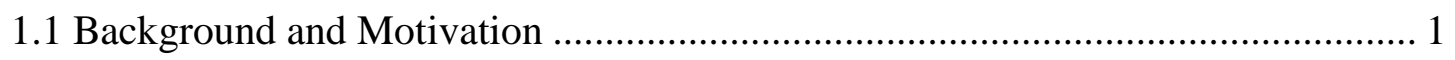

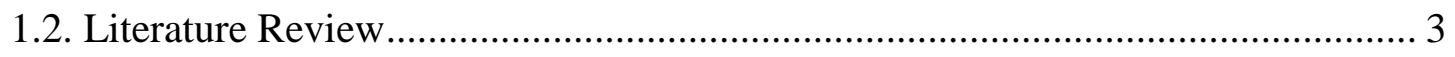

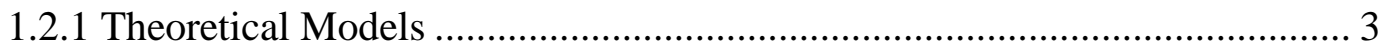

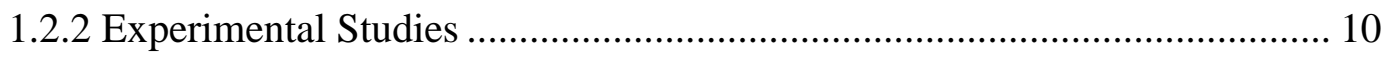

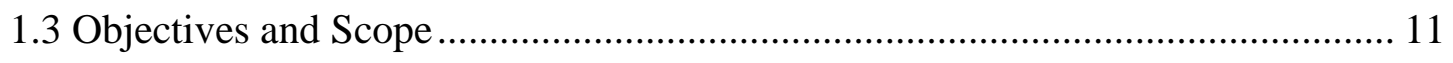

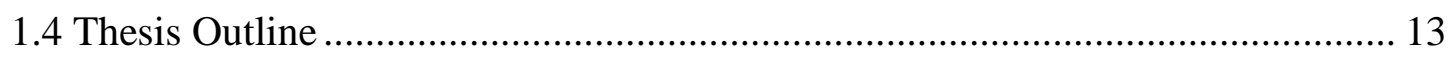

Chapter 2: Test Methodology and Instrumentation ............................................. 15

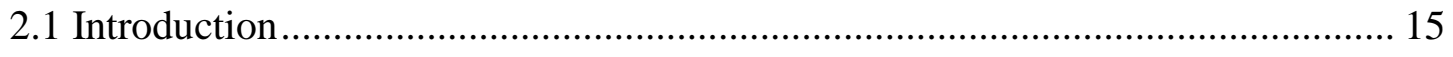




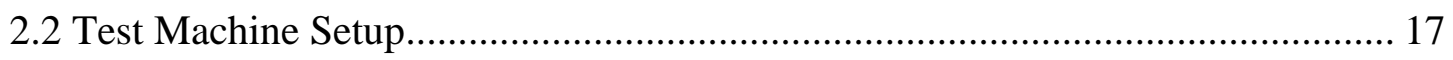

2.2.1 Test Setup Configuration for Gear Loading .............................................. 17

2.2.2 Test Setup Configuration for Single-Tooth Loading .................................... 25

2.3 Test Specimens and Test Matrix...................................................................... 28

2.4 Instrumentation, Data Acquisition, and Analysis ............................................... 33

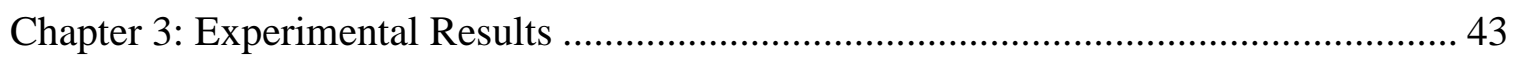

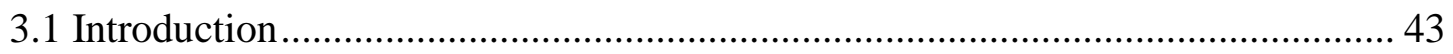

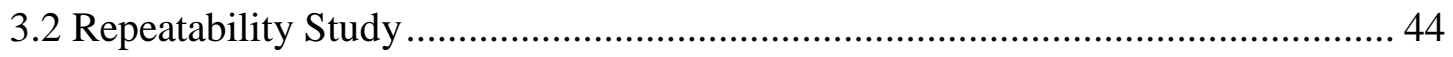

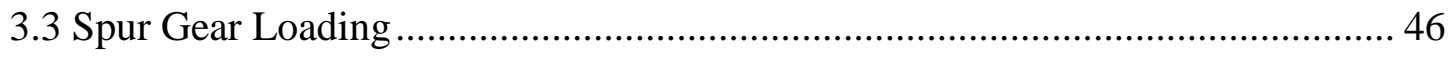

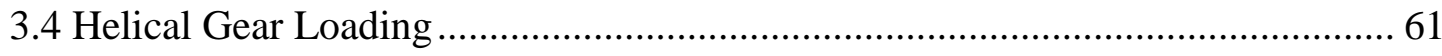

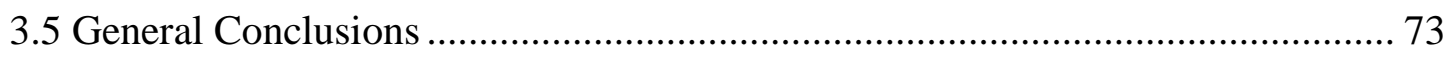

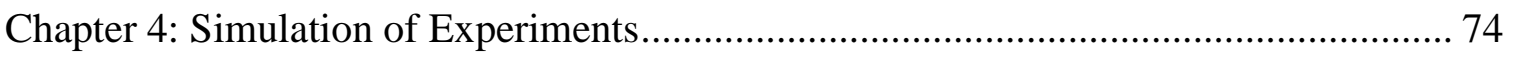

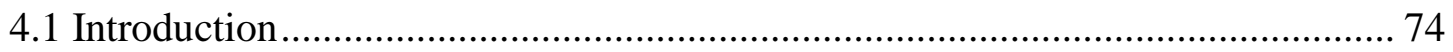

4.2 Development of FE-Based Splined Joint Root Stress Predictions......................... 74

4.3 Validation of FE Splined Joint Root Stress Predictions ...................................... 82

4.4 Comparison of FE Splined Joint Root Stress Predictions to Experimental Results 


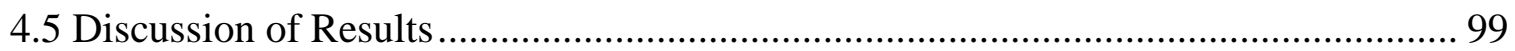

Chapter 5: Conclusion........................................................................................ 101

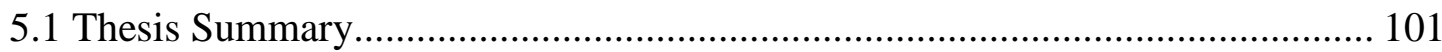

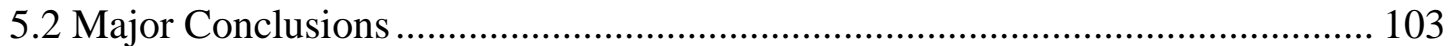

5.3 Recommendations for Future Work............................................................ 105

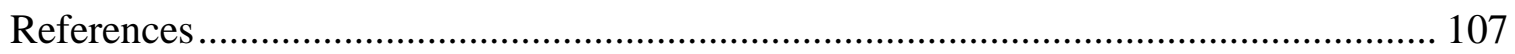

Appendix A: Additional Figures of Experimental Results ....................................... 112 


\section{LIST OF TABLES}

Table 2.1: Basic design parameters of the spline used in this study. (All units are in $\mathrm{mm}$ unless otherwise specified.)

Table 2.2: Design parameters of the gear pairs used to load the splined joint [21, 24, 26, and 27]. (All units are in mm unless otherwise specified.).........................34

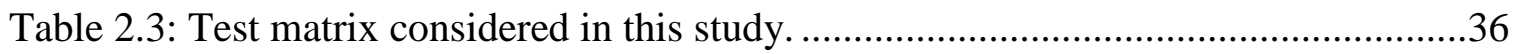




\section{LIST OF FIGURES}

Figure 1.1: Illustrations of (a) clearance-fit (side-fit), (b) major diameter-fit, and (c) minor diameter-fit splines. Adapted from Reference [1].

Figure 1.2: Spline model with (a) pure torsion loading with no radial force and no moment, (b) spur gear loading with both a torque and a radial force, (c) helical gear loading with a torque, radial force, and an overturning moment. Adapted from Reference [7].

Figure 1.3: Definition of the potential contact area of a tooth pair of a clearancefit spline defining start of active profile (SAP) and end of active profile (EAP) for both the internal and external spline components.

Figure 1.4: Example of the predicted load distributions of a nominal spline without index errors under (a) torsional loading, (b) spur gear loading, and (c) helical gear loading [10]. .8

Figure 1.5: Example of the predicted load distributions of the spline of Figure 1.4 with (a) random values of index errors under, (b) torsional loading, (c) spur gear loading, and (d) helical gear loading [11]

Figure 2.1: Experimental test setup used in this study.................................................18

Figure 2.2: Top-view drawing of the test setup. ……….............................................19 
Figure 2.3: Cross-sectional side-views of (a) test shaft assembly and (b) reaction shaft assembly with key components labeled.

Figure 2.4: (a) Instrumented external spline piece, (b) spur and helical gears with internal splines, and (c) mating spur and helical gears of the reaction shaft.

Figure 2.5: Experimental test setup with the loaded torque arm illustrating the torque application process

Figure 2.6: Experimental test setup with the single-tooth point loading configuration. (Upper halves of bearing pedestals are removed for demonstration purposes.)

Figure 2.7: Solid model side-view of single-tooth assembly.....

Figure 2.8: Side-view drawing of (a) the splined joint defined in Table 2.1 and (b) a zoomed in view of the top teeth.

Figure 2.9: Index errors for (a) external spline, (b) internally splined spur gear, and (c) internally splined helical gear after taking the mean and performing FFT.

Figure 2.10: Index error locations for (a) test \#1, (b) test \#2, (c) test \#3, and (d) test \#4.

Figure 2.11: Definition of strain gauge location on an external spline tooth. (All units in mm.) .37

Figure 2.12: Picture of strain gauges mounted on external spline teeth. .39 
Figure 2.13: Example set of raw data from a single tooth loaded at $600 \mathrm{Nm}$.

Figure 3.1: Repeatability of the first instrumented tooth for test \#3 in Table 2.3 at $600 \mathrm{Nm}$ for (a) gauge 1 through (e) gauge 5.

Figure 3.2: Repeatability of the second instrumented tooth for test \#3 in Table 2.3 at $600 \mathrm{Nm}$ for (a) gauge 1 through (e) gauge 5.

Figure 3.3: Definition of rotational position for a spline tooth with the location of the gear mesh specified. .48

Figure 3.4: Variation of stress for a single spline tooth under spur gear loading conditions at $600 \mathrm{Nm}$.

Figure 3.5: Root stress of the first instrumented tooth for test \#1 of Table 2.3 under spur gear loading conditions at (a) $150 \mathrm{Nm}$, (b) $300 \mathrm{Nm}$, (c) 450 $\mathrm{Nm}$, and (d) $600 \mathrm{Nm}$. .52

Figure 3.6: Root stress of the first instrumented tooth for test \#1 of Table 2.3 under spur gear loading at angular positions of a) $30^{\circ}$ (maximum stress position), (b) $70^{\circ}$, (c) $130^{\circ}$, (d) $190^{\circ}$, (e) $250^{\circ}$, and (f) $310^{\circ}$. .54

Figure 3.7: Root stress of the second instrumented tooth for test \#1 of Table 2.3 under spur gear loading conditions at (a) $150 \mathrm{Nm}$, (b) $300 \mathrm{Nm}$, (c) 450 $\mathrm{Nm}$, and (d) $600 \mathrm{Nm}$. 
Figure 3.8: Root stress of the second instrumented tooth for test \#1 of Table 2.3 under spur gear loading at angular positions of a) $30^{\circ}$ (maximum stress position), (b) $70^{\circ}$, (c) $130^{\circ}$, (d) $190^{\circ}$, (e) $250^{\circ}$, and (f) $310^{\circ}$. .57

Figure 3.9: Mean stress over an entire revolution under spur gear loading for 4 index error locations at (a) $150 \mathrm{Nm}$, (b) $300 \mathrm{Nm}$, (c) $450 \mathrm{Nm}$, and (d) 600 $\mathrm{Nm}$

Figure 3.10: Root stress due to a $600 \mathrm{Nm}$ spur gear loading condition for four index error locations for (a) gauge 1 through (e) gauge 5.

Figure 3.11: Variation of stress for a single spline tooth under helical gear loading conditions at $600 \mathrm{Nm}$.

Figure 3.12: Root stress of the first instrumented tooth for test \#3 of Table 2.3 under helical gear loading conditions at (a) $150 \mathrm{Nm}$, (b) $300 \mathrm{Nm}$, (c) 450 $\mathrm{Nm}$, and (d) $600 \mathrm{Nm}$

Figure 3.13: Root stress of the first instrumented tooth for test \#3 of Table 2.3 under helical gear loading at angular positions of a) $50^{\circ}$ (maximum stress position), (b) $70^{\circ}$, (c) $130^{\circ}$, (d) $190^{\circ}$, (e) $250^{\circ}$, and (f) $310^{\circ}$.

Figure 3.14: Root stress of the second instrumented tooth for test \#3 of Table 2.3 under helical gear loading conditions at (a) $150 \mathrm{Nm}$, (b) $300 \mathrm{Nm}$, (c) 450 $\mathrm{Nm}$, and (d) $600 \mathrm{Nm}$ .69 
Figure 3.15: Root stress of the second instrumented tooth for test \#3 of Table 2.3 under helical gear loading at angular positions of (a) $50^{\circ}$ (maximum stress position), (b) $70^{\circ}$, (c) $130^{\circ}$, (d) $190^{\circ}$, (e) $250^{\circ}$, and (f) $310^{\circ}$. .70

Figure 3.16: Mean stress over an entire revolution under helical gear loading for 4 index error locations at (a) $150 \mathrm{Nm}$, (b) $300 \mathrm{Nm}$, (c) $450 \mathrm{Nm}$, and (d) 600 $\mathrm{Nm}$.

Figure 3.17: Root stress due to a $600 \mathrm{Nm}$ helical gear loading condition for four index error locations for (a) gauge 1 through (e) gauge 5.

Figure 4.1: Finite element model mesh of the external spline segment.

Figure 4.2: (a) Contact stress distribution and (b) corresponding grid cell force distribution on a spline tooth as predicted by Hong et al. [10]. .78

Figure 4.3: Mapping of the root and contact stress on a spline tooth. .80

Figure 4.4: Predicted (a) contact stress, (b) tensile root stress, and (c) compressive root stress of each tooth of the splined joint of Table 2.1 under spur gear loading at $600 \mathrm{Nm}$. .81

Figure 4.5: Predicted (a) contact stress, (b) tensile root stress, and (c) compressive root stress of each tooth of the splined joint of Table 2.1 under helical gear loading at $600 \mathrm{Nm}$. 
Figure 4.6: Predicted tensile root stress as a function of rotational position for 5 gauges on the face width of a spline tooth as shown in Figure 2.11. Spur gear loading at $600 \mathrm{Nm}$.

Figure 4.7: Predicted tensile root stress as a function of rotational position for 5 gauges on the face width of a spline tooth as shown in Figure 2.11. Helical gear loading at $600 \mathrm{Nm}$.

Figure 4.8: (a) Contact stress point load on a single tooth obtained by applying unrealistic tooth modifications, and (b) corresponding root stress prediction.

Figure 4.9: Predicted contour plot of root stress for a single tooth of the splined joint along with the gauge locations within which the upper and lower bounds of predictions were extracted.

Figure 4.10: Comparison of single-tooth point load measurements on teeth 3 and 4 when the point load is at the location of (a) gauge 1 through (e) gauge 5 to the predictions of the FE splined joint root stress model. Applied torque is $16.2 \mathrm{Nm}$.

Figure 4.11: Comparison of experimental results from tooth 3 of test \#1 in Table

2.3 to predictions under spur gear loading at $150 \mathrm{Nm}$.

Figure 4.12: Comparison of experimental results from tooth 3 of test \#1 in Table

2.3 to predictions under spur gear loading at $600 \mathrm{Nm}$. 
Figure 4.13: Three dimensional representation of the variation of the root stress with respect to rotational and axial positions for (a) the experimental results and (b) the maximum prediction. Spur gear loading at $600 \mathrm{Nm}$.

Figure 4.14: Comparison of experimental results from tooth 3 of test \#3 in Table 2.3 to predictions under helical gear loading at $150 \mathrm{Nm}$. .96

Figure 4.15: Comparison of experimental results from tooth 3 of test \#3 in Table 2.3 to predictions under helical gear loading at $600 \mathrm{Nm}$. .97

Figure 4.16: Three dimensional representation of the variation of the root stress with respect to rotational and axial positions for (a) the experimental results and (b) the maximum prediction. Helical gear loading at $600 \mathrm{Nm}$. .98

Figure A.1: Root stress of the first instrumented tooth for test \#2 of Table 2.3 under spur gear loading conditions at (a) $150 \mathrm{Nm}$, (b) $300 \mathrm{Nm}$, (c) 450 $\mathrm{Nm}$, and (d) $600 \mathrm{Nm}$

Figure A.2: Root stress of the first instrumented tooth for test \#2 of Table 2.3 under spur gear loading at angular positions of a) $10^{\circ}$, (b) $70^{\circ}$, (c) $130^{\circ}$, (d) $190^{\circ}$, (e) $250^{\circ}$, and (f) $310^{\circ}$.

Figure A.3: Root stress of the second instrumented tooth for test \#2 of Table 2.3 under spur gear loading conditions at (a) $150 \mathrm{Nm}$, (b) $300 \mathrm{Nm}$, (c) 450 $\mathrm{Nm}$, and (d) $600 \mathrm{Nm}$ 115 
Figure A.4: Root stress of the second instrumented tooth for test \#2 of Table 2.3 under spur gear loading at angular positions of a) $10^{\circ}$, (b) $70^{\circ}$, (c) $130^{\circ}$, (d) $190^{\circ}$, (e) $250^{\circ}$, and (f) $310^{\circ}$

116

Figure A.5: Root stress of the first instrumented tooth for test \#4 of Table 2.3 under helical gear loading conditions at (a) $150 \mathrm{Nm}$, (b) $300 \mathrm{Nm}$, (c) 450 $\mathrm{Nm}$, and (d) $600 \mathrm{Nm}$

Figure A.6: Root stress of the first instrumented tooth for test \#4 of Table 2.3 under helical gear loading at angular positions of a) $10^{\circ}$, (b) $70^{\circ}$, (c) $130^{\circ}$, (d) $190^{\circ}$, (e) $250^{\circ}$, and (f) $310^{\circ}$

Figure A.7: Root stress of the second instrumented tooth for test \#4 of Table 2.3 under helical gear loading conditions at (a) $150 \mathrm{Nm}$, (b) $300 \mathrm{Nm}$, (c) 450 $\mathrm{Nm}$, and (d) $600 \mathrm{Nm}$.

Figure A.8: Root stress of the second instrumented tooth for test \#4 of Table 2.3 under helical gear loading at angular positions of a) $10^{\circ}$, (b) $70^{\circ}$, (c) $130^{\circ}$, (d) $190^{\circ}$, (e) $250^{\circ}$, and (f) $310^{\circ}$. 120 


\section{CHAPTER 1}

\section{INTRODUCTION}

\subsection{Background and Motivation}

Splined joints are commonly used to transmit rotary motion from a shaft to machine elements such as gears. A splined joint consists of two components, an internal spline and an external spline. Both components have the same number of teeth that are conformal so that they are able to fit tightly together. This forms a joint that is coaxial; both the shaft and its splined mate rotate about the same axis at the same angular velocity. Since all teeth of a splined joint are in contact, a load applied to the spline or shaft is potentially distributed among all the teeth, making it a preferred choice when compared to keys, set screws, or other methods of joining.

There are three main types of splines: (a) clearance-fit (side-fit) splines, (b) major diameter-fit splines, and (c) minor diameter-fit splines. The difference between these three spline types is how the internal and external splines mate with each other. Figure 1.1(a) shows a clearance-fit spline that only makes contact along the drive side of the teeth. In Figure 1.1(b), a major-fit spline is shown with additional contact along the major 


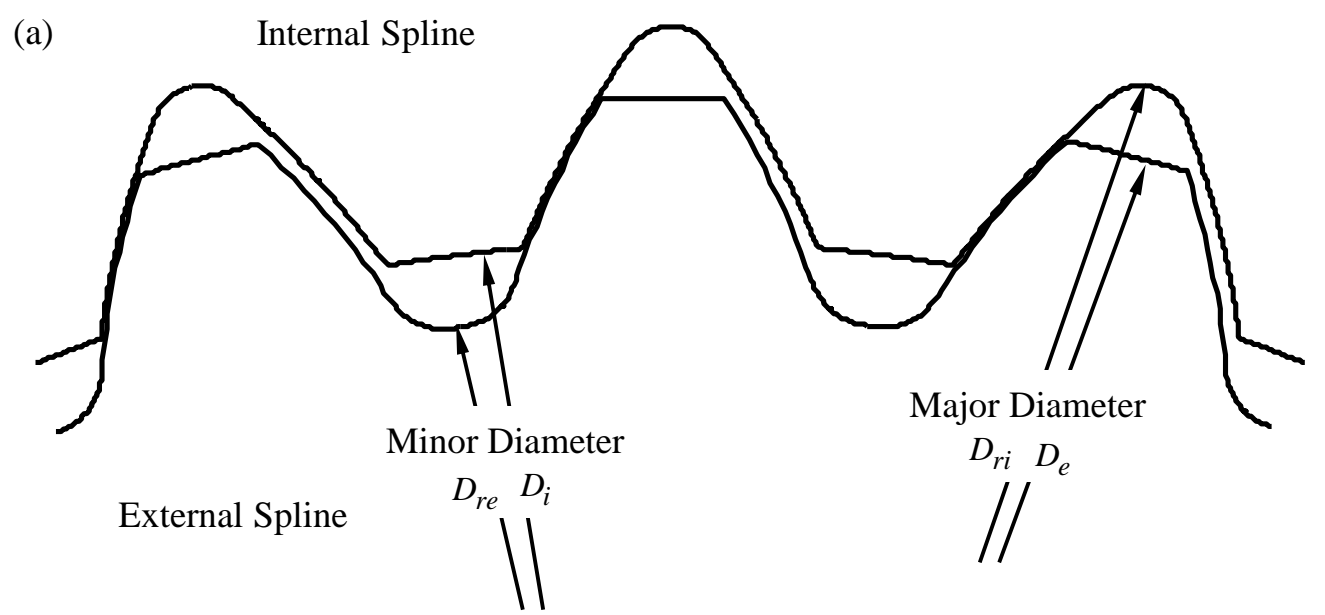

(b)

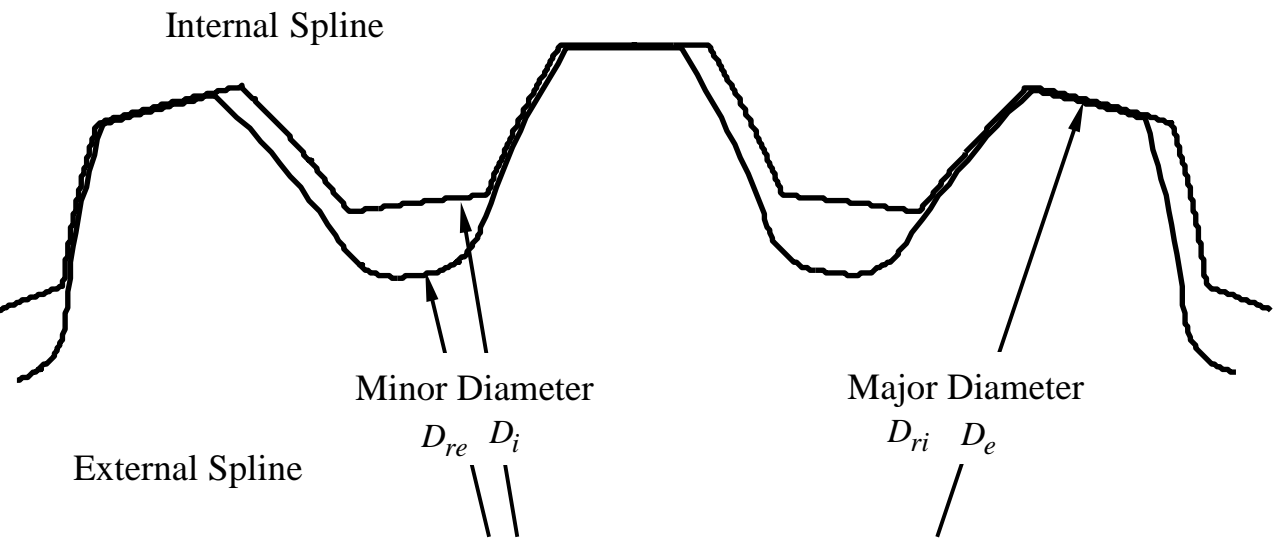

(c)

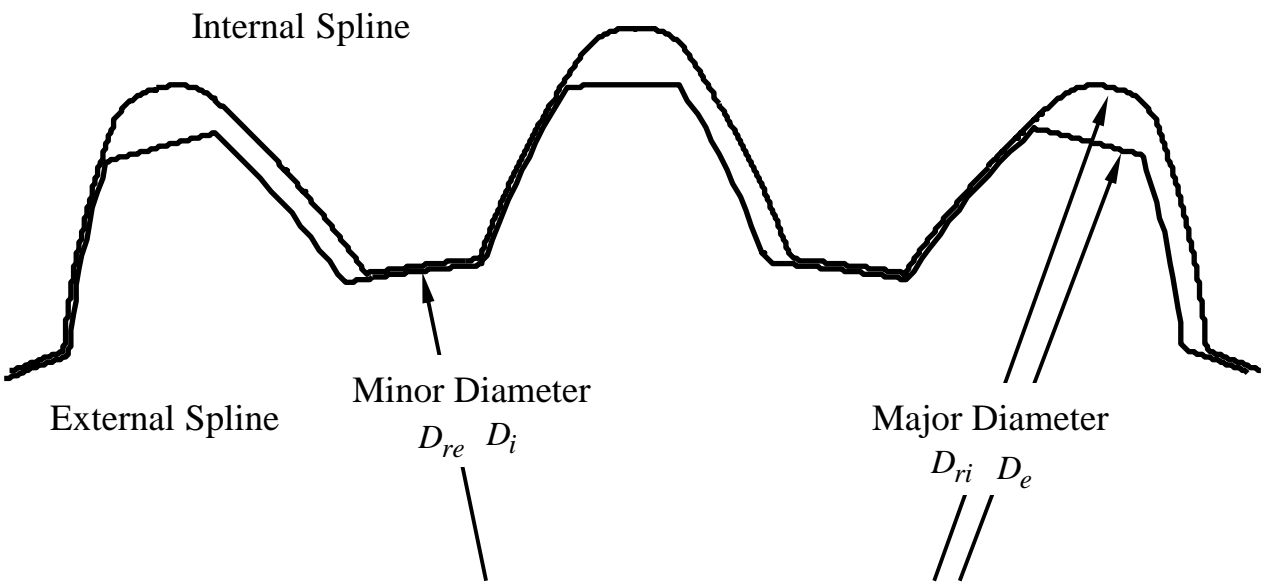

Figure 1.1: Illustrations of (a) clearance-fit (side-fit), (b) major diameter-fit, and (c) minor diameter-fit splines. Adapted from Reference [1]. 
diameter of the spline. Finally, in Figure 1.1(c), a minor-fit spline is shown that has additional contact along the minor diameter of the spline [1]. In major and minor diameter-fit splines, there is often a circumferential clearance such that the torque is carried by one side of the tooth flanks while the contact along the major or minor diameter centers the components. Due to the different areas of contact, each spline type has different characteristics when it comes to load carrying ability and local load distribution.

While the use of splined joints in product applications is wide-spread, sophisticated design and analysis tools are not only relatively new but also not validated due to the lack of high-fidelity experimental data on their load distributions. The aim of this thesis is to (i) establish an experimental database of splined joints subject to gear loading conditions in order to (ii) assess the validity of a recently developed spline load distribution model.

\subsection{Literature Review}

\subsubsection{Theoretical Models}

One of the common methods to simulate load distribution of splined joints has been to use finite element (FE) analysis. Tjernberg [2] used the commercially available FE software, ABAQUS, to determine the stress concentration factor between a shaft and a sleeve. Barsoum et al. [3] also used ABAQUS to determine the torsional strength of hardened shafts by using the detailed geometry of an involute spline and the material gradation. Studies by Barrot et al. [4] as well as Cura and Mura [5] also used FE models to predict pressure distributions on spline couplings. Other researchers used a similar technique of the boundary element (BE) method; Adey et al. [6] used a commercial BE 
package, BEASY, to predict contact stress and load transfer mechanisms. The aforementioned computational models were limited to torsional loading conditions without index errors present. A recent study by Hong et al. [7] used an FE gear contact solver, CALYX, to predict contact stresses and tooth-to-tooth load distributions of clearance-fit splined joints. This model surpassed the other FE-based models as it could predict contact stresses for diverse loading conditions including (a) pure torsion loading with no radial force and no moment, (b) spur gear loading creating both a torque and a radial force, and (c) helical gear loading with a torque, radial force, and an overturning moment, as illustrated in Figure 1.2 [7].

In addition to FE models, analytical models have also been proposed to study spline behavior. Barrot et al. [8] calculated both pressure distribution and tooth stiffness to show the mutual influence between the two. However, this model was limited to pure torsional loading. Wink and Nakandakar [9] also proposed an analytical model that allowed radial loads produced by spur gear loading on the load distribution of spline teeth.

Most of the current models cited above were limited in their predictive capabilities since they focused solely on pure torsion loading. In other words, a moment is applied to one of the two members (internal or external) of the splined joint along the rotational axis of the joint. This torsional loading results in an axisymmetric load distribution where all teeth have the same load distribution. A recent study by Hong et al. [1, 10-12] produced a family of analytical models which significantly surpassed the capabilities of the previous models. As shown in Figure 1.3, the clearance-fit spline model of Hong et al. [10] considers the regions of contact on each tooth of the splined joint from the start of active profile (SAP) to end of active profile (EAP) of the external spline. 


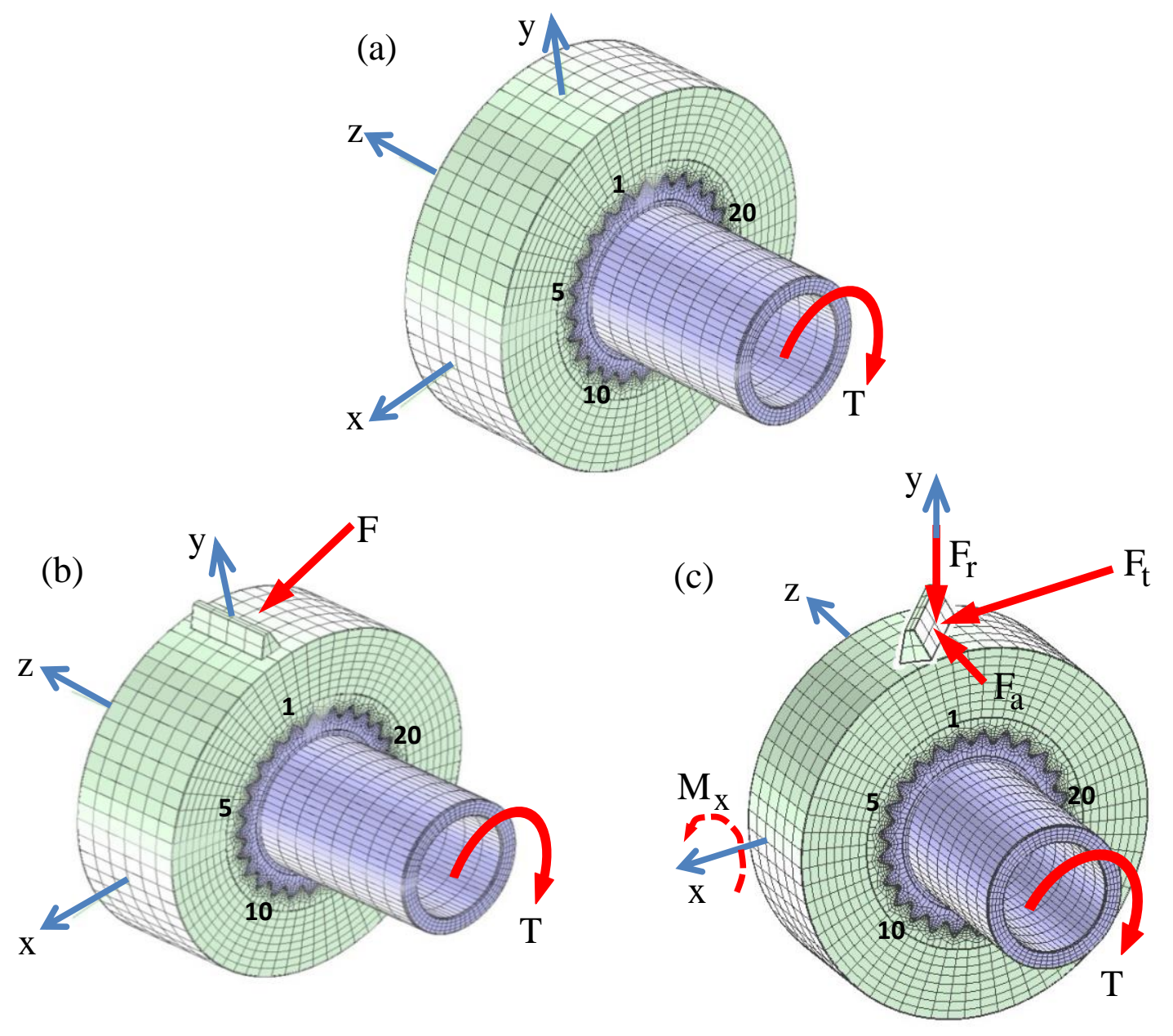

Figure 1.2: Spline model with (a) pure torsion loading with no radial force and no moment, (b) spur gear loading with both a torque and a radial force, (c) helical gear loading with a torque, radial force, and an overturning moment. Adapted from Reference [7]. 


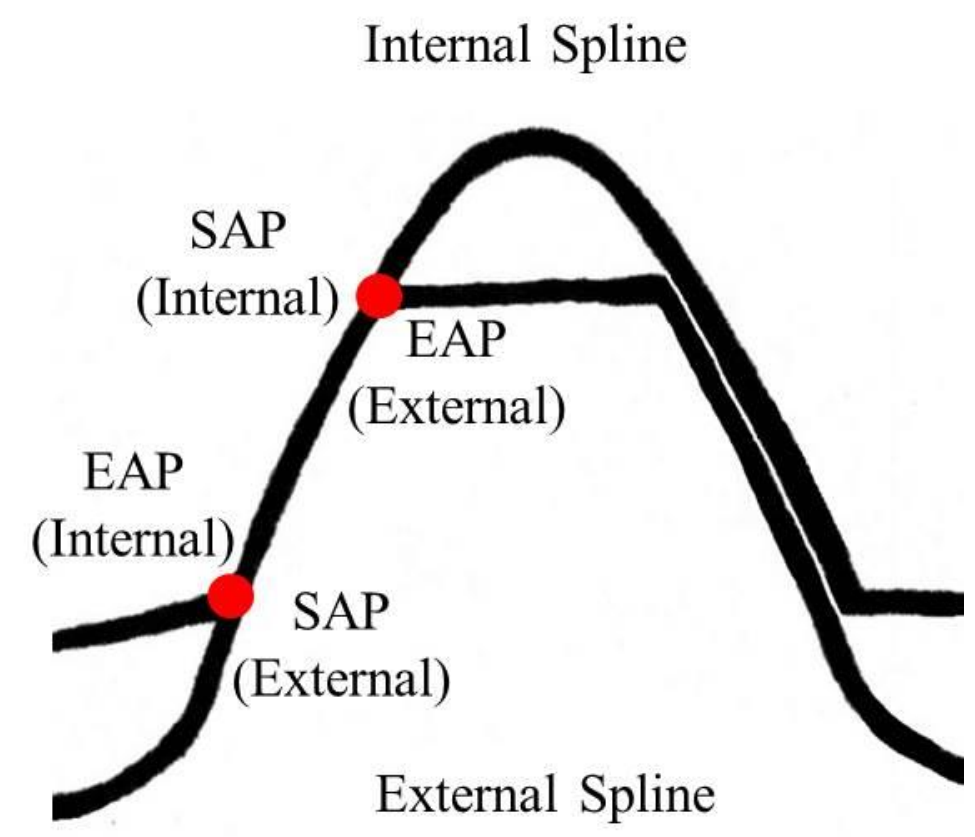

Figure 1.3: Definition of the potential contact area of a tooth pair of a clearance-fit spline defining start of active profile (SAP) and end of active profile (EAP) for both the internal and external spline components. 
With the three common spline loading conditions included, the model of Hong et al. [10] replicated the predictions of the FE-based model by the same authors [7]. Yet its use of semi-analytical formulation and a multi-step discretization scheme to solve the contact problem was shown to reduce computational time by more than two orders of magnitude (from several hours to a fraction of a minute). This model also captured the impact of loading type on the resultant load distribution of the joint. It illustrated that, under purely torsional loaded conditions without tooth index errors, each spline tooth is subject to identical load distributions, as depicted in Figure 1.4(a). In this case, a stress gradient along the face width of the splined joint is evident with the highest contact stress at the side where torque is applied to the external spline. For the case of spur gear loading, the model showed that tooth-to-tooth load sharing is no longer equal as the radial force supported by the splined joint causes circumferential variations in load distributions, as illustrated in Figure 1.4(b). Finally, the overturning moment created by the helical gear loading, as seen in Figure 1.2(c), was predicted to result in tooth-to-tooth load distribution variations both along both the circumferential and face width directions, as illustrated in Figure 1.4(c).

Hong et al. [1] later expanded their clearance-fit model to include major and minor diameter-fit spline simulations. Furthermore, they studied the influence of index errors on the resultant load distributions [11]. This study revealed that index errors may significantly alter the nominal load distribution by drastically increasing load on some teeth while completely unloading other teeth. Figure 1.5 shows a load distribution of the same spline presented in Figure 1.4, to illustrate the effect of the presence of a sequence of random index errors. Most recently, the same authors [12] proposed a formulation for 

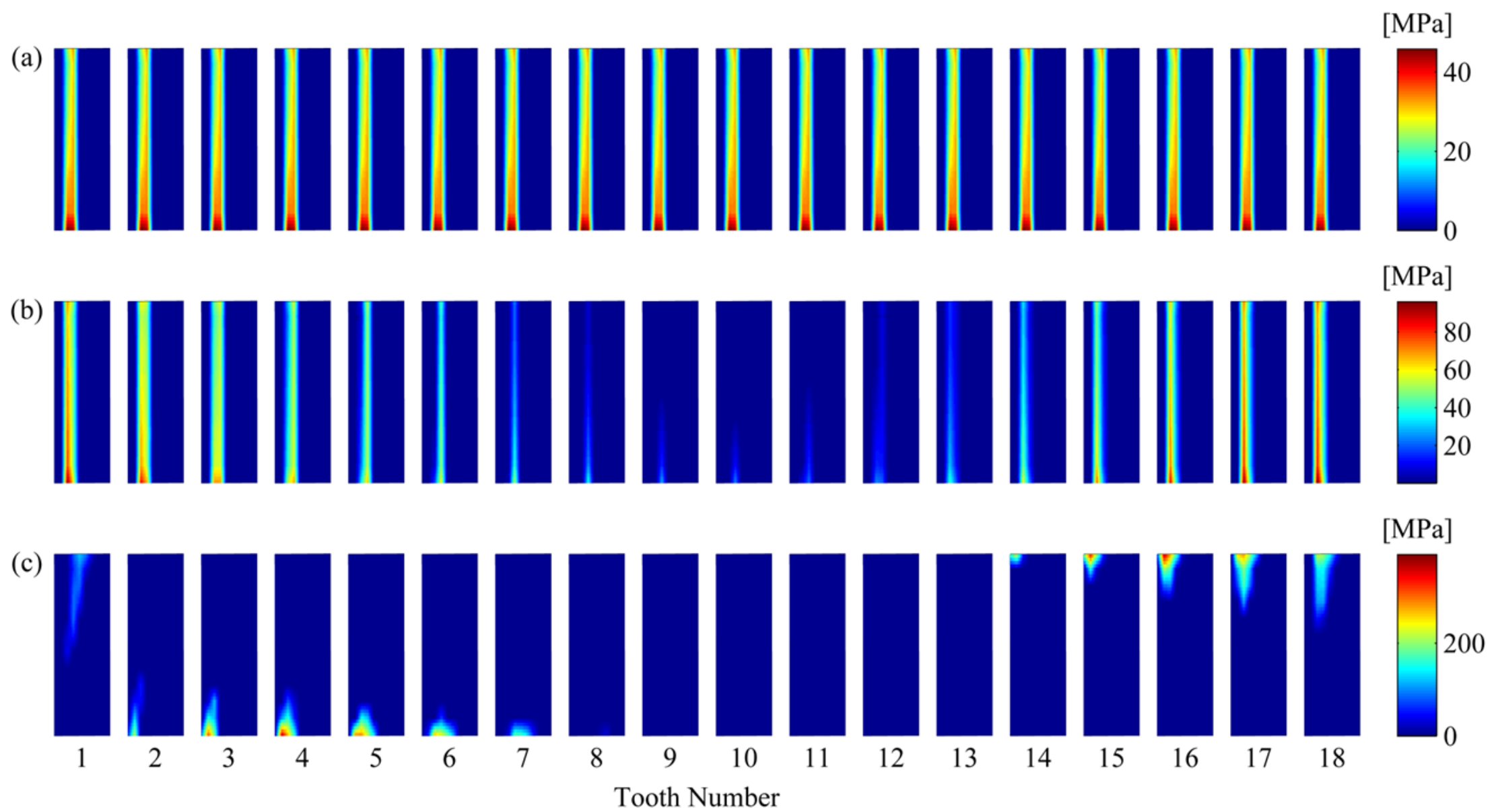

Figure 1.4: Example of the predicted load distributions of a nominal spline without index errors under (a) torsional loading, (b) spur gear loading, and (c) helical gear loading [10]. 
(a)

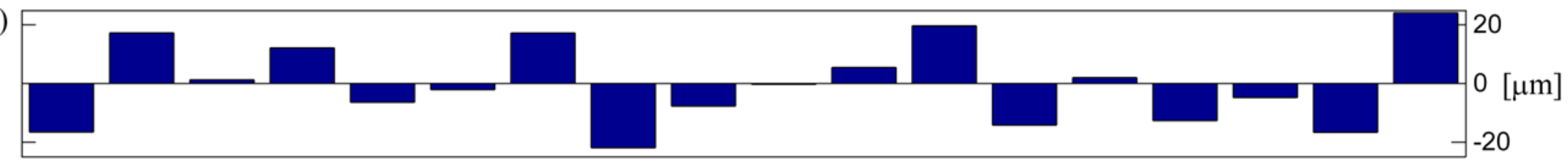

(b)

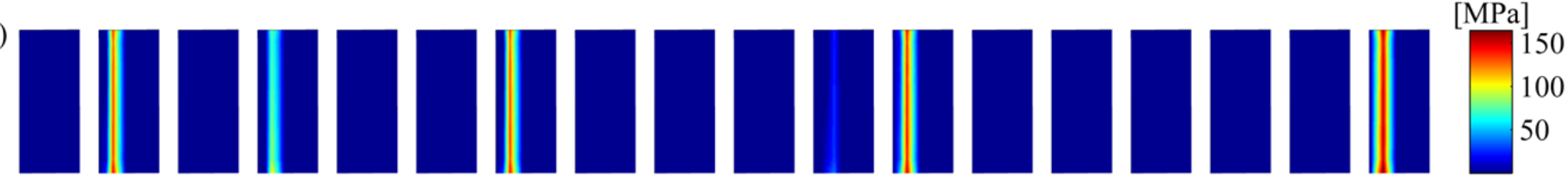

(c)
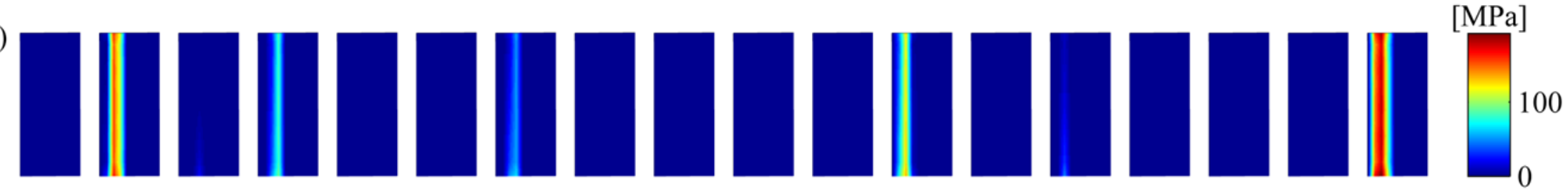

(d)
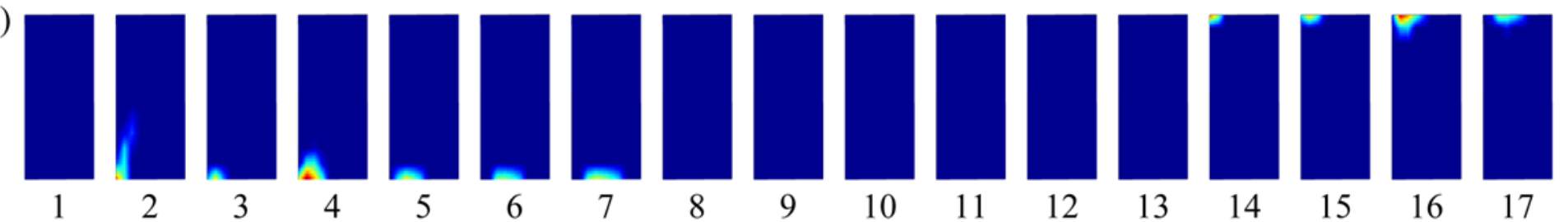

[MPa]

Tooth Number

Figure 1.5: Example of the predicted load distributions of the spline of Figure 1.4 with (a) random values of index errors under, (b) torsional loading, (c) spur gear loading, and (d) helical gear loading [11]. 
defining the stiffness matrix of splined joints.

\subsubsection{Experimental Studies}

While the studies by Hong et al. [1, 10-12] indicate that their proposed method is advantageous in capturing key effects and providing computationally efficient analyses, it lacks experimental validation; so do the other models cited previously. The literature contains several experimental studies on splined joints investigating surface wear and fatigue. Weatherford et al. [13] experimentally compared spline wear under multiple lubricating conditions and observed, most significantly, that "wear of spline teeth may proceed more rapidly in the presence of greases than in the unlubricated case." $\mathrm{Ku}$ and Valtierra [14] studied the effects of angular misalignment on splines and concluded that better spline alignment allows for greater flexibility of lubrication, maintenance, and spline design. Brown [15] specifically looked at spline couplings in aircraft applications, noting that spline wear is accelerated due to both misalignments and the absence of effective lubrication. In addition to these earlier papers, there are more recent experimental studies addressing fatigue issues. Wavish et al. [16] used a test setup to mimic combined torque, axial, and bending load fretting conditions of spline teeth in a laboratory environment. Ratsimba et al. [17] created a methodology to predict fretting wear in reduced scale aero-engine type spline couplings subjected to cyclic load cases. Other experimental studies on splines have examined additional issues. Cura and Mura [18] experimentally investigated the effect of angular misalignments between a hub and 
shaft while also comparing experimentally obtained spline tooth stiffness data to theoretical results. Cuffaro et al. [19] experimentally determined the pressure distribution between two engaging spline teeth by using pressure indicating film and comparing the experimental results to the output from an analytical model. Phardi and Khamankar [20] used the experimental technique of photoelasticity to compare stress found in splines under various loading conditions to results of a commercial FE model.

Root stress measurements are relatively straightforward and common for gear pairs and have been used to show how tooth loads change under dynamic conditions [21] or as a function of misalignments [22] and index errors [23, 24]. However, these measurements have not been done for splined joints despite the fact that the measurements have the potential of providing the same type of information as for gear pairs.

\subsection{Objectives and Scope}

The literature review shows that no rigorous and extensive experimental data has been collected that can be used to validate a splined joint model. Furthermore, there is an

apparent gap between what is predicted and what is measureable. Consequently, this thesis has two main objectives. The first objective is to establish an experimental database of splined joints subject to gear loading conditions. The specific experimental objectives are as follows:

(i) Design and fabricate a spline-specific test setup that allows splines to be tested under various gear loading conditions. 
(ii) Instrument an external spline with root strain gauges for data collection.

(iii) Execute a test matrix within a range of torques under spur and helical gear loading conditions in order to generate spline root stress data as a function of circumferential and face width positions of the spline teeth.

The second objective is to assess the accuracy of the clearance-fit spline model of Hong et al. [10]. As the formulation of this model was the basis for their other studies $[1,11,12]$, any reasonable correlation of this model to experiments would provide a certain level of confirmation for those other studies as well. Yet, these models focused on contact stress distributions that cannot be feasibly measured under realistic loading conditions. The above experimental objectives have limited relevance here unless the model of Hong et al. [10] is complemented by a root stress prediction capability. As such, the model validation objectives are as follows:

(i) Develop an FE-based spline tooth root stress prediction capability that combines the gear tooth segment FE model of Talbot [25] with the tooth contact load distribution predictions of Hong et al. [10]. This will provide a direct quantitative comparison between experimental data and the prediction of the root stresses at the same gauge locations.

(ii) Compare experimental data to simulations under both spur and helical gear loading conditions in order to assess the accuracy of the model created by Hong et al. [10]. 
The experimental work will be limited to a static analysis as dynamic effects are beyond the scope of this study. Likewise, pure torsion loading conditions are not of interest here as the focus will be on geared splines. Finally, backside contact, contact of the major/minor-diameters of the splined joint, and a detailed study on effects of index errors will be left for future studies.

\subsection{Thesis Outline}

Chapter 2 details the methodology devised to conduct the experimental spline load distribution study. The unique features and components of the test setup, which was designed and fabricated specifically for this project, are presented in this chapter. Test setup descriptions are followed by specifications of the test specimens and test matrix. Finally, the instrumentation, data acquisition procedure, and conversion of the data to stress are explained.

Chapter 3 presents the results of the experimental study. First, a repeatability study is presented to demonstrate the accuracy and repeatability of the proposed methodology. Next, spline root stress measurements under spur and helical gear loading conditions are presented at torque levels and specific testing conditions defined in Chapter 2. Lastly, general conclusions are made from the experimental results.

Chapter 4 describes the process of combining the gear tooth segment FE model of Talbot [25] with the tooth contact load distribution predictions of Hong et al. [10]. Next, single-tooth point loading measurements are shown to validate the root stress predictions. 
Lastly, based on direct comparisons to the experimental results for spur gear loading and helical gear loading tests presented in Chapter 3, the accuracy of the model created by Hong et al. [10] is assessed.

Finally, Chapter 5 summarizes the study and presents its major findings and contributions. Also included in this chapter are a number of recommendations for future work on splined joints. 


\section{CHAPTER 2}

\section{TEST METHODOLOGY AND INSTRUMENTATION}

\subsection{Introduction}

As stated in Chapter 1, one of the experimental objectives of this study was to design and fabricate a spline-specific test setup that allows splines to be tested under various gear loading conditions. As such, the final design of the setup must meet several requirements.

(i) As evident from the literature review presented in Chapter 1, most of the published experimental and theoretical studies on load distributions of splined joints focused on pure torsional loading; a moment is applied to one of the two members (internal or external) of the splined joint along its rotational axis. As demonstrated by the modeling work of Hong et al. [7, 10], such torsional loading results in an axisymmetric load distribution where all teeth have the same load distribution, provided that there are no index errors [11]. Since the main interest of this study is the load distribution of splines supporting gears on shafts, the test setup must be designed to be able to load a splined joint 
through both a spur and a helical gear mesh interface. In order for the spur and helical gear loading cases to be compatible with each other, it is desirable to have spur and helical test gears with identical transverse geometry (diameter, module, backlash, and transverse tooth thickness). Since design and fabrication of new spur and helical gears is a lengthy and costly process, gears used in a number of previous studies (Hotait and Kahraman [21], Blankenship and Kahraman [26] and Kubur et al. [27]) were modified to be used in this study.

(ii) Since the strains induced by gear meshes in the roots of spline teeth are typically modest, the test setup must allow for application of robust levels of torque to the system. Under heavy loading conditions, however, shafts and support bearings typically experience deflections, which may result in loaddependent misalignments along the splined joint. In order to prevent such deflections, each shaft must have a large diameter and a short span between its two supports. In addition, it has to have rigid support bearings or bushings.

(iii) Spur gear loading conditions result in a radial force on the splined joint in addition to a torque. Furthermore, helical gear loading conditions apply a radial force, a torque, and an overturning moment [10]. Both loading conditions result in a different load distribution for each spline tooth, depending on the position of the tooth in relation to the gear mesh loading the joint. Since it is impractical to instrument every spline tooth to capture such tooth-to-tooth variations, the splined joint should be able to rotate in relation to the gear mesh loading position. This way, a single instrumented spline tooth 
may be located at different circumferential positions in order to capture the load distribution variation. As such, the setup must have the capability to load the splined joint at different circumferential positions.

(iv) One main challenge in measuring root strains of gears is the uncertainty induced by gauge mounting errors [21]. Since the stress gradient is very steep in the root locations where gauges are mounted, gauge placement error, regardless of how small, may result in tangible gauge-to-gauge variations. However, index errors present in a splined joint prevent proper assessment of such uncertainties. In order to remove uncertainties, each instrumented spline tooth (in this case, the external spline tooth) needs to be able to be loaded individually rather than to be loaded as part of the entire spline. As such, the setup must allow torsional loading of the shaft of the instrumented external spline.

\subsection{Test Machine Setup}

\subsubsection{Test Setup Configuration for Gear Loading}

A test setup was designed and fabricated to satisfy the above requirements. Figure 2.1 shows an overall view of this setup while Figure 2.2 shows the top-view drawing. Figure 2.3(a) and (b) show the assembly cross-sectional side-views of the test and reaction shafts with key components labeled. 


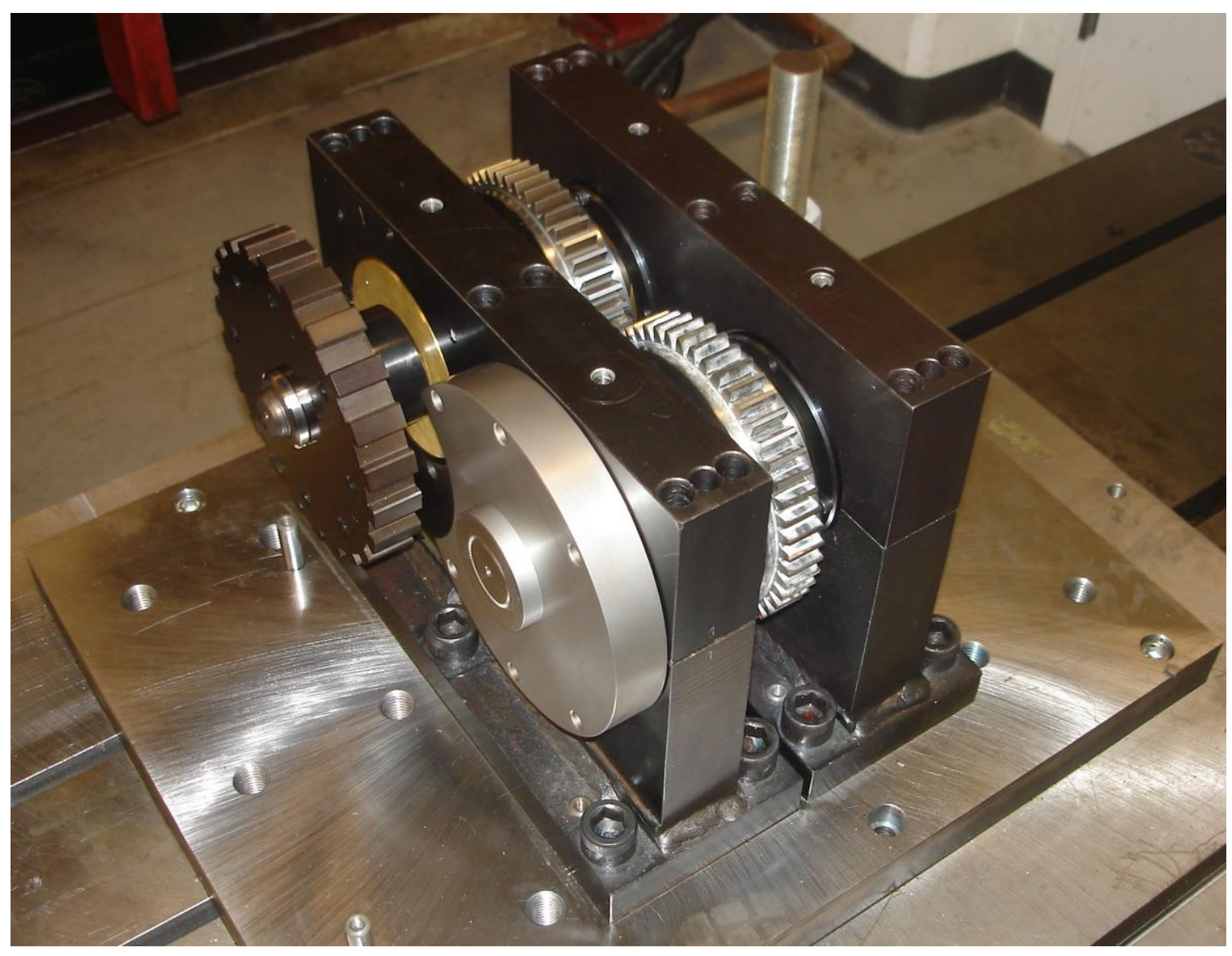

Figure 2.1: Experimental test setup used in this study. 


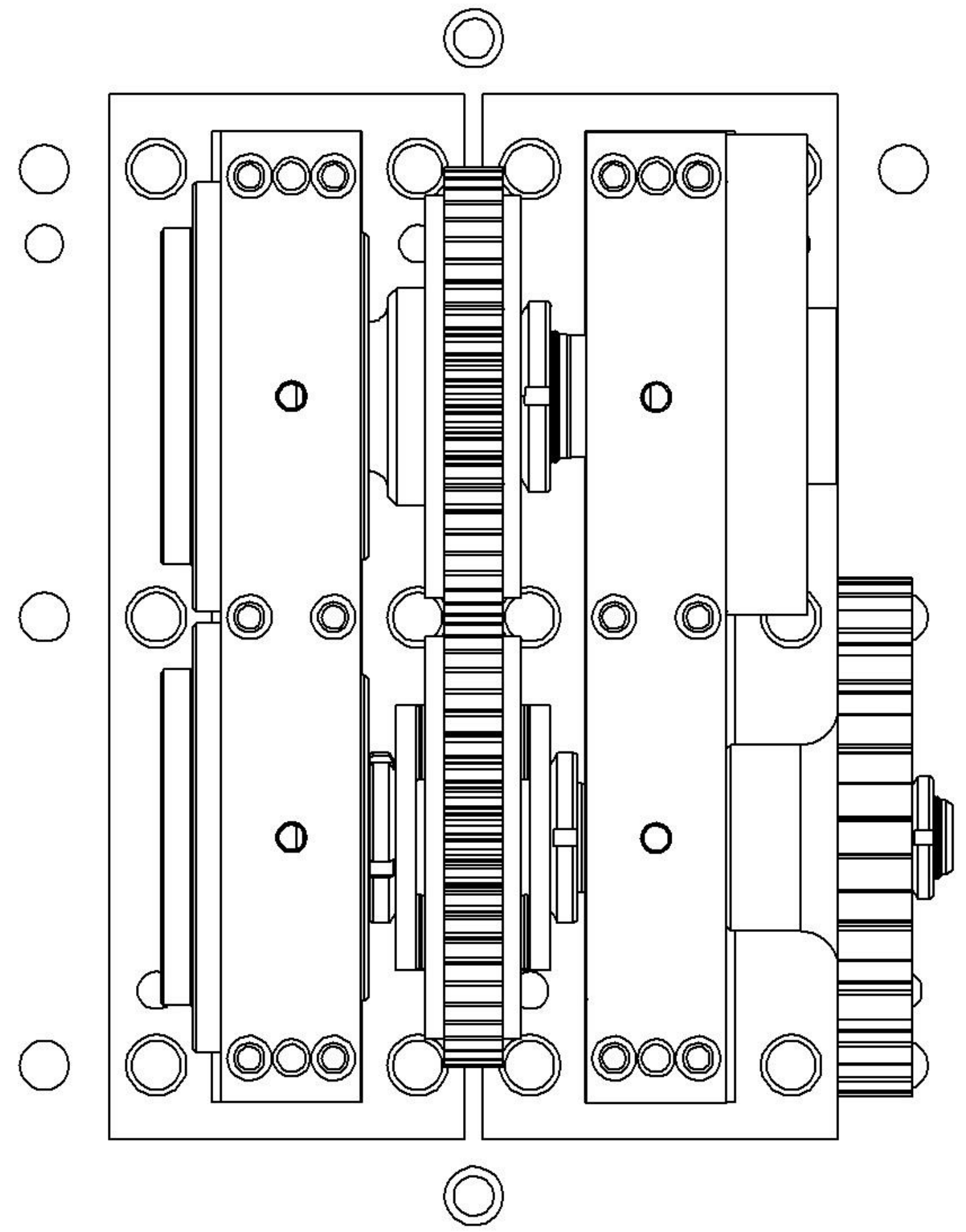

Figure 2.2: Top-view drawing of the test setup. 
(a)

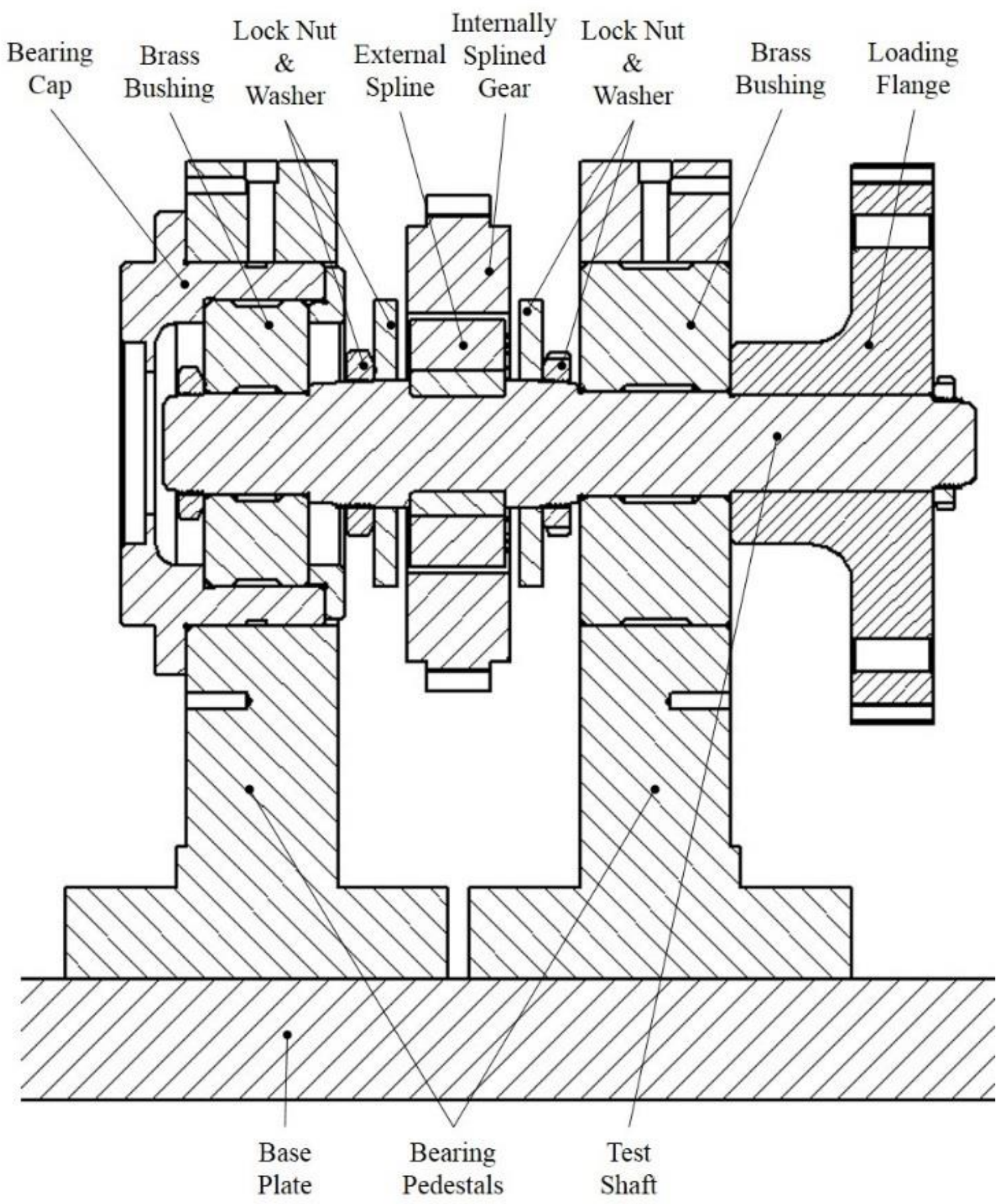

Figure 2.3: Cross-sectional side-views of (a) test shaft assembly and (b) reaction shaft assembly with key components labeled. 
Figure 2.3 Continued

(b)

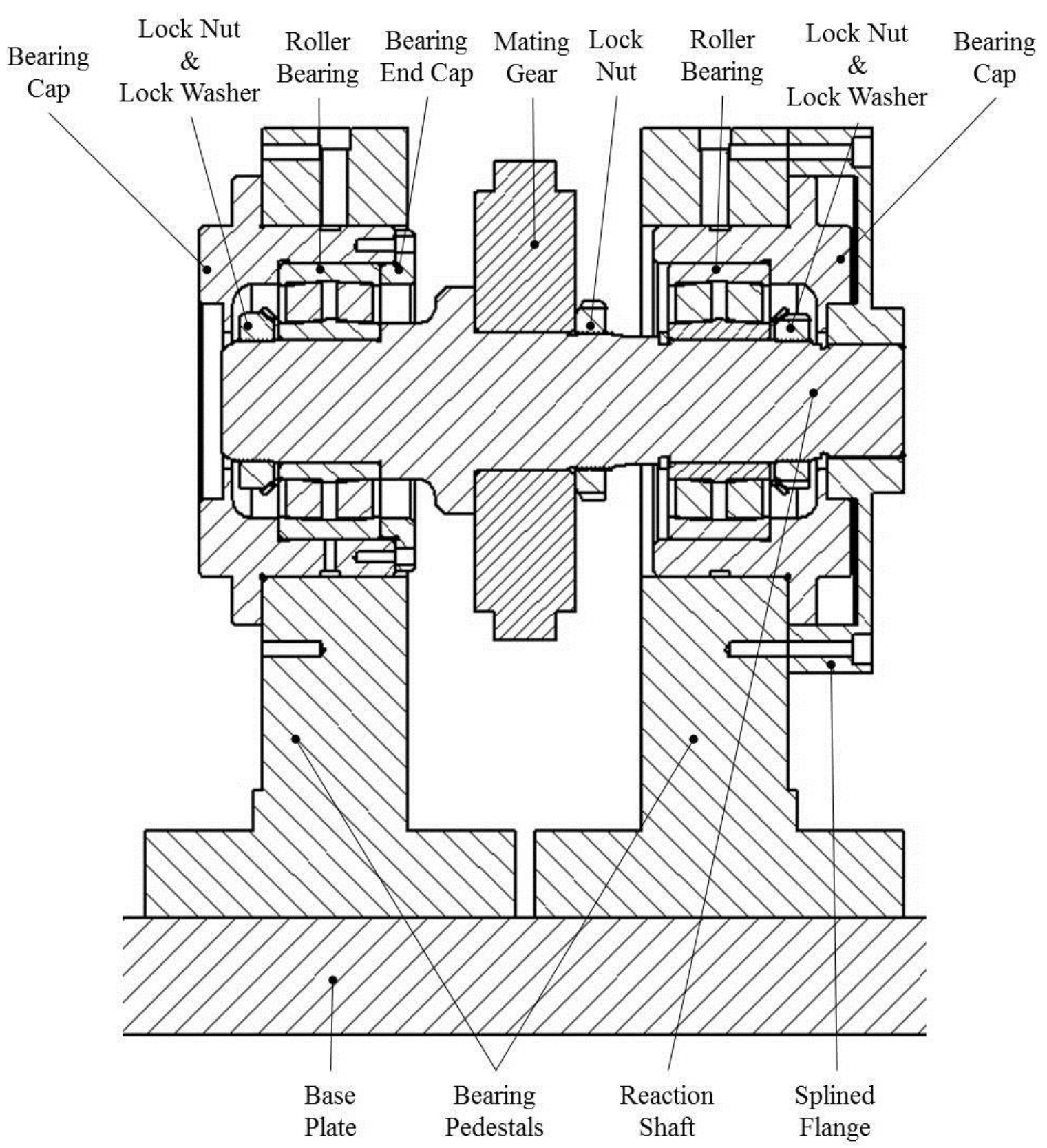


The test shaft was supported by two massive brass bushings within the bearing pedestals. In between these bushings, the external spline piece shown in Figure 2.4(a) was keyed and shrunk-fit on the test shaft. This provided a rigid connection between the external spline and the test shaft which eliminated any rigid body motions of the external spline. The spur and helical gears that were machined at the internal diameters are shown in Figure 2.4(b) and the other gears, forming the pairs, are shown in Figure 2.4(c). Once assembled, two spacers and lock nuts on either side of the gear supported the internal piece axially, as shown in Figure 2.3(a). The spacers were designed such that only a part of the spacer came in contact with the external spline and gear to restrain it axially. The bushing to the left of the splined joint in Figure 2.3(a) was housed by a bearing cap that was piloted radially by, and held axially to, the bearing pedestal. Meanwhile, the bushing to the right had a much larger outside diameter to occupy the space between the input shaft and the pedestal without the need for a bearing cap. At the right end of the input shaft, a loading flange was mounted in a slightly cantilevered manner in order to apply torque. Torque was applied using a moment arm and calibrated weights, as illustrated in Figure 2.5.

Figure 2.3(b) shows the cross-sectional view of the reaction shaft assembly with key components labeled. The reaction shaft was supported by two oversized spherical roller bearings which were placed in bearing caps. The gear, spur or helical, as shown in Figure 2.4(c), was mounted against a shoulder using a slide-fit interface and held axially by a lock nut. In addition, two shear pins went through both the shoulder and the gear so that the gear would not rotate independent of its shaft. At the right end of the reaction 
(a)

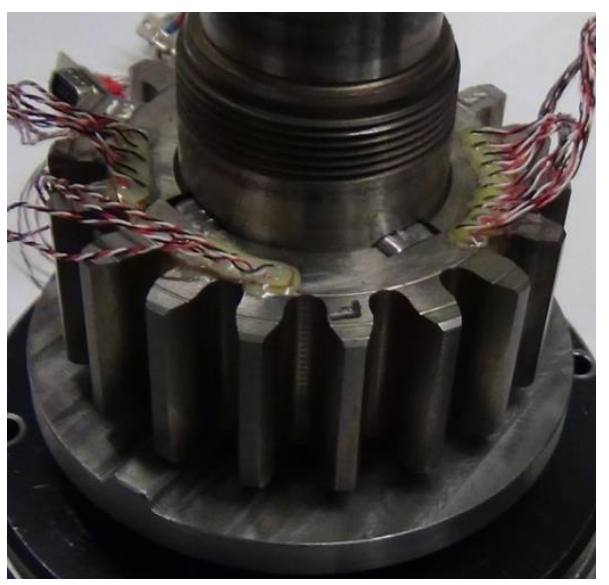

(b)

(c)
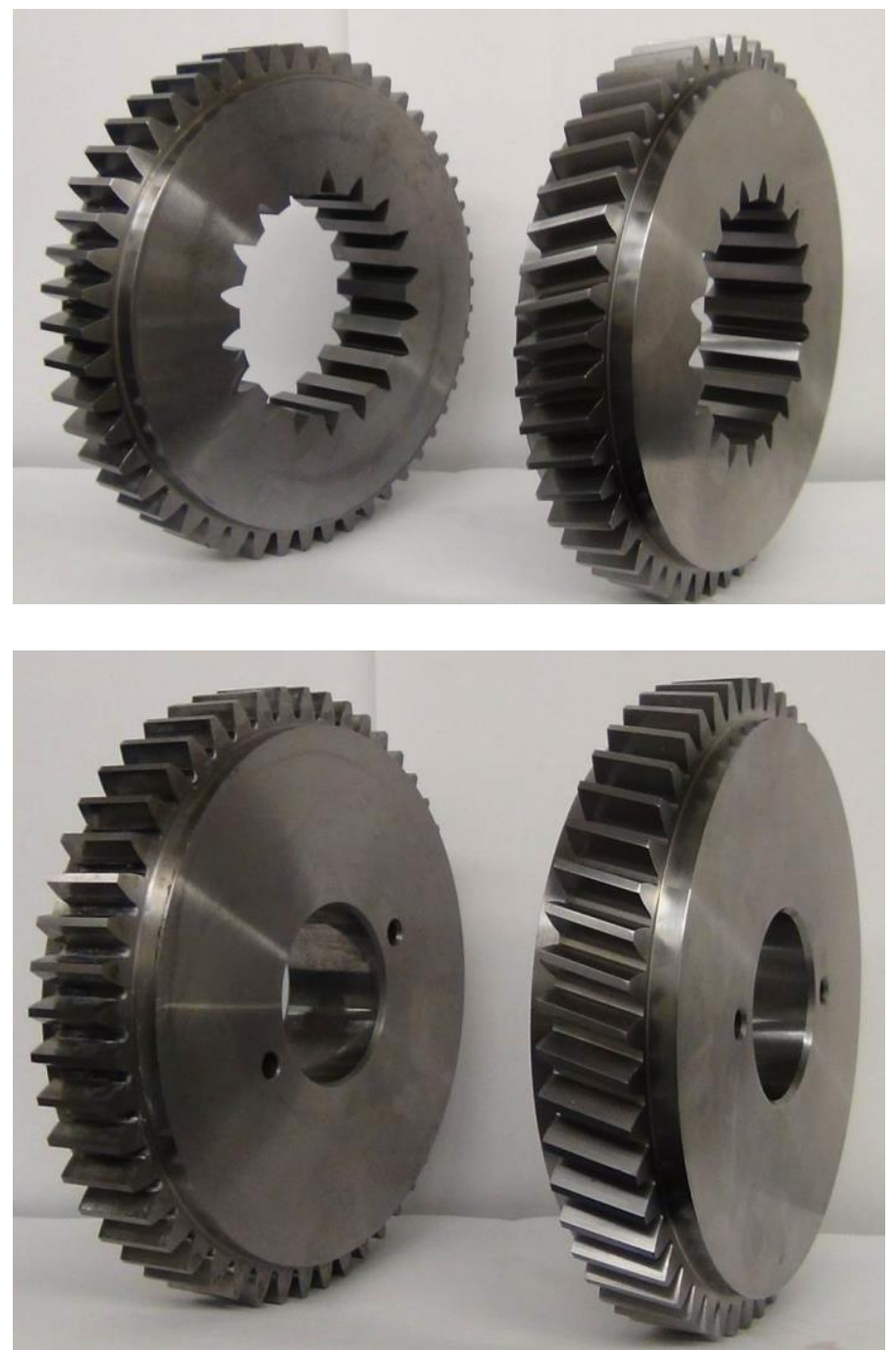

Figure 2.4: (a) Instrumented external spline piece, (b) spur and helical gears with internal splines, and (c) mating spur and helical gears of the reaction shaft. 


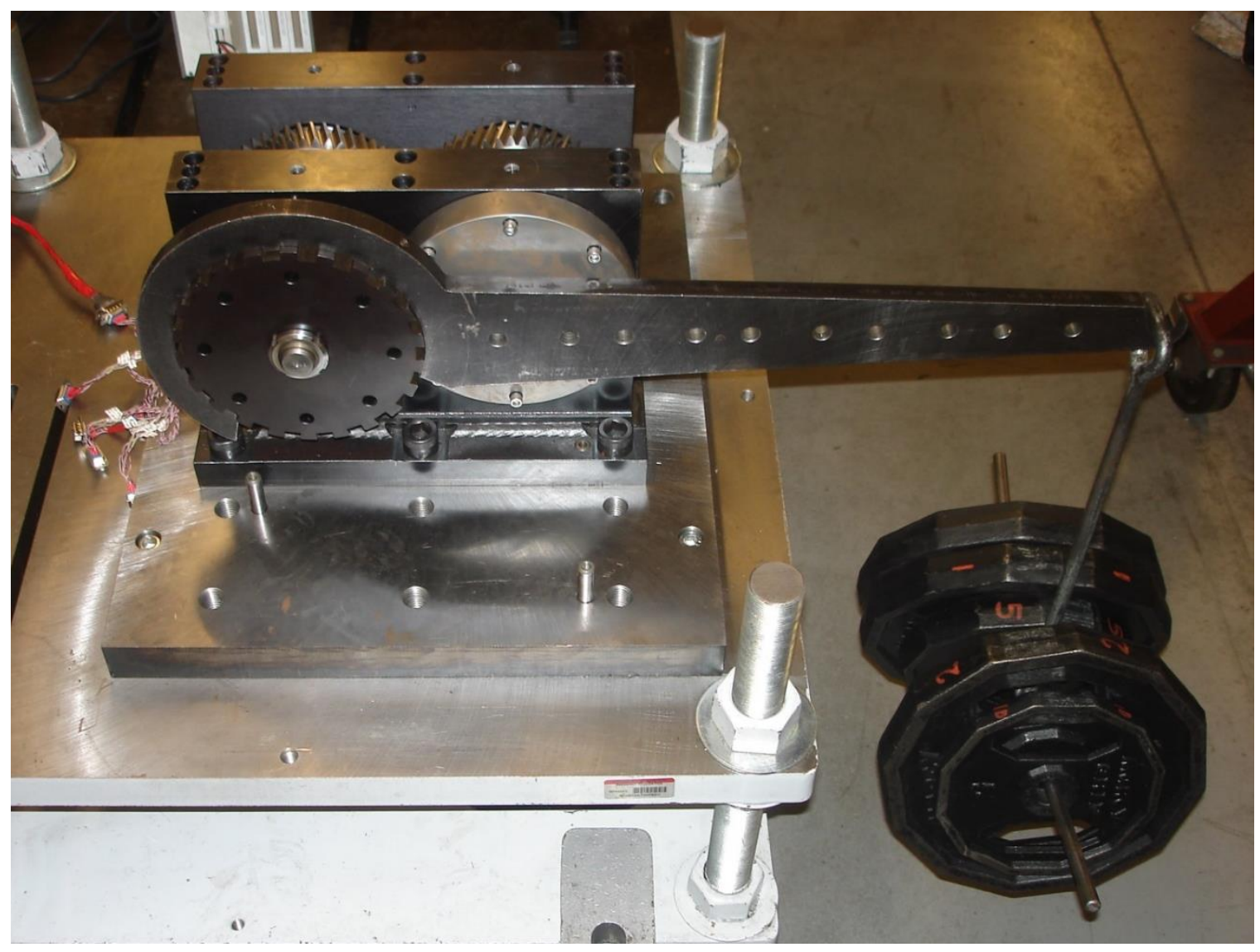

Figure 2.5: Experimental test setup with the loaded torque arm illustrating the torque application process. 
shaft, a 72-tooth spline was machined. A mating flange was fastened to the bearing pedestal through a set of bolts, which provided a "fixed" boundary condition. This fixed boundary condition balanced the torque applied to the test shaft through the loaded gear mesh. The 72-tooth splined joint at the end of the reaction shaft allowed the gears to be

held at 72 equally-spaced rotational positions at an increment of $360^{\circ} / 72=5^{\circ}$ such that the rotational variations mentioned above, due to the asymmetric gear loading, could be captured.

In order to obtain different testing configurations with respect to the index errors of the splined joint, the test shaft was removed and the internal spline was rotated relative to a specifically marked reference tooth on the external spline. Then the test shaft was placed back on the brackets and tested again. This process was repeated for both the spur and helical gear loading conditions.

\subsubsection{Test Setup Configuration for Single-Tooth Loading}

In order to assess the consistency of the placement of the gauges along the spline roots, a single tooth loading configuration was designed and implemented such that any external spline tooth could be loaded individually rather than as part of a splined joint. The single-tooth loading configuration allowed for the application of a known torque at a specific face width position of a single tooth. Figure 2.6 shows the point load setup with the top bearing pedestals removed so that the additional fixtures implemented to apply the point load can be seen. Figure 2.7 shows the solid model of the same configuration. 


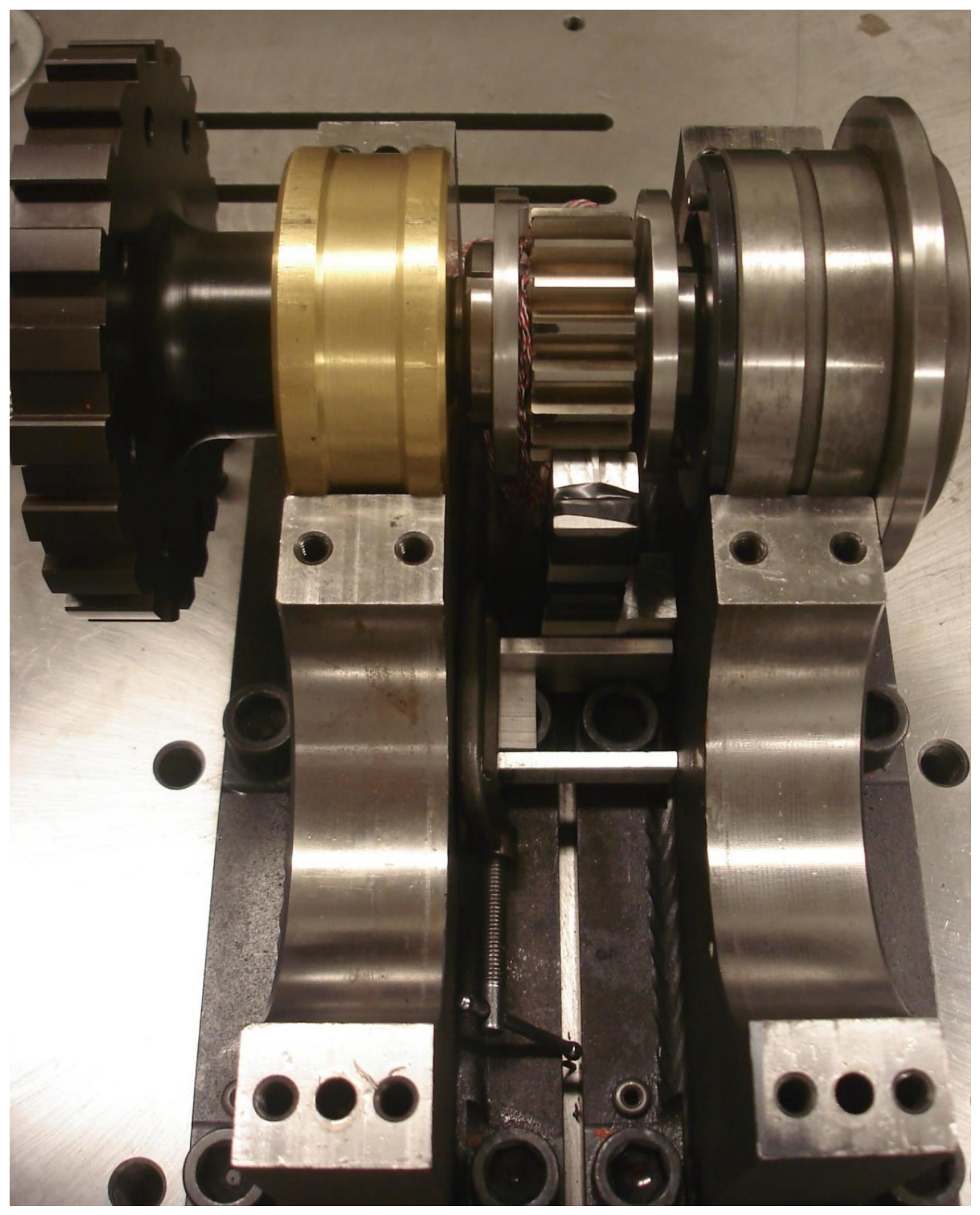

Figure 2.6: Experimental test setup with the single-tooth point loading configuration. (Upper halves of bearing pedestals are removed for demonstration purposes.) 


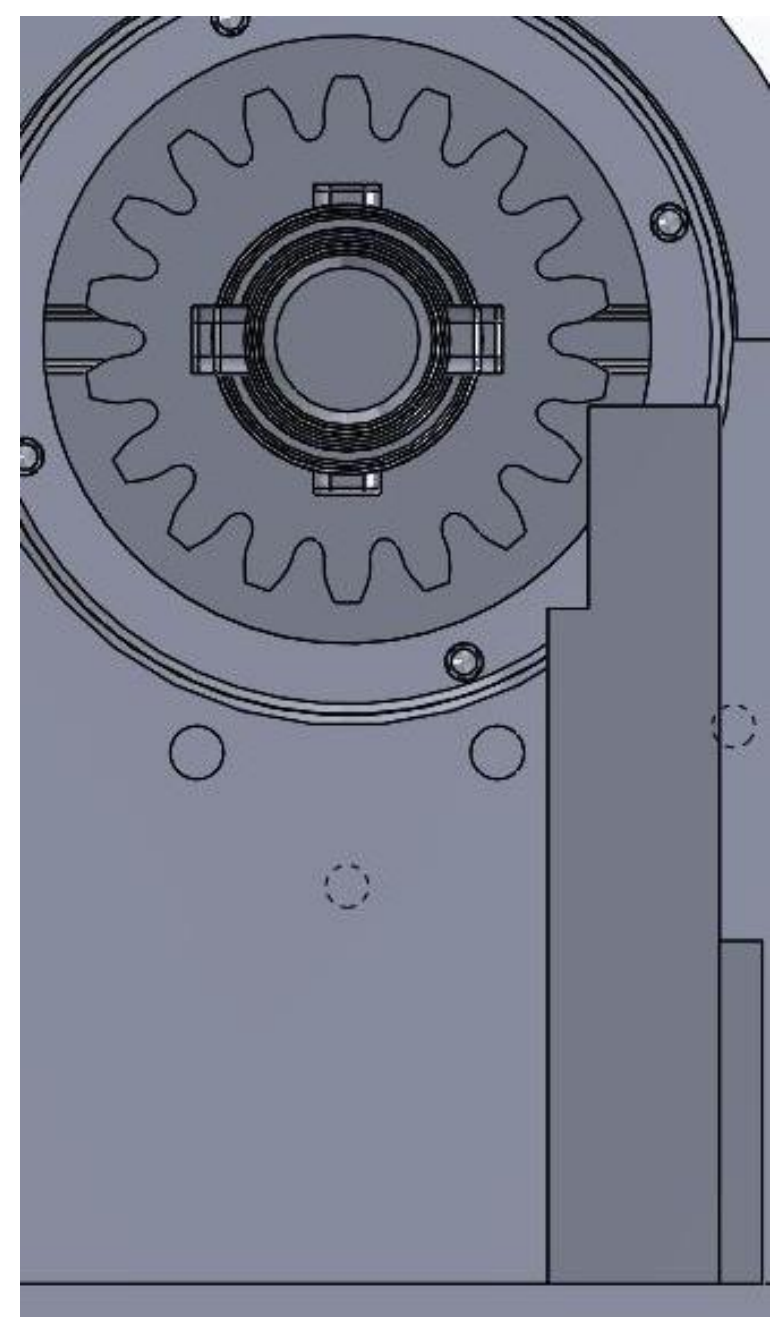

Figure 2.7: Solid model side-view of single-tooth assembly. 
The test shaft remained unchanged when compared to the spur and helical gear loading case, with the exception that there was no internally splined gear mated to the external spline. The reaction shaft was completely removed from the test setup and a vertical block, to react with an external spline tooth, was placed. Furthermore, a narrow (1 mm wide) and thin (1 mm thick) strip of metal (a shim) was located between the reaction block and the spline tooth so that the spline tooth could be loaded at various face width positions to create point loading conditions suitable for simulation (as will be described in Chapter 4). The vertical position, controlled by the height of the reaction block plus the shim thickness, was designed such that the contact of the shim with the spline tooth would take place on the horizontal plane, with the common normal of the contact surfaces being vertical. This prevented any corner contact conditions that would be difficult to model.

\subsection{Test Specimens and Test Matrix}

The external spline test specimen used in this study was designed in such a manner as to allow instrumentation and testing under static conditions. In product applications, splines often use smaller module (fine-pitch teeth) and lack space in the root or tip areas

since the radial clearances are kept small. With these typical designs, the root fillet radii are rather small and have significant stress concentrations and steep stress gradients. Even with the smallest gauges feasible for this application, such designs would have posed difficulties for experimentation.

Table 2.1 lists the basic parameters of the splined joint considered in this study. It was a clearance-fit (side-fit) spline with 18 teeth at a reasonably large pitch diameter of 
Table 2.1: Basic design parameters of the spline used in this study. (All units are in $\mathrm{mm}$ unless otherwise specified.)

\begin{tabular}{|c|c|c|}
\hline Parameter & External & Internal \\
\hline Number of Teeth & \multicolumn{2}{|c|}{18} \\
\hline Module & \multicolumn{2}{|c|}{4.00} \\
\hline Pressure Angle [degrees] & \multicolumn{2}{|c|}{20} \\
\hline Base Diameter (ref) & \multicolumn{2}{|c|}{67.658} \\
\hline Pitch Diameter (ref) & \multicolumn{2}{|c|}{72.00} \\
\hline Major Diameter & $77.87 / 78.00$ & $81.80(\max )$ \\
\hline Form Diameter & 67.20 & 78.80 \\
\hline Minor Diameter & 60.00 & $68.00 / 68.13$ \\
\hline Max./Min. Circular Tooth Thickness & $5.50 / 5.45$ & $5.55 / 5.50$ \\
\hline Fillet Radius & $1.80(\mathrm{~min})$ & 0.7 (min) \\
\hline
\end{tabular}


$72 \mathrm{~mm}$, resulting in a $4 \mathrm{~mm}$ module that was suitable for mounting strain gauges. Likewise, the root radius of the external piece was $60 \mathrm{~mm}$, such that a larger clearance could be created with a reasonable root radius. Figure 2.8(a) shows a side-view of the entire splined joint and Figure 2.8(b) shows a close-up of a few teeth to display the root clearance mentioned above. This clearance was only created on the external piece so that it could be mated with both internally splined spur and helical gears. This reduced the instrumentation effort while making spur and helical loading data compatible.

The splined joint was called out to be quality Class 4. In addition to the parameters listed in the table, it was also specified that the external spline have only a lead crown modification of $10 \pm 3 \mu \mathrm{m}$ and no profile modification. Measurements of the profile and lead of the external spline, as well as the tooth-to-tooth spacing and index errors, were performed using a computerized gear coordinate measurement machine (CMM). The internal splines of the spur and helical gears were also called out to be quality Class 4 , with the spline parameters listed in Table 2.1. Similarly, CMM measurements of the internal spline teeth were also performed to find tooth-to-tooth spacing and index errors.

Since both the external and internal splines were mounted on an arbor, or chuck, in order to obtain CMM measurements, there was the possibility for run-out to occur. Therefore, tooth-to-tooth spacing and index error measurements were not repeatable. In an attempt to obtain reliable results, three measurements were taken for both the tooth-totooth spacing and the index errors. The mean of these three measurements was taken and then a Fast Fourier Transform (FFT) was performed in an attempt to remove the run-out. Figure 2.9(a), (b), and (c) show the resulting index errors of the active left flank (the 


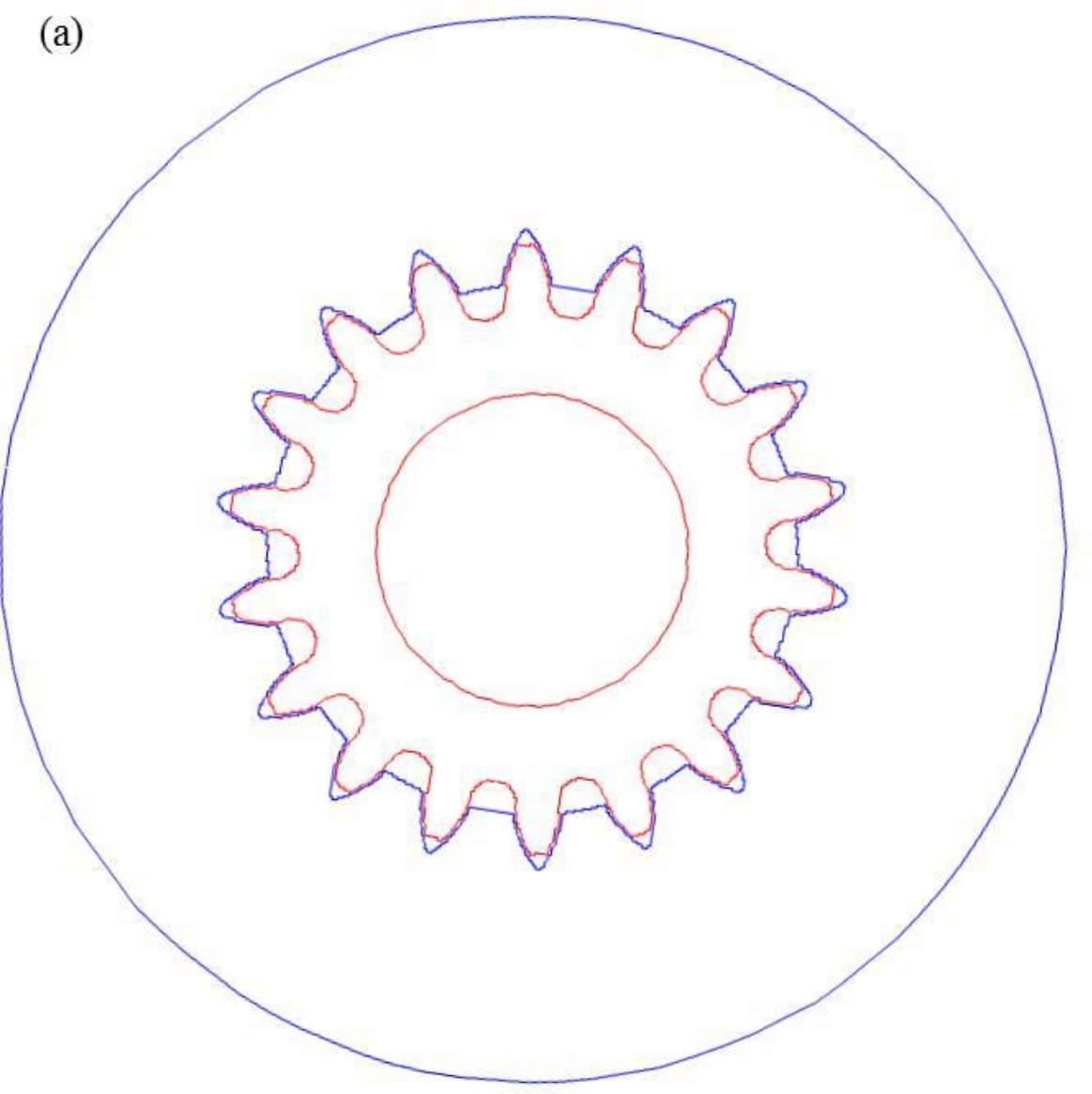

(b)

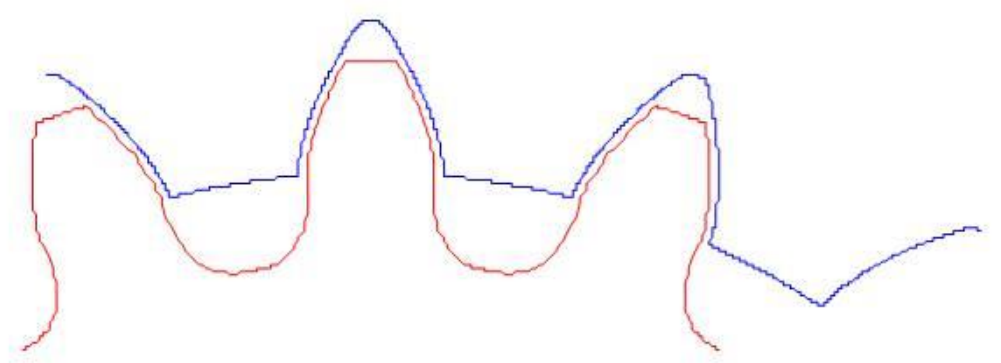

Figure 2.8: Side-view drawing of (a) the splined joint defined in Table 2.1 and (b) a zoomed in view of the top teeth. 
(a)
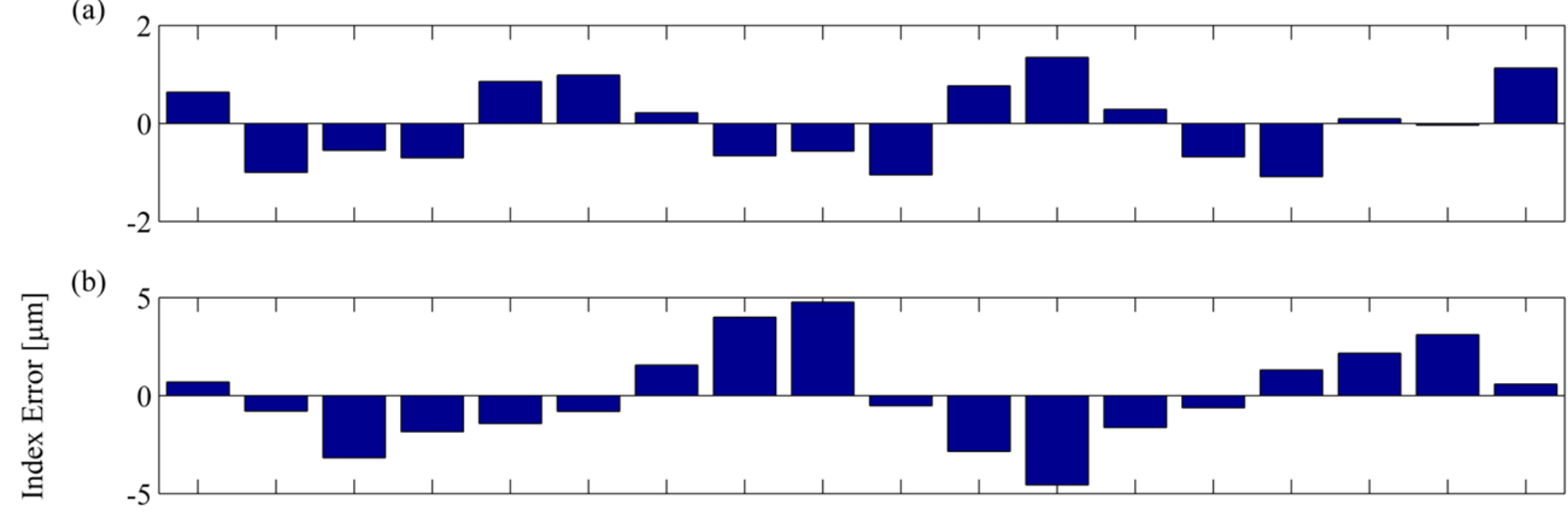

(c)

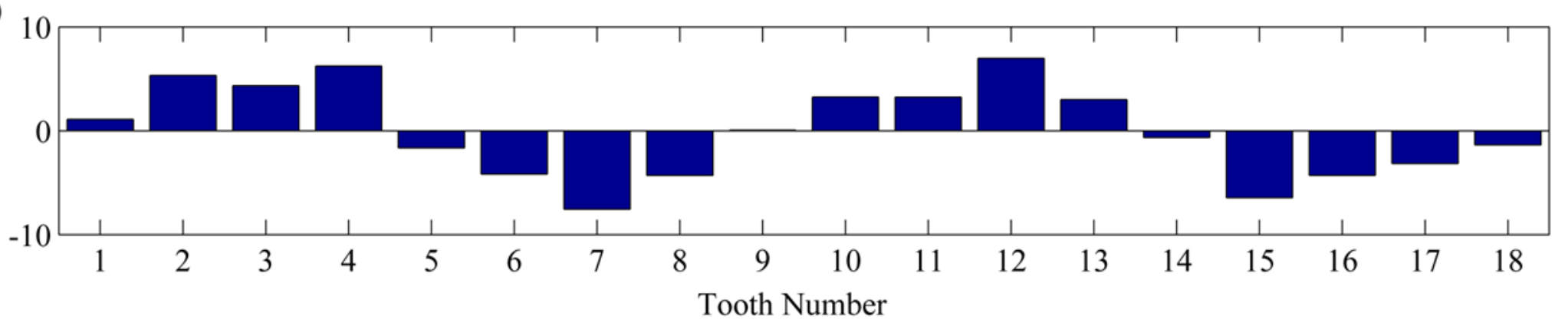

Figure 2.9: Index errors for (a) external spline, (b) internally splined spur gear, and (c) internally splined helical gear after taking the mean and performing FFT. 
flank that comes in contact when loaded, as shown in Figure 2.5) of the external spline, internally splined spur gear, and internally splined helical gear, respectively.

Table 2.2 lists the design parameters of the unity-ratio (1:1) spur and helical gears used in this study. These gear geometries were used in numerous gear dynamic studies including References [21], [24], [26], and [27].

Four different index error locations (two teeth each at two locations) were considered for both spur and helical gear loading, to represent different configurations in relation to the index errors. Figure 2.10(a) through Figure 2.10(d) show the splined joint in each of the different index error configurations. For each of these index error locations, data was taken at $20^{\circ}$ increments for a full $360^{\circ}$ rotation of the spline, relative to the location where the load was applied. At each rotational increment, experiments were repeated under four different torque levels of 150, 300, 450, and $600 \mathrm{Nm}$. Table 2.3 summarizes the test matrix executed in this study.

\subsection{Instrumentation, Data Acquisition, and Analysis}

The root stress instrumentation consisted of five strain gauges placed along the face width of the external spline, as shown in Figure 2.11. The strain gauges were placed below the start of active profile (SAP) at a radius of $32.22 \mathrm{~mm}$ so that they would not interfere with the contact interfaces of the internal and external splines. Furthermore, the gauges were aligned along the profile direction so that strain measurements could be 
Table 2.2: Design parameters of the gear pairs used to load the splined joint $[21,24,26$, and 27]. (All units are in mm unless otherwise specified.)

\begin{tabular}{|c|c|c|}
\hline Parameter & Spur & Helical \\
\hline Number of Teeth & \multicolumn{2}{|c|}{50} \\
\hline Module & 3.000 & 2.898 \\
\hline Normal Pressure Angle [degrees] & 20.00 & 19.37 \\
\hline Helix Angle [degrees] & 0.0 & 15.0 \\
\hline Base Diameter (ref) & \multicolumn{2}{|c|}{140.95} \\
\hline Pitch Diameter (ref) & \multicolumn{2}{|c|}{150.00} \\
\hline Major Diameter & \multicolumn{2}{|c|}{156.00} \\
\hline Minor Diameter & \multicolumn{2}{|c|}{$140.62 / 140.74$} \\
\hline Normal Circular Tooth Thickness & 4.64 & 4.46 \\
\hline TIF [degrees] & \multicolumn{2}{|c|}{12.15} \\
\hline
\end{tabular}


(a)

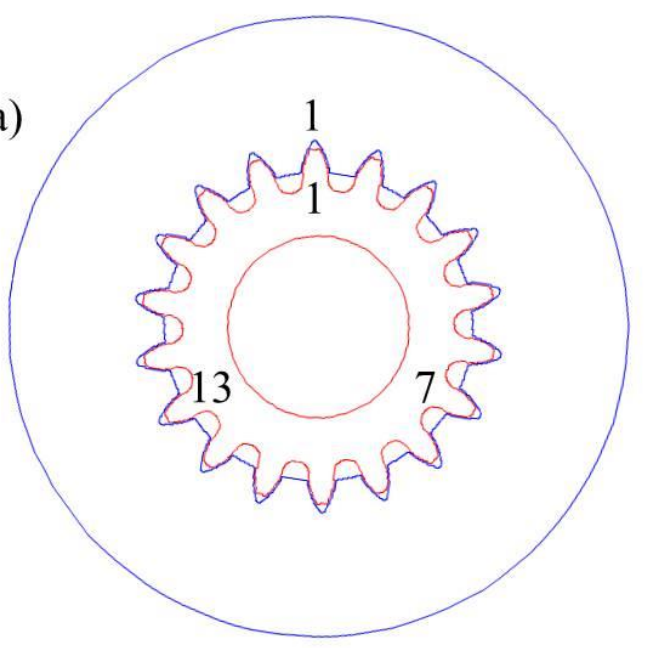

(c)

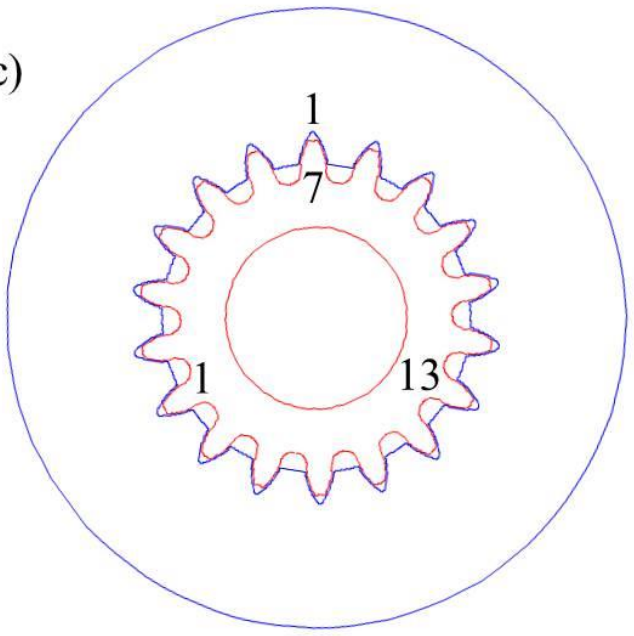

(b)

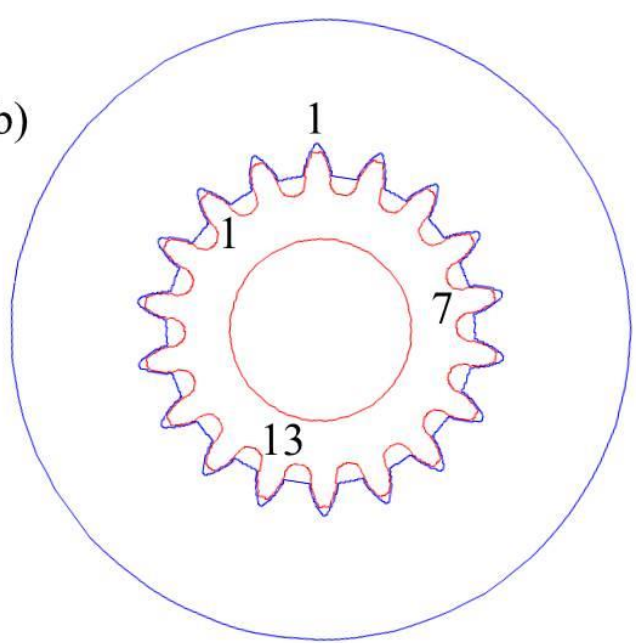

(d)

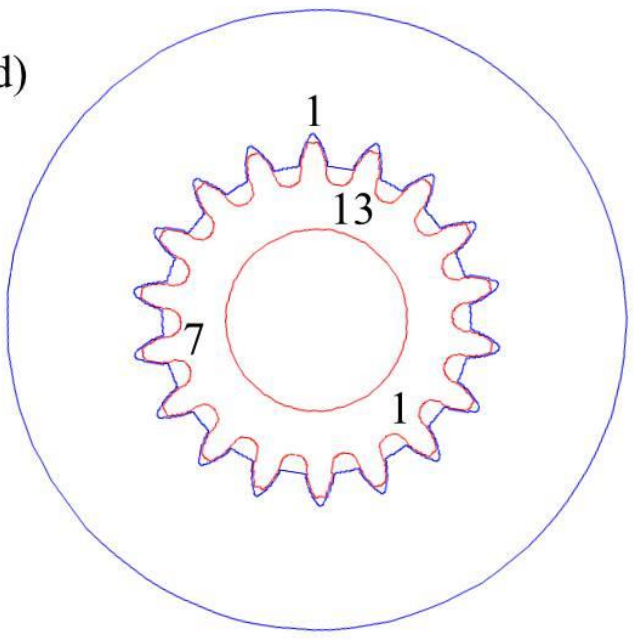

Figure 2.10: Index error locations for (a) test \#1, (b) test \#2, (c) test \#3, and (d) test \#4. 
Table 2.3: Test matrix considered in this study.

\begin{tabular}{cccc}
\hline Test \# & $\begin{array}{c}\text { Loading } \\
\text { Condition }\end{array}$ & $\begin{array}{c}\text { Mated Internal/External } \\
\text { Tooth Pair }\end{array}$ & $\begin{array}{c}\text { Torque } \\
(\mathrm{Nm})\end{array}$ \\
\hline 1 & Spur & $\# 1-\# 1$ & $150-600$ \\
2 & Spur & $\# 1-\# 3$ & $150-600$ \\
3 & Helical & $\# 1-\# 7$ & $150-600$ \\
4 & Helical & $\# 1-\# 12$ & $150-600$ \\
\hline
\end{tabular}




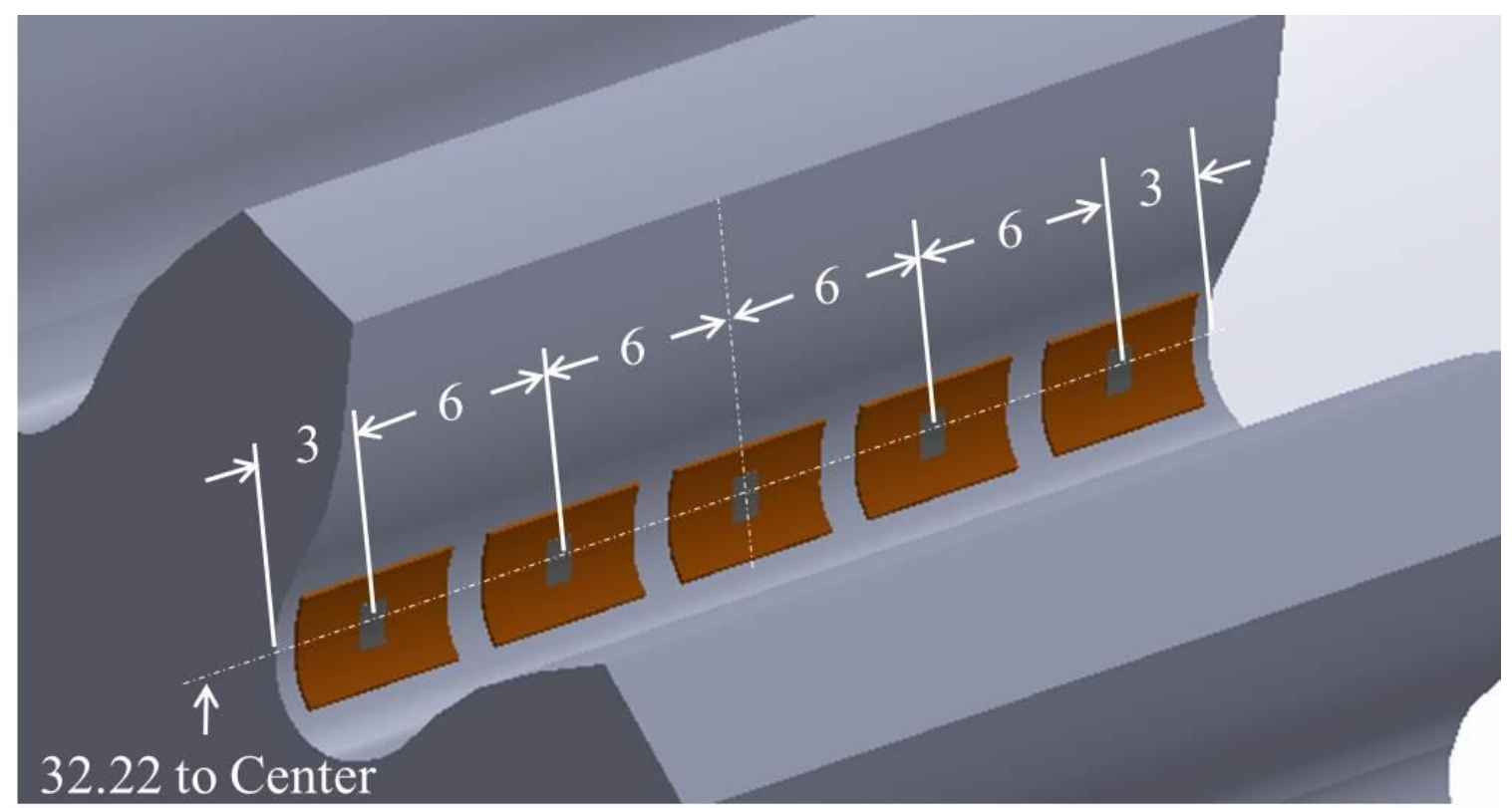

Figure 2.11: Definition of strain gauge location on an external spline tooth. (All units in $\mathrm{mm}$.) 
used to calculate bending stress of the spline teeth. The gauges were ordered 1 to 5 along the face width, with gauge 1 being the one closest to the loading flange and gauge 5 being the one farthest from the loading flange, as seen in Figure 2.3(a). Six different spline teeth were instrumented, with gauges in pairs of two consecutive teeth being gauged at $120^{\circ}$ increments. Figure 2.12 shows one of instrumented tooth pairs. Only one of the three tooth pairs was used, with the other two instrumented pairs providing redundancy in case of failure of any of the gauges within the tested tooth pair.

The strain gauges (Vishay Micro-Measurements SK-06-031EC-350) had overall dimensions of $1.07 \mathrm{~mm}$ by $3.56 \mathrm{~mm}$, a resistance of $350 \Omega$, and a gauge factor of 1.97 . Each strain gauge was wired using a three-wire, quarter-bridge circuit. The lead wires from the strain gauges were connected to solder tabs on the side of the external spline and were protected by epoxy. In order to collect data from all 5 strain gauges on a single tooth at one time, the 15 wires ( 3 wires per gauge, 5 gauges per tooth) were soldered to a male coupler and a female coupler was connected to the data acquisition system.

A National Instruments (NI) data acquisition system was used to collect data from the root strain gauges. The female coupler was connected to an NI SCXI-1314 terminal block which had $350 \Omega$ resistors in it to complete the quarter-bridge circuit. The terminal block was connected with an NI SCXI-1520 module, which was docked in an NI SCXI1000 chassis that connected to the computer. LabVIEW was used for the computer interface. Within LabVIEW, the strain gauge resistance, gauge factor, lead resistance, 


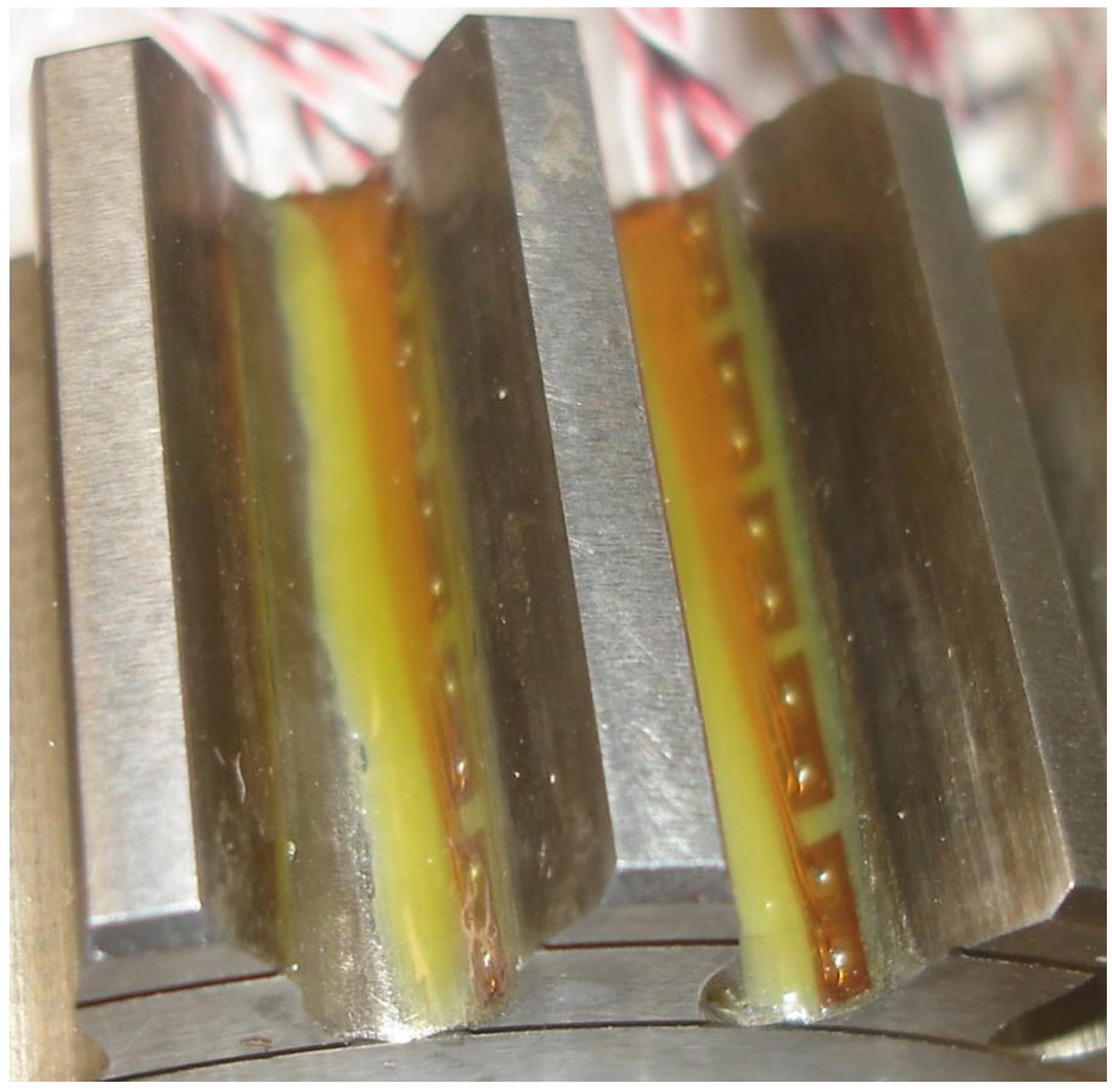

Figure 2.12: Picture of strain gauges mounted on external spline teeth. 
excitation voltage, and other parameters could be set for the strain gauges. Although "warm up" of the gauges was not accounted for, the strain gauges were recalibrated when a coupler was plugged or unplugged, and before a torque was applied. Data was collected for a specific time interval (which was the same for every test) at a sampling rate of 100 Hz. During each test, an excitation voltage of $V_{e}=1.5 \mathrm{~V}$ was sent to the strain gauges and data was received and stored in a text file. Figure 2.13 shows a graph of typical raw data from all five gauges of a single tooth loaded at $600 \mathrm{Nm}$.

In order to convert the raw data from voltage to stress, $\sigma$, the following equations were used [28]. First the voltage ratio, $V_{r}$, was obtained:

$$
V_{r}=\frac{V_{s}-V_{u s}}{V_{e}}
$$

where $V_{s}$ is the mean value of the raw voltage from a single gauge in Figure 2.13, $V_{u s}=0 \mathrm{~V}$ is the mean unstrained value of the raw voltage from the same gauge ( 0 valued since the gauge was calibrated under no load before any data was taken). $V_{r}$ was then converted to strain, $\varepsilon$, using the relationship for a quarter-bridge circuit:

$$
\varepsilon=\frac{4 V_{r}}{G F\left(1+2 V_{r}\right)}\left(1+\frac{R_{L}}{R_{g}}\right)
$$

where $G F=1.97$ is the gauge factor, $R_{L} \approx 0 \Omega$ is the lead wire resistance from the wires 


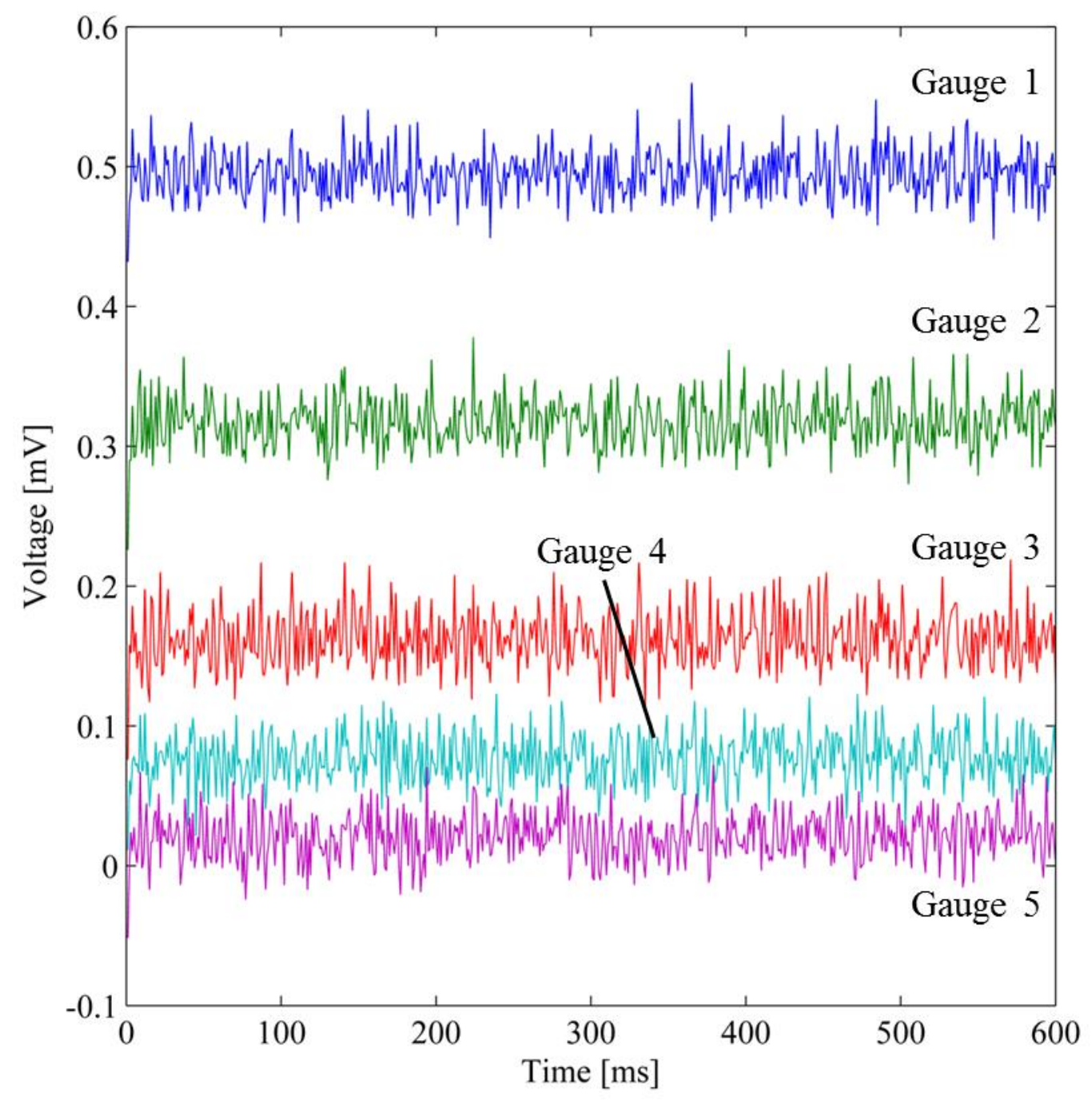

Figure 2.13: Example set of raw data from a single tooth loaded at $600 \mathrm{Nm}$. 
connected to the strain gauge, and $R_{g}=350 \Omega$ is the nominal resistance of the strain gauge. Finally, assuming no shear, Hooke's Law was used to convert from strain, $\varepsilon$, to stress, $\sigma$. This process provided a single data point. The process was repeated for each gauge at each rotational position and for each torque level. 


\section{CHAPTER 3}

\section{EXPERIMENTAL RESULTS}

\subsection{Introduction}

This chapter presents the experimental data collected using the test setup and methodology described in Chapter 2. It is arranged into three main sections. The first section presents results of a repeatability study to demonstrate that the data included in this chapter is repeatable in terms of setup assembly, instrumentation, and data analysis. In accordance with the test matrix of Table 2.3, Section 3.3 presents measurements under spur gear loading conditions, covering the data taken from each of the two instrumented teeth for test \#1. Likewise measurements from test \#3, from Table 2.3, for helical gear loading conditions are presented in Section 3.4. Since the results from test \#2 and test \#4 show similar behavior, they will not be discussed here. 


\subsection{Repeatability Study}

A spline that has good tooth-to-tooth load sharing is expected to have relatively low strain amplitudes. Since this is the case here, the accuracy and repeatability of the measurements taken using the test setup, instrumentation, and data analysis method described in Chapter 2 must be verified. In order to verify the strain measurements (which were used to calculate stress), a repeatability test was performed. For this to constitute a true repeatability test, tear-downs of the test setup and measurements for other tests were taken between the primary test and its repeat.

At the completion of all of the tests listed in Table 2.3, one of the tests (test \#3) was arbitrarily chosen to be repeated. This test condition consisted of helical gear loading at $600 \mathrm{Nm}$ with the mated internal to external tooth pair of tooth 1 to tooth 7 , as seen in Figure 2.10(c). In order to make sure that the testing conditions were repeatable, the test shaft was completely removed from the bearing pedestals and the internally splined gear was removed from the external spline. Then the splined joint was reassembled, making sure that it had the desired index error matching (tooth 1 to tooth 7 ), and the test shaft was placed back on the pedestals.

Figure 3.1 compares original test \#3 results to the results from the repeat test. Here, angular variations of measured root stress collected from gauges 1 to 5 are compared. The original test and the repeat test capture both the shape of the stress caused by the rotation of the splined joint as well as the stress amplitudes at each rotational position. Maximum deviations for gauges 1 through 5 are within 39, 27, 16, 22, and $40 \mathrm{MPa}$, 


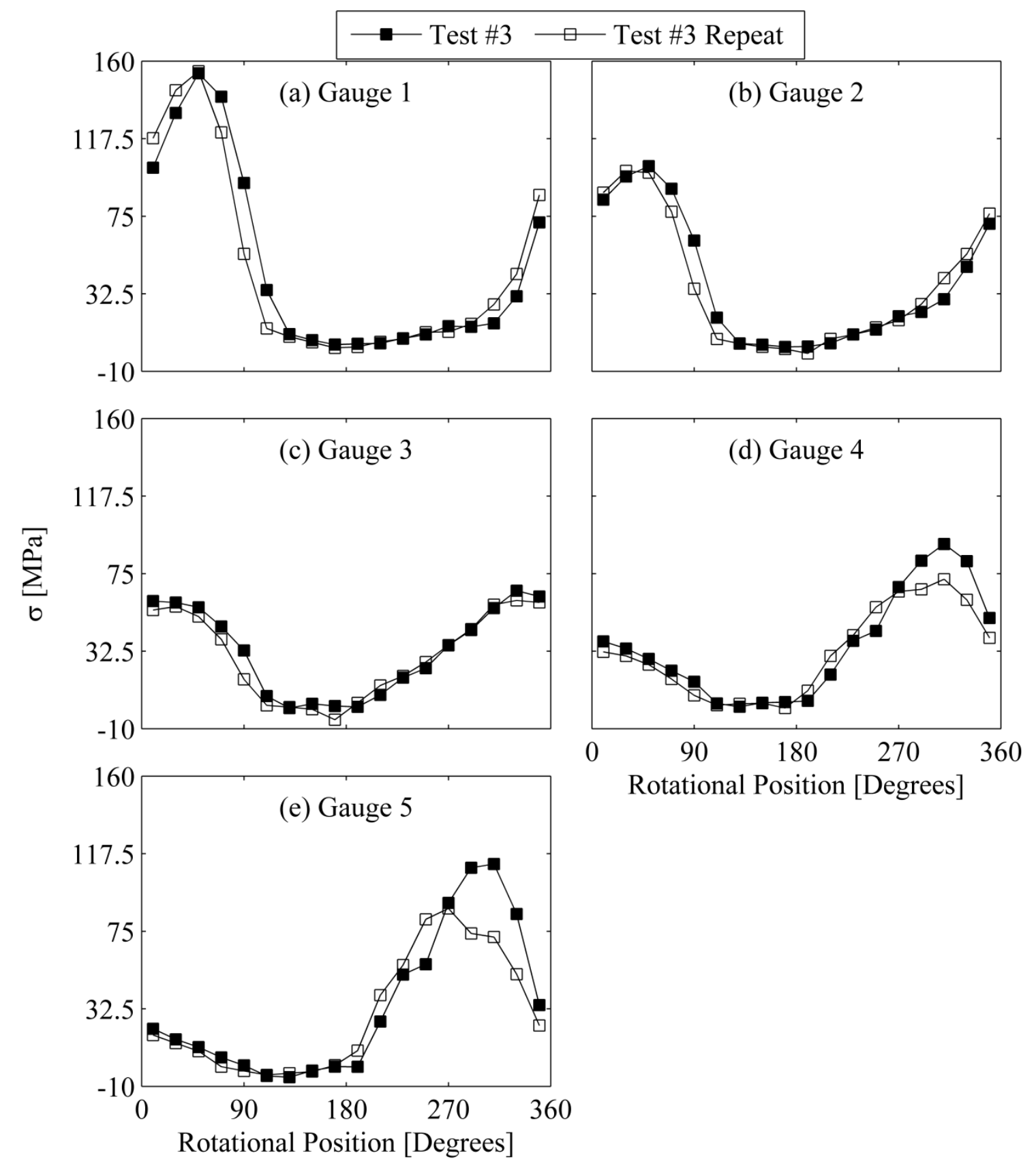

Figure 3.1: Repeatability of the first instrumented tooth for test \#3 in Table 2.3 at $600 \mathrm{Nm}$ for (a) gauge 1 through (e) gauge 5 . 
respectively. These values are acceptable given the complexity of the fixturing used in these experiments.

Figure 3.2 shows results similar to Figure 3.1, for a different index error position (the second tooth from which data was collected for test \#3 in Table 2.3). In Figure 3.2, the differences in measured stress amplitudes are even closer to each other than in Figure 3.1. Maximum deviations for gauges 1 through 5 are within 31, 25, 14, 14, and $18 \mathrm{MPa}$, respectively. The rotational variations of the stress from the two tests are almost identical.

The data presented in this section indicates that the data collected using the test setup, instrumentation, and data analysis method is repeatable. As such, the behavior presented in the next two sections represents the true behavior of splines.

\subsection{Spur Gear Loading}

Spur gear loading of a splined joint produces both a torque and a radial force, as illustrated in Figure 1.2(b). The radial force from the spur gear loading causes a circumferential variation in the overall load distribution, as is obvious in Figure 1.4(b) [10]. As such, the root stress experienced by a single spline tooth is expected to vary significantly based on the relative angular position of that spline tooth with respect to the angular position of the gear mesh interface. For this reason, data was collected for a full rotation of $360^{\circ}$ at increments of $20^{\circ}$. Figure 3.3 shows the spline position relative to the gear mesh location. A spline tooth is at $0^{\circ}$ when it is at the location of the gear mesh interface; it is the closest tooth to the gear mesh. 


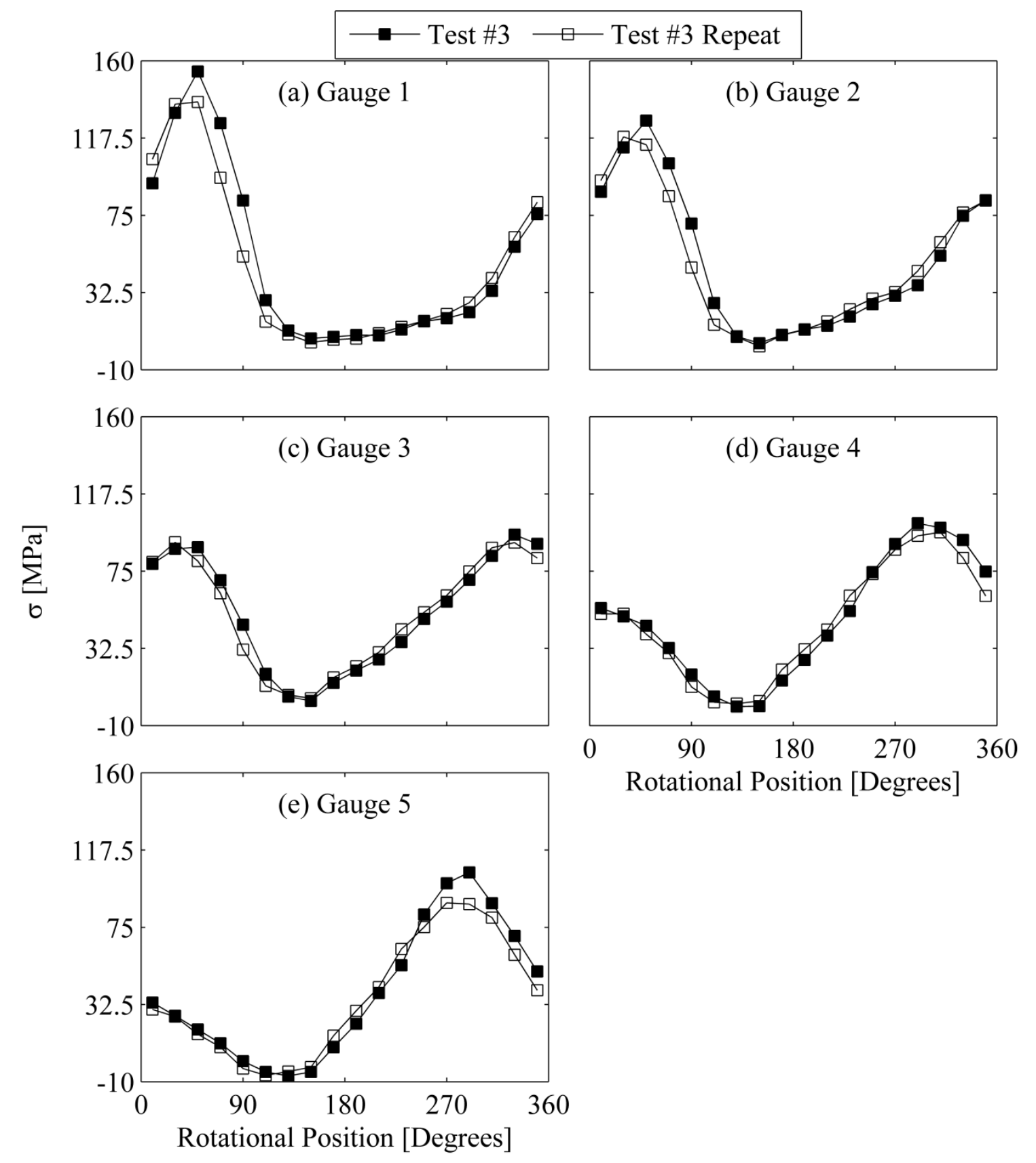

Figure 3.2: Repeatability of the second instrumented tooth for test \#3 in Table 2.3 at 600 $\mathrm{Nm}$ for (a) gauge 1 through (e) gauge 5. 


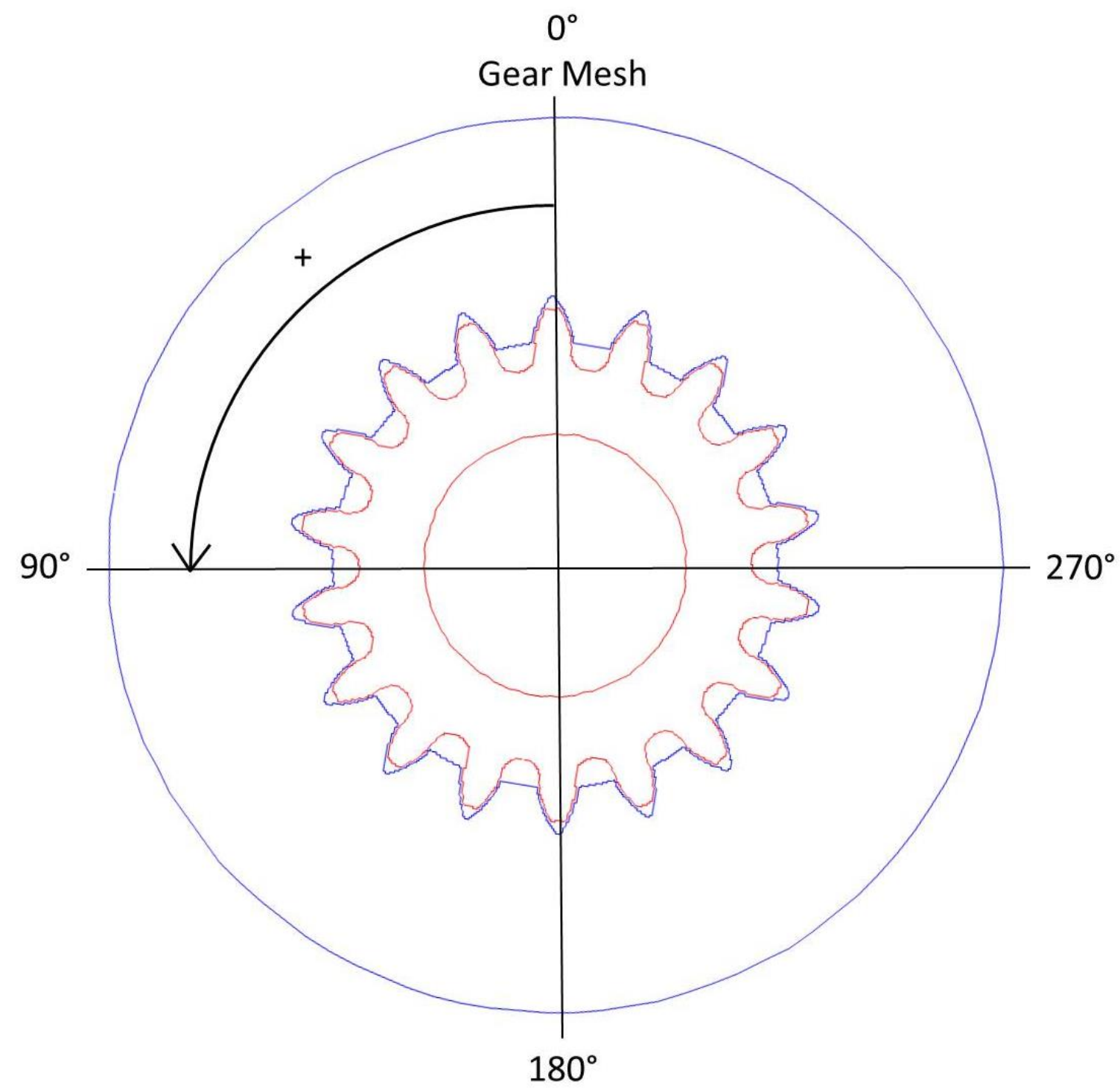

Figure 3.3: Definition of rotational position for a spline tooth with the location of the gear mesh specified. 
Figure 3.4 shows the variation of stress for a single tooth of the splined joint over a $360^{\circ}$ rotation during test $\# 1$ (of Table 2.3) at an applied torque of $600 \mathrm{Nm}$. The stress shown in this figure was calculated from the strain measured from gauge 3, which was located at the center of the face width of the spline tooth. Once balanced by the spur gear mesh formed by the gears (described in Table 2.2) the applied torque of $600 \mathrm{Nm}$ produced a radial force of approximately $8.5 \mathrm{kN}$ along the direction of the plane of action of the spur gear pair. Although the maximum stress seen by a spline tooth is expected to occur at the same angular position as the gear mesh interface, in Figure 3.4, the maximum stress occurs at an angular position of $30^{\circ}$, reaching a value of just over $77 \mathrm{MPa}$. As the tooth of the splined joint moves away from the location of the gear mesh, the measured strain and corresponding stress on this tooth decreases, reaching its minimum within the range of $150^{\circ}$ and $210^{\circ}$. While the absolute minimum stress would be expected to occur at a position that is $180^{\circ}$ away from the absolute maximum stress position at $210^{\circ}$, it actually occurs at $150^{\circ}$ due to potential effects of index errors. Yet, the variation of stress within the range of $150^{\circ}$ and $210^{\circ}$ is only $4 \mathrm{MPa}$. Furthermore, there is clear evidence of the cyclic nature of the stress seen by the spline tooth due to spur gear loading. The stress ratio at the location of gauge 3 is $R=\frac{\sigma_{\min }}{\sigma_{\max }}=\frac{4.4}{77.3}=0.056 \quad$ with $\sigma_{\text {mean }}=\frac{1}{2}\left(\sigma_{\min }+\sigma_{\text {max }}\right)=40.9 \mathrm{MPa}$, indicating that the spline tooth is experiencing almost fully released cyclic loading for each revolution of the shaft. In contrast, a pure torsional load would not result in any cyclic variation of stress. 


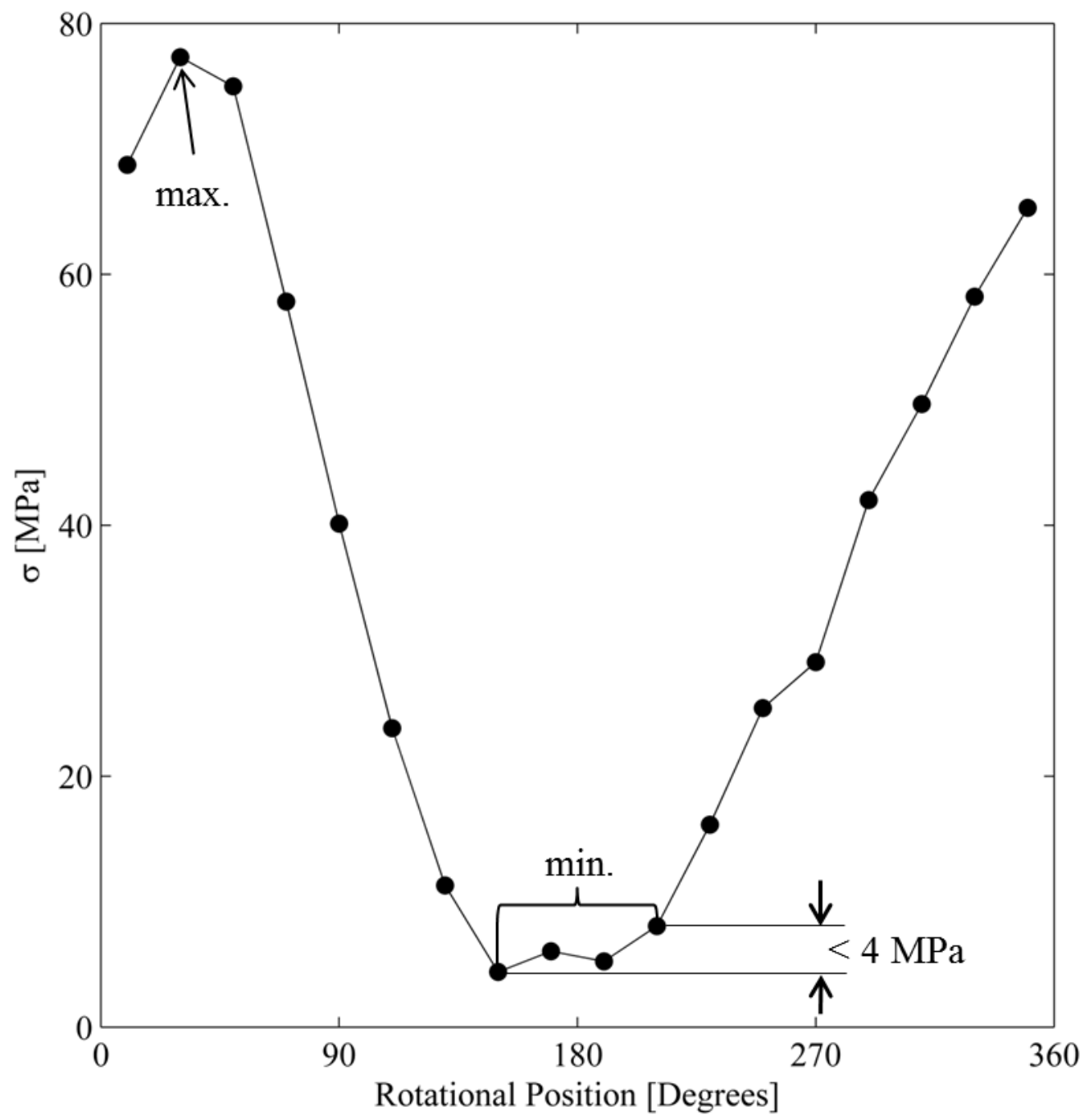

Figure 3.4: Variation of stress for a single spline tooth under spur gear loading conditions at $600 \mathrm{Nm}$. 
Figure 3.5 shows the values of root stress from the first of the two teeth from which data was collected during test \#1 (spur gear loading with the first index error matching in Figure 2.10(a)). This figure displays stresses calculated from all five gauges on the spline tooth as a function of the rotational position. Data at each of the four torque values is presented individually. Several observations may be made from this figure:

- The cyclic variation of root stress for one shaft revolution is evident for all face width (gauge) locations and applied load values. The maximum stress amplitudes occur at $30^{\circ}$ for the most loaded gauges 1 through 3 for three of the four loading cases. (The maximum amplitude occurs at $50^{\circ}$ for an applied load of $150 \mathrm{Nm}$.)

The stress ratios for gauges 1 through $5, R_{i}=\frac{\sigma_{\min , i}}{\sigma_{\max , i}}(i \in[1,5])$, are -0.004 , $-0.044,-0.052,0.019$, and -0.048 at an applied torque of $150 \mathrm{Nm}$, respectively. For an applied torque of $600 \mathrm{Nm}$, the stress ratios for gauges 1 through 5 are $0.034,0.032,0.057,0.117$, and 0.120 , respectively.

- The effect of applied torque is seen to be proportional to the calculated root stress regardless of the face width (gauge) location or rotational position. With an applied torque of $150 \mathrm{Nm}$ in Figure 3.5(a), the maximum magnitude of stress seen by gauge 1 is $\sigma_{\max , 1}=25 \mathrm{MPa}$, whereas in Figure 3.5(d), with an applied torque of $600 \mathrm{Nm}$, the maximum stress is $\sigma_{\max , 1}=87 \mathrm{MPa}$. This indicates that the torque-stress relationship is nonlinear. This nonlinear relationship is expected 


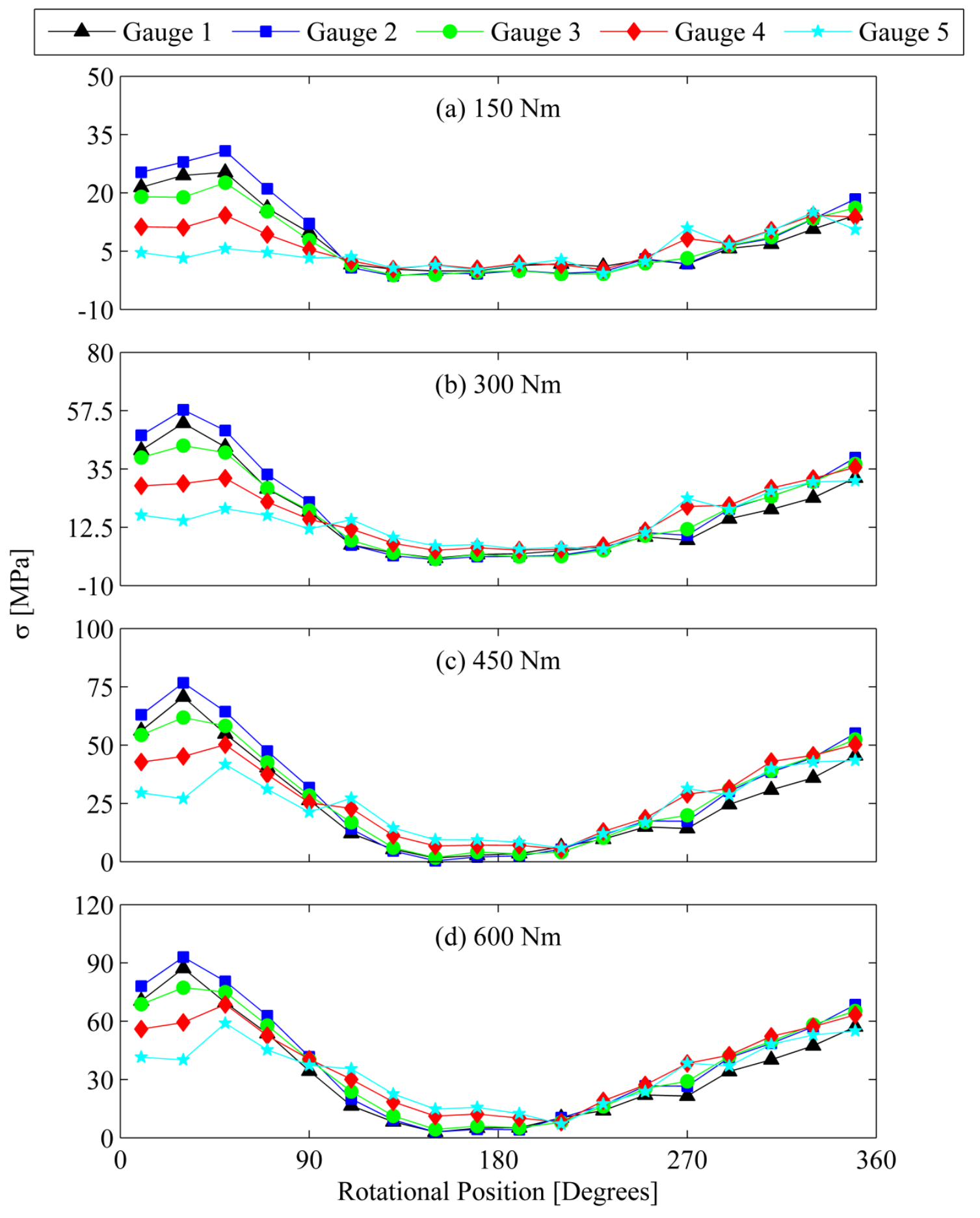

Figure 3.5: Root stress of the first instrumented tooth for test \#1 of Table 2.3 under spur gear loading conditions at (a) $150 \mathrm{Nm}$, (b) $300 \mathrm{Nm}$, (c) $450 \mathrm{Nm}$, and (d) $600 \mathrm{Nm}$. 
because an increase in applied torque brings more surface area into contact and causes the joint stiffness to increase [12].

- In the case of an unmodified purely involute spline under spur gear loading, one would expect that gauge 1 (located at the edge of the face width on the side where the load was applied, as shown in Figure 2.11) would experience the highest magnitude of stress. This is clearly not the case here. The reason is that the teeth of the external spline have a lead crown modification of $10 \pm 3 \mu \mathrm{m}$, as mentioned in Chapter 2. The lead crown would ideally move the stress distribution closer to the center of the face width of the spline tooth. However, the application of torque on one side would still cause larger loads at that side. The combined influence of these two effects result in the location of the second gauge seeing the highest magnitudes of $\sigma_{\max }$ which were $42,73,92$, and $112 \mathrm{MPa}$ at applied loads of 150 , 300, 450, and $600 \mathrm{Nm}$, respectively.

The data in Figure 3.5 is displayed in a different format than in Figure 3.6 in order to illustrate the variation of root stress along the face width of the spline tooth at different rotational positions and torque levels. It is clear that the highest $\sigma_{\max }$ value takes place at a rotational position of $30^{\circ}$, as shown in Figure 3.6(a). The same figure also illustrates that the magnitude of root stress is larger closer to the side of torque application, while tapering off slightly due to the lead crown. It is also seen that the face width location of the highest root stress varies with rotational position. Finally, it is noted 


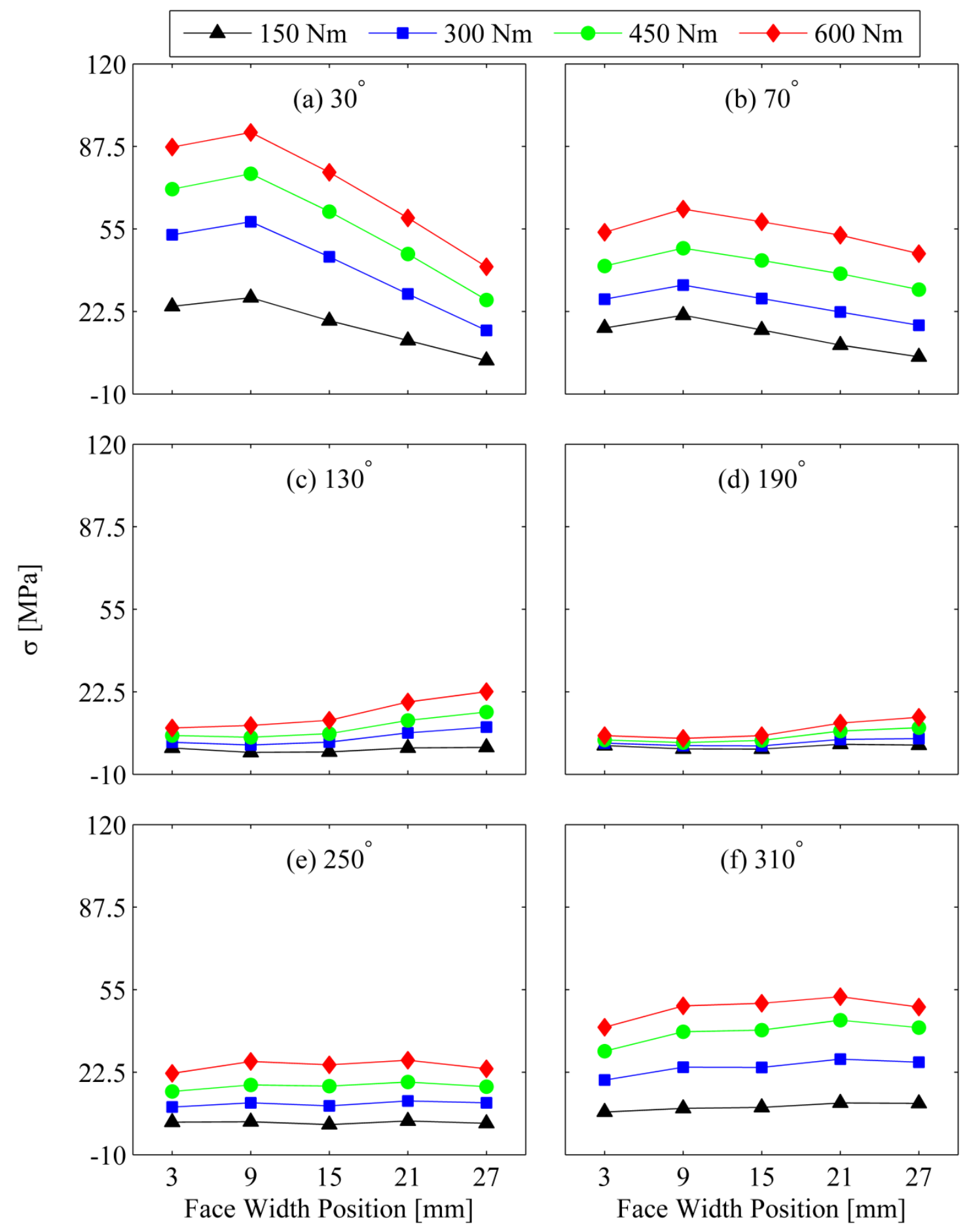

Figure 3.6: Root stress of the first instrumented tooth for test \#1 of Table 2.3 under spur gear loading at angular positions of a) $30^{\circ}$ (maximum stress position), (b) $70^{\circ}$, (c) $130^{\circ}$, (d) $190^{\circ}$, (e) $250^{\circ}$, and (f) $310^{\circ}$. 
that the spacing between the curves for each torque value is not equal. This is due to the nonlinear relationship between the applied torque and the resultant stress.

The measured data from the second tooth for test \#1 in Table 2.3 is presented in Figure 3.7 and Figure 3.8, in the same formats as in Figure 3.5 and Figure 3.6. In Figure 3.7, variation of root stress with rotational position follows the same general trend as in Figure 3.5. However, the overall stress levels, regardless of rotational position and gauge locations are larger for Figure 3.7. This shows the direct influence of index errors of the internal and external components of the splined joint. For instance, in Figure 3.7(d) at $600 \mathrm{Nm}, \sigma_{\max , 2}=112 \mathrm{MPa}$ compared to Figure 3.5(d) where $\sigma_{\max , 2}=93 \mathrm{MPa}$. Such differences are evident for the other gauges as well, indicating that the index error acting on the gauged tooth causes this tooth to carry more load than its nominal value [11]. Such increases are also visible when comparing Figure 3.8 to Figure 3.6. In addition, Figure 3.8 shows the influence of the lead crown on the external spline; it prevents the location of the gauge closest to the loaded side from having the largest magnitude of stress.

In order to further demonstrate the influence of tooth index errors, test \#2 was conducted to provide two additional cases of index error (one for each tooth that was instrumented). Figure 3.9 shows the mean stress calculated over one revolution, for four different index error positions, under spur gear loading, at four load levels. Since all four index error positions should have close to, if not exactly the same magnitudes of stress 


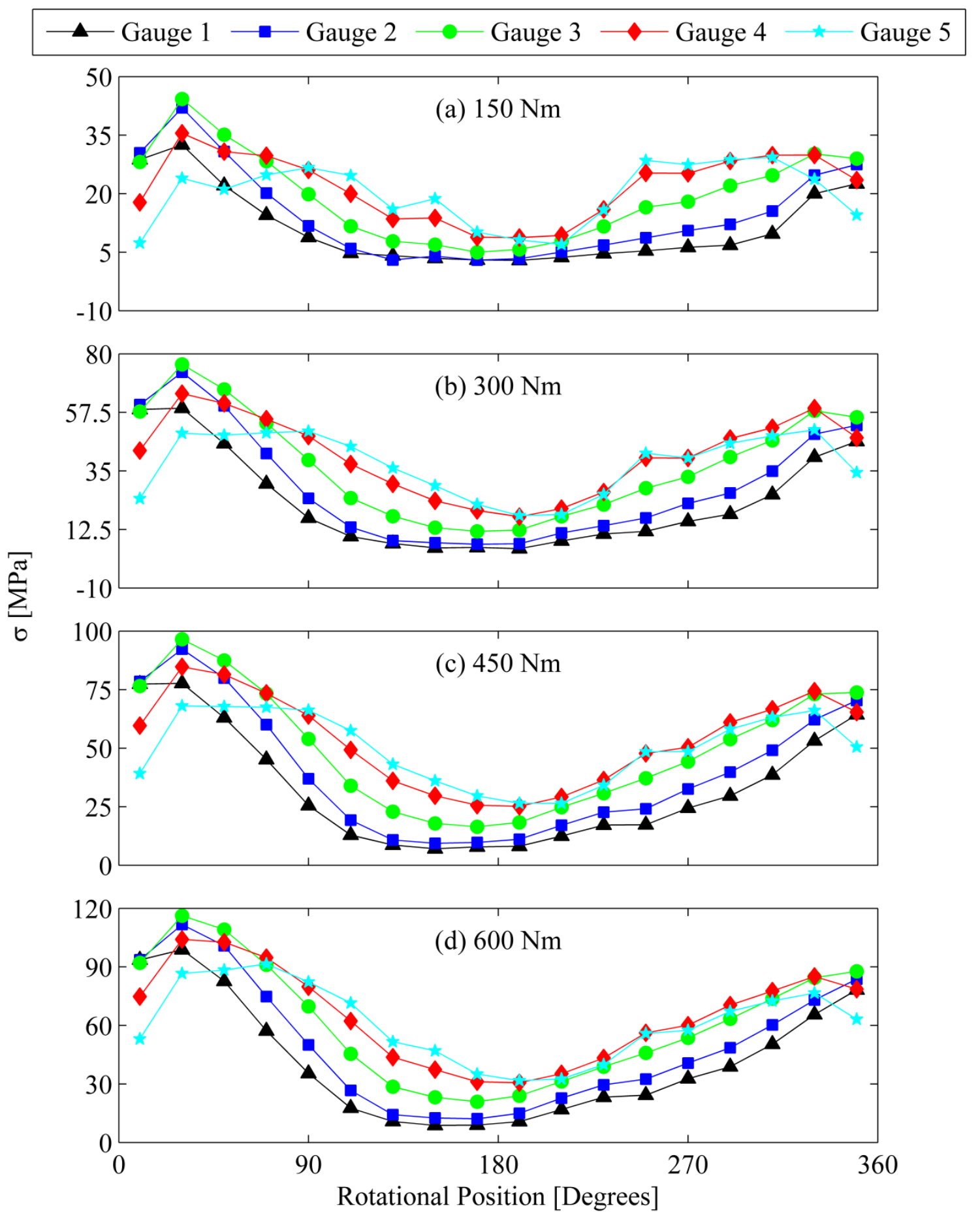

Figure 3.7: Root stress of the second instrumented tooth for test \#1 of Table 2.3 under spur gear loading conditions at (a) $150 \mathrm{Nm}$, (b) $300 \mathrm{Nm}$, (c) $450 \mathrm{Nm}$, and (d) $600 \mathrm{Nm}$. 


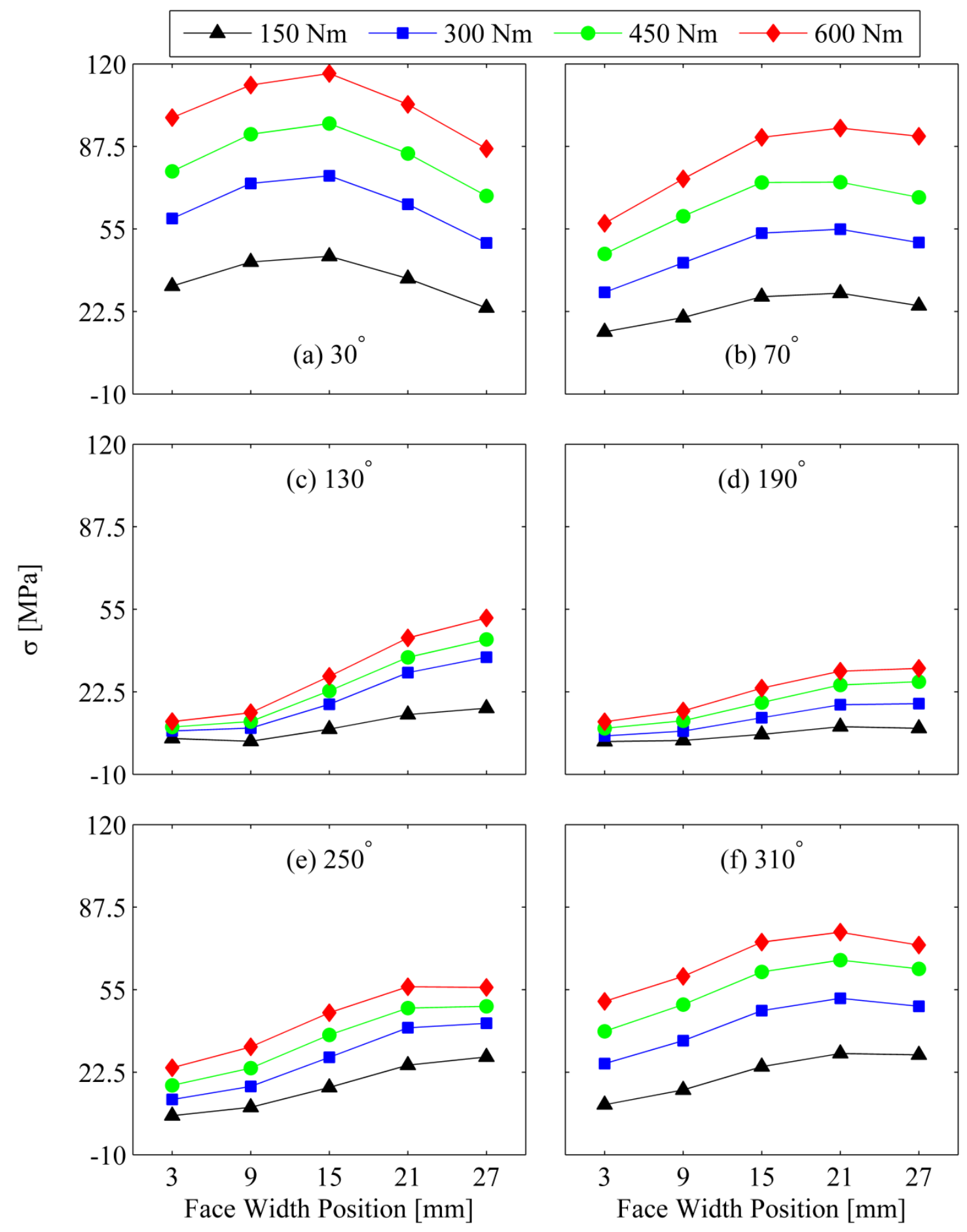

Figure 3.8: Root stress of the second instrumented tooth for test \#1 of Table 2.3 under spur gear loading at angular positions of a) $30^{\circ}$ (maximum stress position), (b) $70^{\circ}$, (c) $130^{\circ}$, (d) $190^{\circ}$, (e) $250^{\circ}$, and (f) $310^{\circ}$. 

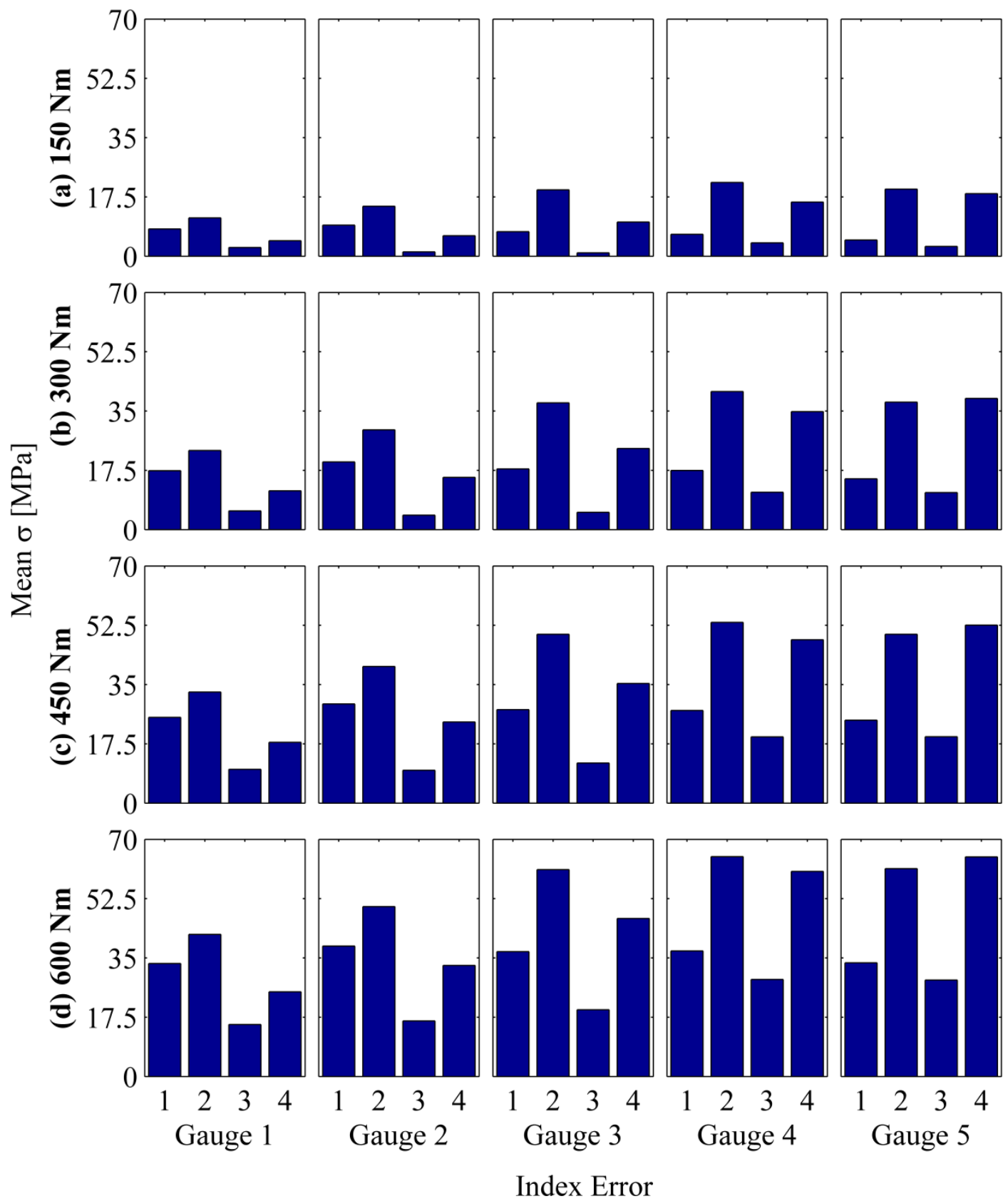

Figure 3.9: Mean stress over an entire revolution under spur gear loading for 4 index error locations at (a) $150 \mathrm{Nm}$, (b) $300 \mathrm{Nm}$, (c) $450 \mathrm{Nm}$, and (d) $600 \mathrm{Nm}$. 
as without index errors, it is clear that the influence of the index errors is not negligible. It elevates or lowers the stress on the tooth regardless of face width location or rotational position. In Figure 3.9(d) at $600 \mathrm{Nm}$ for gauge 3, for instance, there is $\pm 67 \%$ variation of the mean stress between index error 2 and index error 3 . The effect of index errors is even clearer in Figure 3.10, which shows the root stress under a load of $600 \mathrm{Nm}$ for (a) gauge 1 through (e) gauge 5 for the four different index error positions as a function of rotational position. Here one observes that, at specific rotational positions, the stress corresponding to an index error condition is greater than the stress corresponding to a different index error condition; the opposite is true at other rotational positions. Therefore, the observations made about the mean stress values in Figure 3.9, that a single index error location has a higher magnitude of stress at, say, index error 2, cannot be extended to the $\sigma_{\max }$ values.

The strong impact of index errors on the magnitude of stress complicates the model validation efforts that will be presented in the next chapter. It is not practical to fabricate splined joints without any index errors. Even with slight index errors, the toothto-tooth load distributions were shown to change significantly [11]. In addition, a repeatable measurement of a spline's index errors, especially of the internal teeth, is difficult even with state-of-the-art gear CMMs. This is due to run-out imposed by the mounting of the internal spline. As such, the data shown here is significant in terms of the overall behavior, specifically the dependence on rotational and face width locations. However, it is still subject to uncertainties induced by the index errors, which may have an impact on the overall amplitudes. 


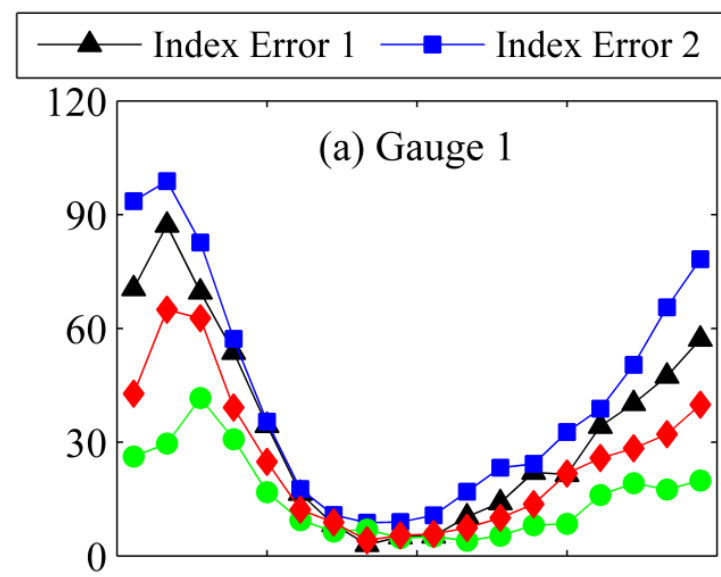

Index Error $3 \multimap$ Index Error 4
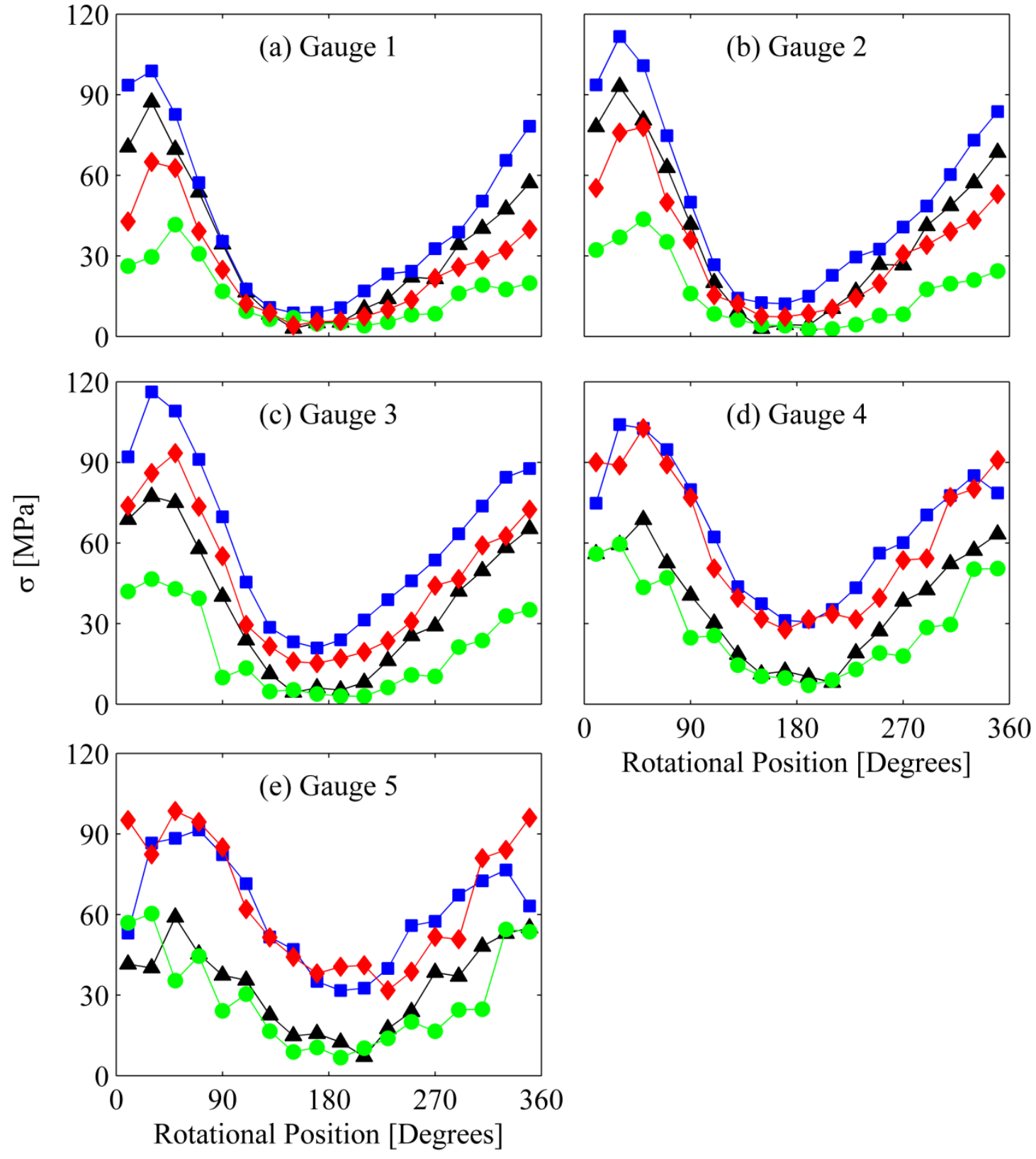

Figure 3.10: Root stress due to a $600 \mathrm{Nm}$ spur gear loading condition for four index error locations for (a) gauge 1 through (e) gauge 5 . 


\subsection{Helical Gear Loading}

Helical gear loading of a splined joint produces a radial force, a torque, and an overturning moment, as illustrated in Figure 1.2(c). Similar to spur gear loading, the radial force causes a circumferential variation in the overall load distribution. Unlike for spur gear loading, however, the overturning moment causes variations both along the face width direction and the circumferential direction, as is evident in Figure 1.4(c) [10]. As such, the root stress experienced by a single spline tooth over one rotation under helical gear loading is expected to vary drastically along both the circumferential and face width directions.

Figure 3.11 illustrates the variation of stress for a single tooth in the splined joint over a $360^{\circ}$ rotation during test \#3 (of Table 2.3) at an applied torque of $600 \mathrm{Nm}$. The stress shown in the figure was calculated from gauge 1 . Gauge 1 was located at the edge of the face width of the spline tooth closest to where the load was applied. For helical gear loading unlike for spur gear loading, the maximum stress does not occur at the location of the gear mesh interface. Also, in general, the maximum magnitude of stress is greater for helical gear loading than for spur gear loading. However, the overall trends for the two loading types are somewhat similar. There is a peak at a specific rotational position, in Figure 3.11 at $50^{\circ}$ with a magnitude of just over $153 \mathrm{MPa}$, and a much lower stress level $180^{\circ}$ away from the peak. The difference between the spur and helical gear loading conditions is that, for the helical gear loading, there is a much longer period where the magnitude of the stress dwells near the minimum value. For the spur gear 


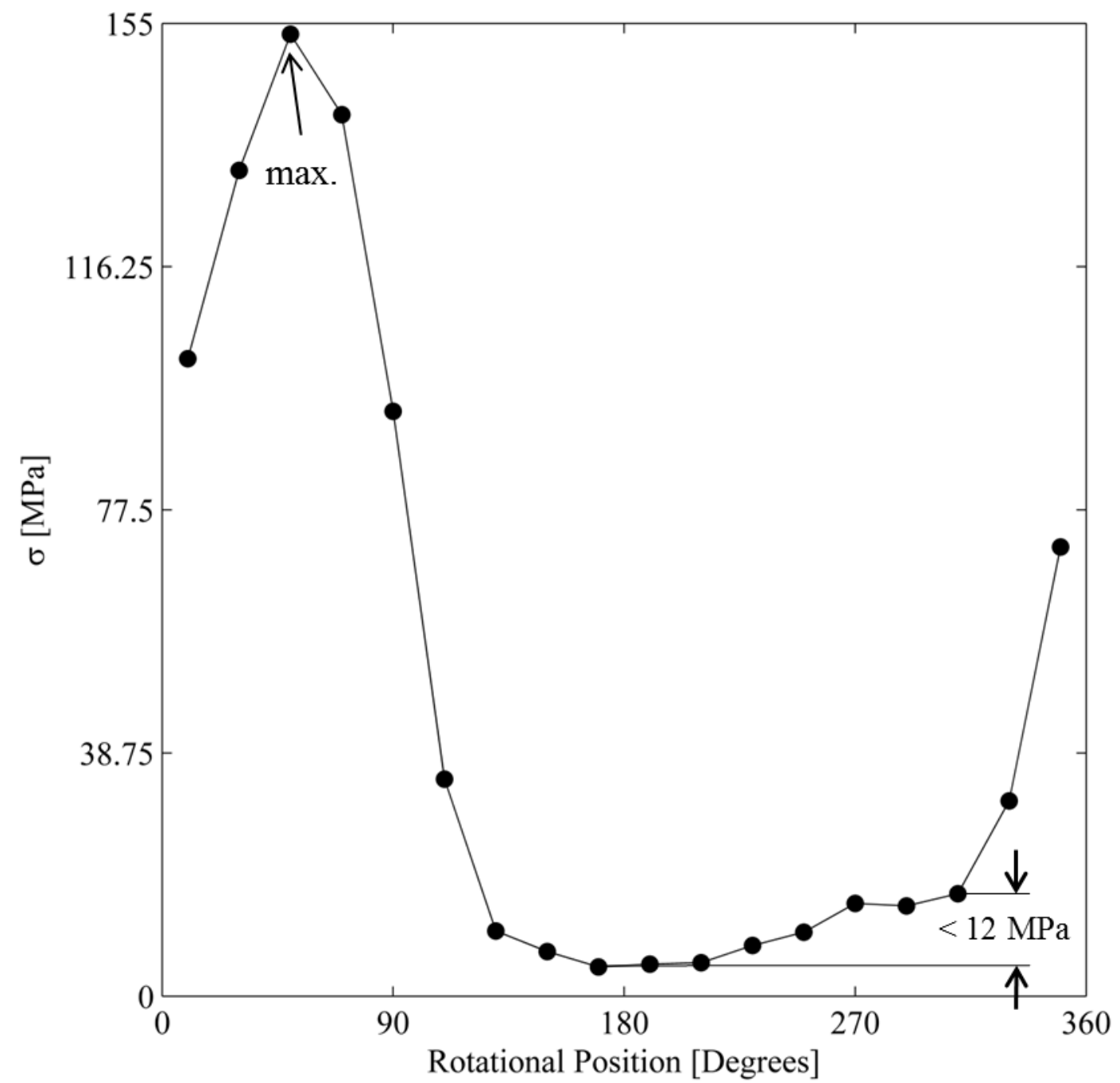

Figure 3.11: Variation of stress for a single spline tooth under helical gear loading conditions at $600 \mathrm{Nm}$. 
loading, shown in Figure 3.4, only $60^{\circ}$ of the rotation is near the minimum point, within 4 MPa. However, for the helical gear loading, shown in Figure 3.11, stress is within a range of $12 \mathrm{MPa}$ of the minimum point for half of the revolution.

For helical gear loading, the dwell near the minimum point is caused by the overturning moment; it moves the point of maximum stress from one side of the face width of the spline tooth to the other side of the face width of the spline tooth as the splined joint rotates. Since the point of maximum stress moves to the opposite face width position from gauge 1, which was used to calculate the stress in Figure 3.11, it appears as if there is very little stress for a larger portion of the revolution for the helical gear loading case than for the spur gear loading case.

The similarities between helical gear loading and spur gear loading continue when comparing the cyclic nature of the stress seen by a spline tooth. Like under spur gear loading, the spline tooth under helical gear loading also experiences cyclic loading for each revolution of the shaft. At the location of gauge 1 , the stress ratio is $R=0.03$ with $\sigma_{\text {mean }}=79 \mathrm{MPa}$.

Figure 3.12 shows the value of root stress from the first of the two teeth from which data was collected during test \#3 (helical gear loading with the first index error matching in Figure 2.10(c)). This figure displays the stresses calculated from all five gauges on the spline tooth as a function of the rotational position. Data at each of the four torque values is presented individually. Several observations, similar to those made for spur gear 


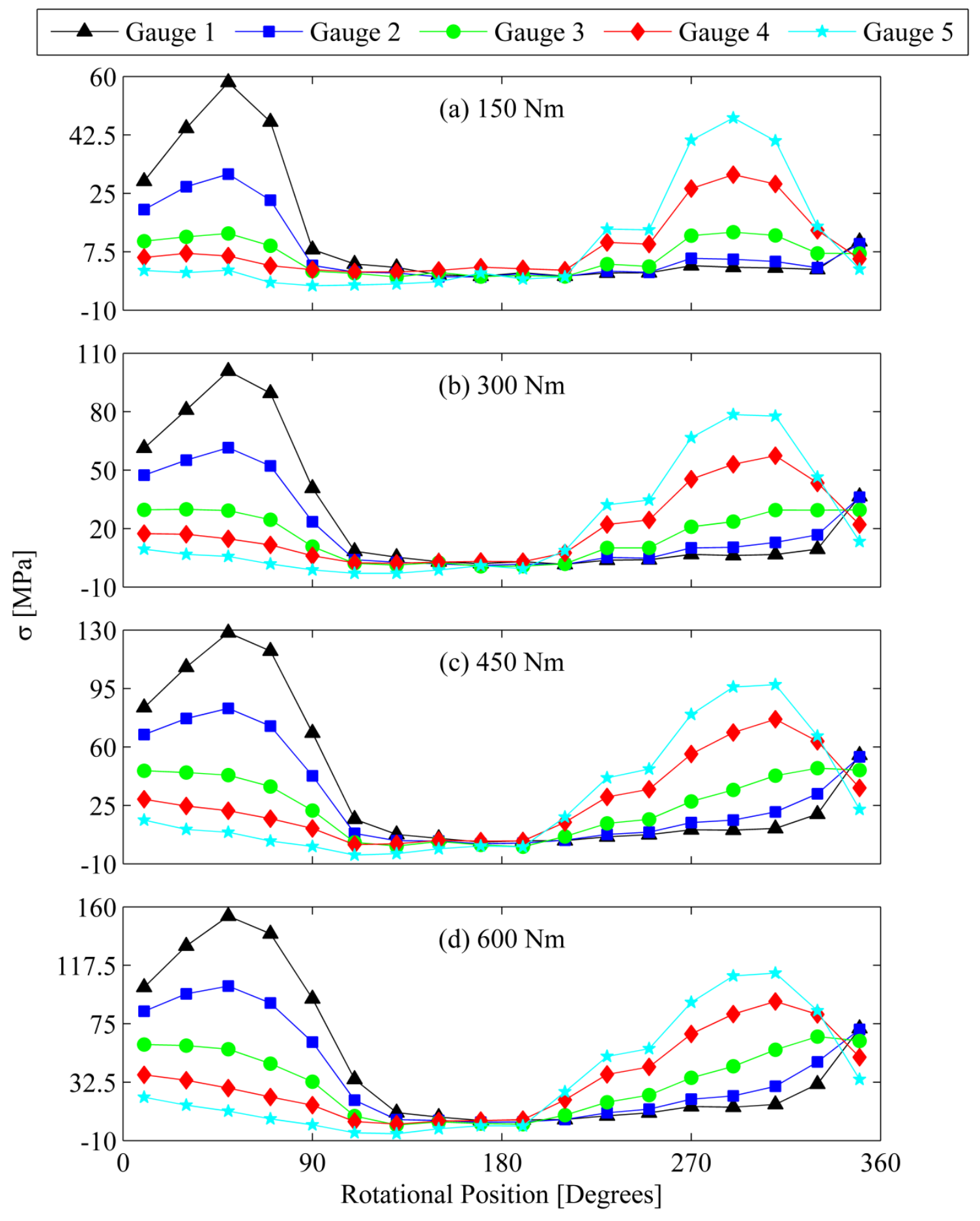

Figure 3.12: Root stress of the first instrumented tooth for test \#3 of Table 2.3 under helical gear loading conditions at (a) $150 \mathrm{Nm}$, (b) $300 \mathrm{Nm}$, (c) $450 \mathrm{Nm}$, and (d) $600 \mathrm{Nm}$. 
loading from Figure 3.5, may be made from this figure:

- The cyclic variation of root stress is evident for all face width (gauge) locations and applied load values. Unlike for spur gear loading, however, maximum stress amplitudes are not all reached at the same angular location relative to the gear mesh position. The overturning moment causes the two gauges along the edge of the face width, away from the loading of the splined joint, to reach a peak at an angular position of $310^{\circ}$ for three of the four loading cases. The two gauges along the edge of the face width closer to the loading of the splined joint reach a peak at an angular position of $50^{\circ}$. Furthermore, the gauge in the middle of the face width reaches a peak at an angular position between the peaks of the other four gauges; it is not consistently at the same rotational position. The peak for gauge 3 would be expected to be at the halfway point, $0^{\circ}$, between the other two peaks. The stress ratios for gauges 1 through 5 are $0.003,-0.001,-0.003,0.048$, and -0.056 at an applied torque of $150 \mathrm{Nm}$, respectively. For an applied torque of $600 \mathrm{Nm}$, the stress ratios for gauges 1 through 5 are $0.030,0.033,0.020,0.022$, and -0.045 , respectively.

- The effect of applied torque is seen to be proportional to calculated root stress regardless of the face width (gauge) location or rotational position. The same nonlinear relationship that applies to spur gear loading also applies to helical gear loading due to the fact that an increase in applied torque brings more surface area into contact. With an applied torque of $150 \mathrm{Nm}$ in Figure 3.12(a), the maximum magnitude of stress seen by gauge 1 is $\sigma_{\max , 1}=58 \mathrm{MPa}$, whereas in Figure 
$3.12(d)$, with an applied torque of $600 \mathrm{Nm}$, the maximum stress is $\sigma_{\max , 1}=153$ MPa.

- Unlike for spur gear loading, in helical gear loading the impact of lead crown does not seem to have a significant effect on which gauge location has the highest stress values. This is likely due to the fact that the overturning moment, which causes the point of maximum stress to shift from one side of the face width of the spline tooth to the other side of the face width of the spline tooth, overshadows the effect of the lead crown. However, the loading location is also important. It is clear that gauge 1, on the edge of the splined joint closer to the point of loading, has the highest magnitudes of $\sigma_{\max }$, which were $58,101,128$, and $153 \mathrm{MPa}$ at applied loads of 150, 300, 450, and $600 \mathrm{Nm}$, respectively.

The data in Figure 3.12 is displayed in a different format than in Figure 3.13 in order to illustrate the variation of root stress along the face width of the spline tooth at different rotational positions and torque levels. The highest $\sigma_{\max }$ value takes place at the rotational position of $50^{\circ}$, as shown in Figure 3.13(d). Although the overturning moment moves the point of maximum stress from one edge of the face width of the spline tooth to the other edge, the magnitude of root stress is larger closer to the side of torque application. Lastly, it is noted that the spacing between the curves for each torque value is not equal, due to the nonlinear relationship between the applied torque and the resultant stress. 


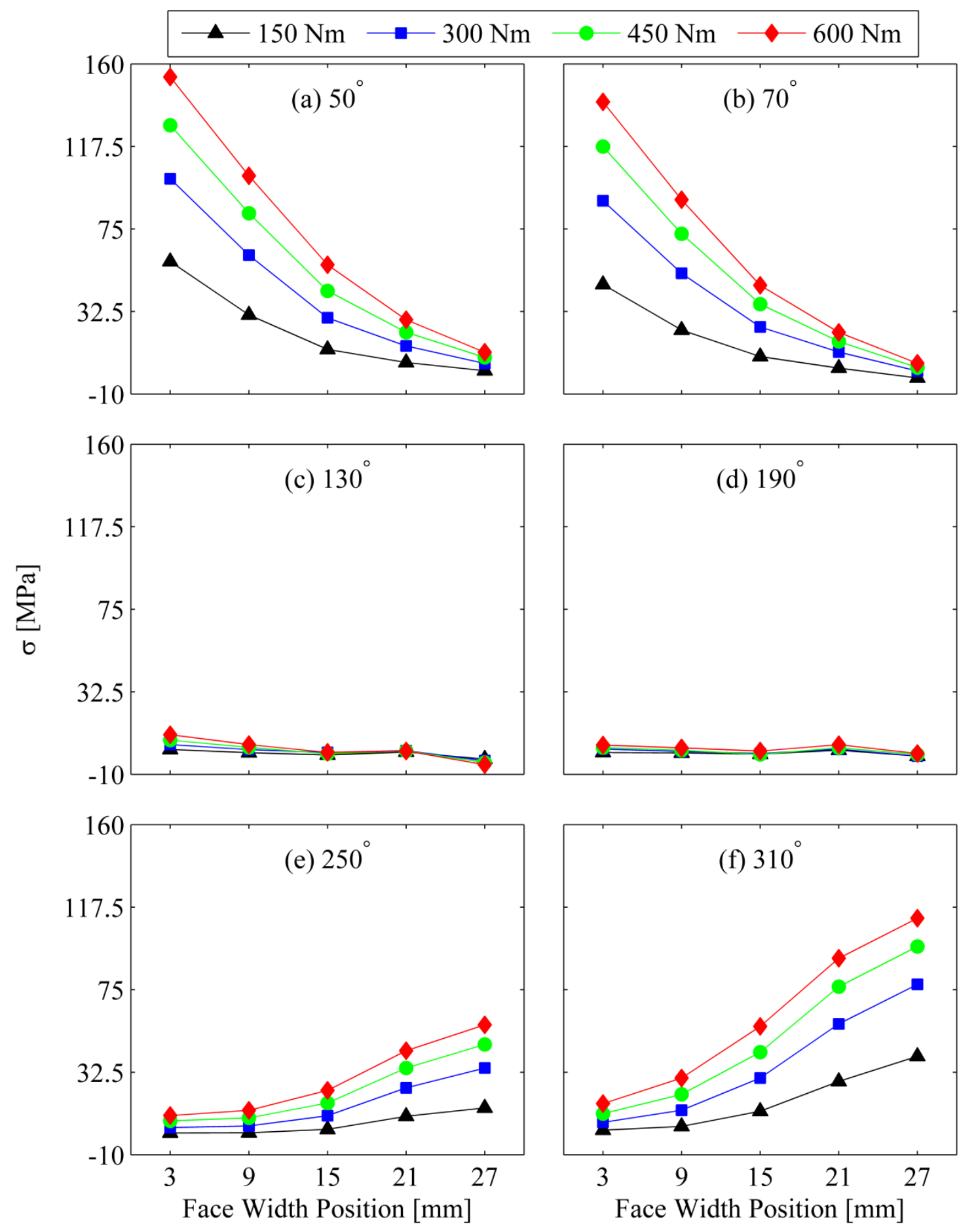

Figure 3.13: Root stress of the first instrumented tooth for test \#3 of Table 2.3 under helical gear loading at angular positions of a) $50^{\circ}$ (maximum stress position), (b) $70^{\circ}$, (c) $130^{\circ}$, (d) $190^{\circ}$, (e) $250^{\circ}$, and (f) $310^{\circ}$. 
The measured data from the second tooth for test \#3 in Table 2.3 is presented in Figure 3.14 and Figure 3.15 in the same formats as Figure 3.12 and Figure 3.13. In Figure 3.14 , variation of root stress with rotational position follows the same general trend as in Figure 3.12. Yet the overall stress levels tend to be slightly smaller in Figure 3.14 under applied loads of 150 and $300 \mathrm{Nm}$ but similar for the loads of 450 and $600 \mathrm{Nm}$. This is a contradiction of the expected influence of index errors. One tooth with a larger index error should have higher stress at all, not some, load levels.

In order to further demonstrate the influence of tooth index errors, test \#4 was conducted to provide two additional cases of index error (one for each tooth that was instrumented). Figure 3.16 shows the mean stress calculated over one revolution, for four different index error positions, under helical gear loading, at four load levels. Unfortunately, unlike for spur gear loading, Figure 3.16 does not show any consistency of a certain index error position always having a higher (or lower) stress than another index error position. Figure 3.17, which shows the root stress under a load of $600 \mathrm{Nm}$ for (a) gauge 1 through (e) gauge 5 for the four different index errors positions as a function of rotational position, also does not show any obvious trends.

Since the index error measurements for helical gear loading do not show any significant trends, this further complicates the model validation efforts presented in the next chapter. Similar to the data for spur gear loading, the data for helical gear loading is significant in terms of the overall behavior, specifically the dependence on rotational and 


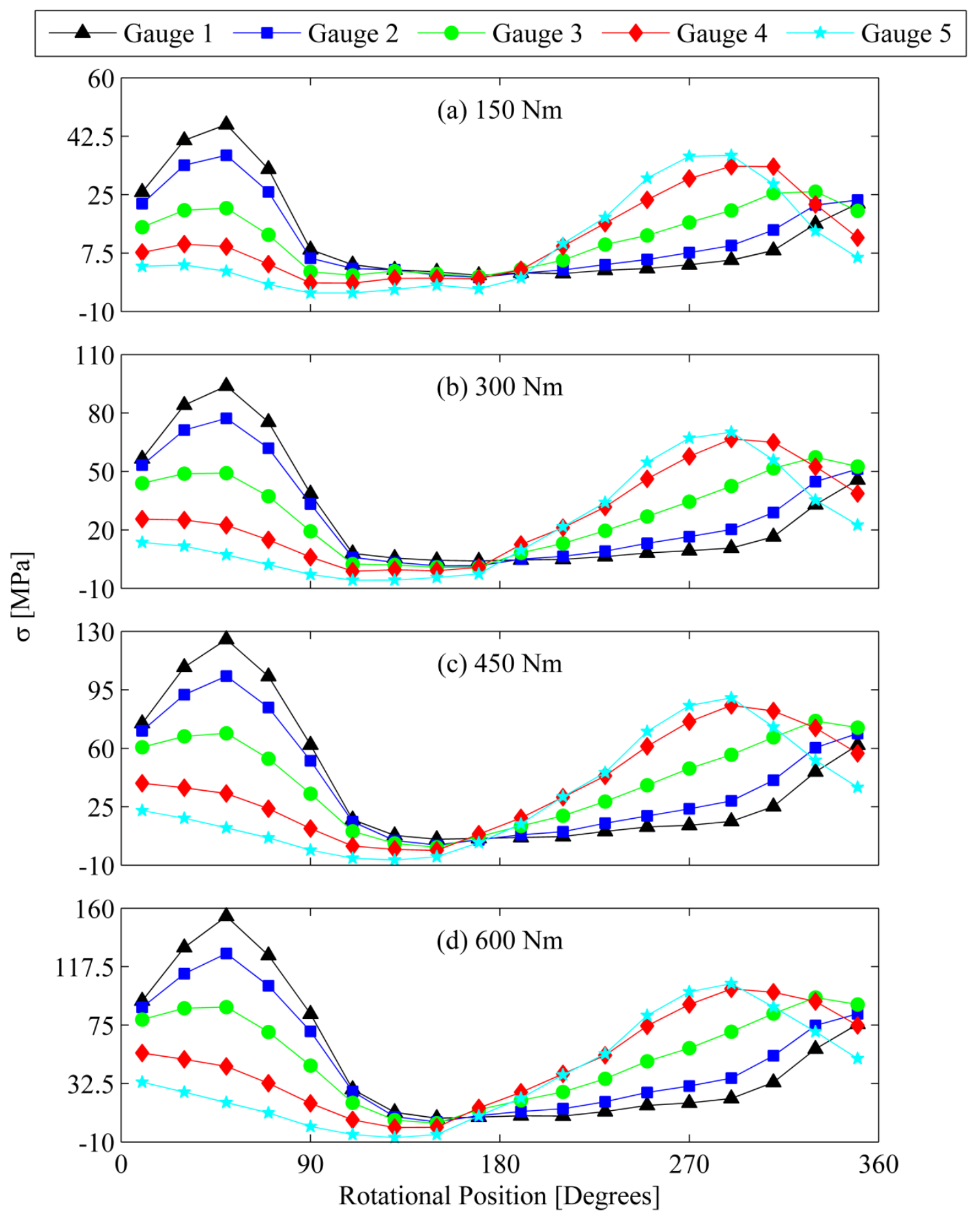

Figure 3.14: Root stress of the second instrumented tooth for test \#3 of Table 2.3 under helical gear loading conditions at (a) $150 \mathrm{Nm}$, (b) $300 \mathrm{Nm}$, (c) $450 \mathrm{Nm}$, and (d) $600 \mathrm{Nm}$. 

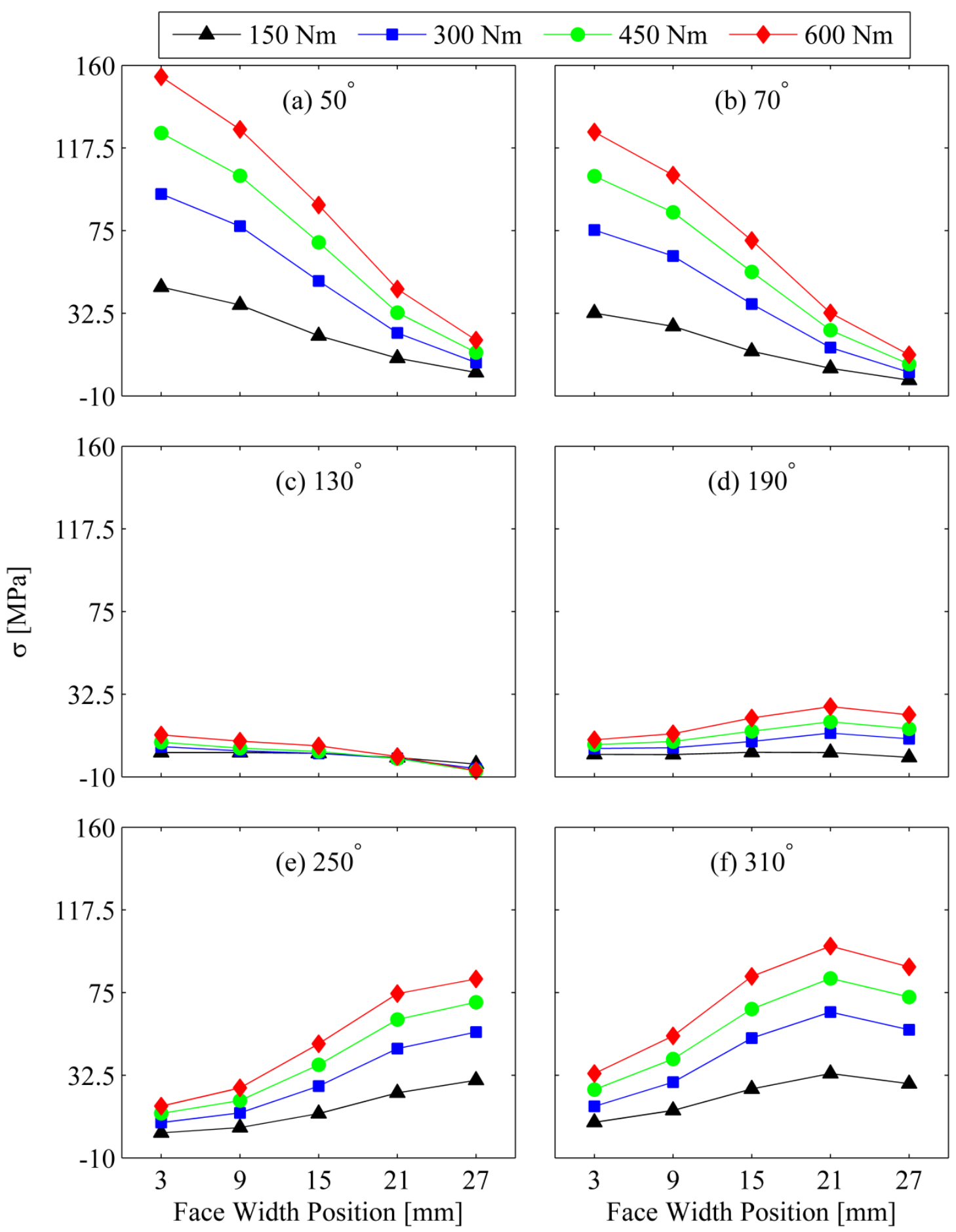

Figure 3.15: Root stress of the second instrumented tooth for test \#3 of Table 2.3 under helical gear loading at angular positions of (a) $50^{\circ}$ (maximum stress position), (b) $70^{\circ}$, (c) $130^{\circ}$, (d) $190^{\circ}$, (e) $250^{\circ}$, and (f) $310^{\circ}$. 

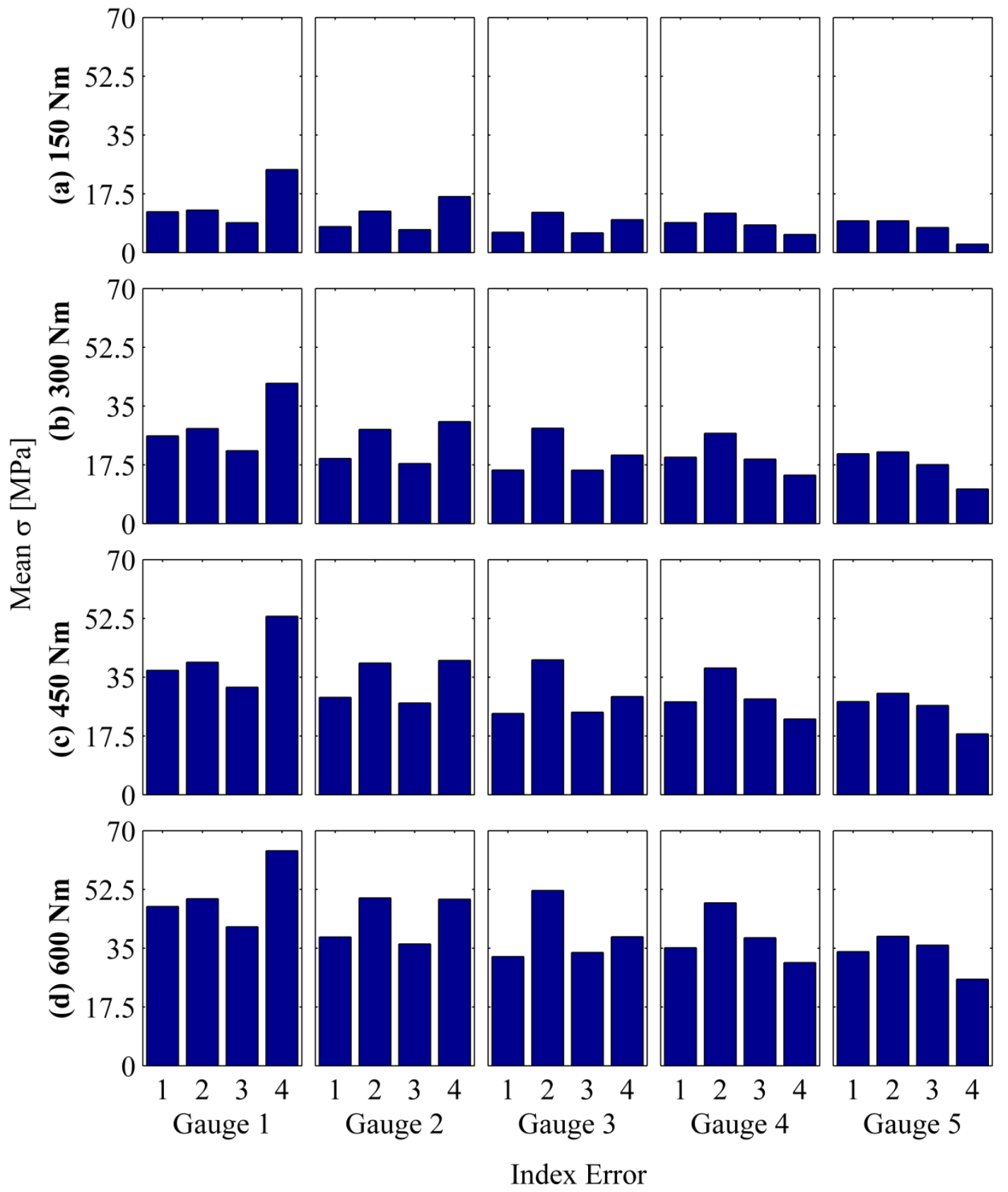

Figure 3.16: Mean stress over an entire revolution under helical gear loading for 4 index error locations at (a) $150 \mathrm{Nm}$, (b) $300 \mathrm{Nm}$, (c) $450 \mathrm{Nm}$, and (d) $600 \mathrm{Nm}$. 


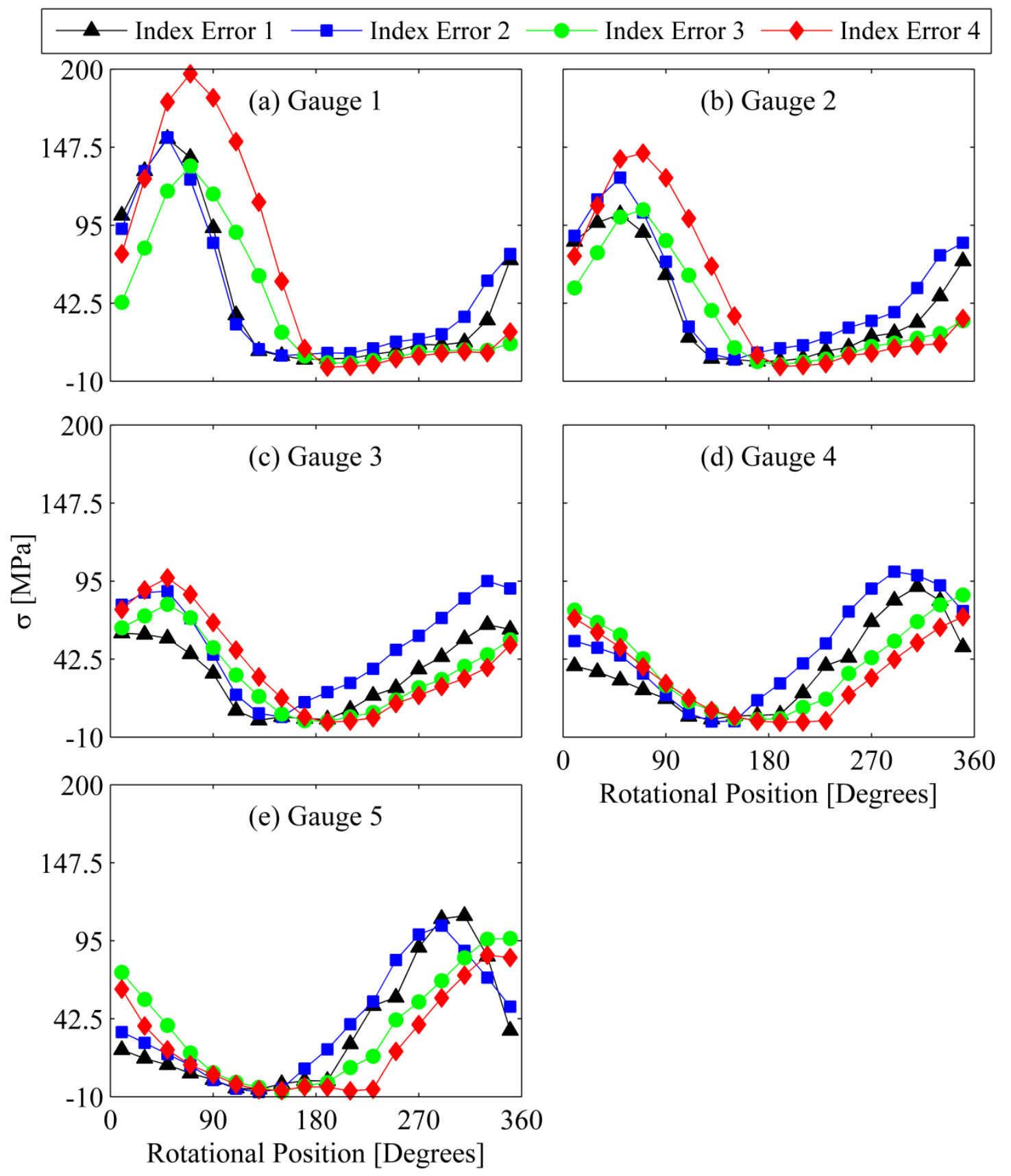

Figure 3.17: Root stress due to a $600 \mathrm{Nm}$ helical gear loading condition for four index error locations for (a) gauge 1 through (e) gauge 5. 
face width locations. However, it is still subject to uncertainties induced by the index errors, which may have an impact on the overall amplitudes.

\subsection{General Conclusions}

The following general conclusions are drawn from the experimental data presented in this chapter.

(i) The experimental data collected is repeatable using the same test setup, testing conditions, and test specimens. As such, the behavior presented represents the true behavior of splines.

(ii) For both spur and helical gear loading conditions, the higher the load applied to the splined joint, the higher the stress on the spline teeth. However, the stiffening of the splined joint causes a nonlinear relationship between the applied torque and the resultant stress.

(iii) For both spur and helical gear loading, higher magnitudes of stress are experienced at locations near the edge of the face width of the splined joint, closer to the side where the load was applied.

(iv) For spur gear loading, the lead crown moves the location of maximum stress away from the edge where the load is applied. This effect is diminished significantly for helical gear loading due to the overturning moment.

Additional figures for test $\# 2$ and test \#4 are presented in Appendix A. 


\section{CHAPTER 4}

\section{SIMULATION OF EXPERIMENTS}

\subsection{Introduction}

The main goal of this chapter is to assess the accuracy of the clearance-fit spline model of Hong et al. [10]. In order to achieve this goal, three individual tasks need to be completed:

(i) Although the spline load distribution model of Hong et al. [10] predicts tooth forces and contact load (stress) distributions along the tooth flanks, it does not have the capability to predict a spline's root stresses. Since experimental measurements of contact stress are not feasible, the model must be upgraded in order to add root stress prediction capability. Root stress prediction capability will allow for direct comparisons between experimental results and model predictions. As such, an existing finite element (FE) template of a gear segment created by Talbot [25] will be adapted to external spline segments. Contact load distributions predictions of the external spline created by Hong et al. [10] will be utilized to load the FE segment model in order to predict the 
distribution of the root stress. This enhancement of the model of Hong et al. [10] is the first topic presented in this chapter.

(ii) Before simulations of an entire splined joint may be utilized with the new root stress prediction capabilities, the root stress predictions must be validated. For this, single-tooth point-load experimental results, obtained using the setup illustrated in Figure 2.6, will be directly compared to the simulation results. These comparisons will not only verify that the FE model developed is accurate, they will also reveal the variation of the gauge locations along the root fillet of the spline tooth.

(iii) The final task in this chapter is to compare the experimental results, presented in detail in Chapter 3, to the root stress predictions of the model. These comparisons provide one with the ability to assess the accuracy of the model of Hong et al. [10] under both spur and helical gear loading conditions.

The next three sections of this chapter describe the aforementioned tasks. The chapter ends with a discussion of the results. It includes an explanation of the reasons for discrepancies between the experimental results and the model, as well as the validity of the spline load distribution model of Hong et al. [10].

\subsection{Development of FE-Based Splined Joint Root Stress Predictions}

In this section, the FE model developed by Talbot [25] for a gear segment will be adapted to apply to an external spline tooth segment. This gear FE template applies to 
splines without any modifications since the spline teeth have similar involute geometry to gears. Figure 4.1 shows the FE model mesh of a 3-tooth segment of a spline. As it is described in Reference [25], the elements used in the FE model mesh are 20-noded isoparametric elements. These quadratic interpolation elements were reported to capture bending and shear of the teeth effectively, while greatly reducing the number of elements required for the solution to converge within an acceptable amount of error [25]. The boundary conditions are "fixed" at both the connection of the external spline-shaft interface, as well as at the cut edges of the segment, shown in Figure 4.1. The general procedure to solve the model consists of (i) applying the mesh and the load distribution, (ii) calculating the displacement field for each mesh position, and (iii) using the strain displacement matrix along with a material matrix to solve for the stress.

With the gear FE template adapted to splines, the spline load distributions must next be applied to the FE model of Figure 4.1. The contact loads from the model of Hong et al. [10], which are already in the form of individual cells in a grid laid on the spline tooth, are converted into a force distribution. These predicted forces at each grid cell are applied to the spline FE model in the tooth surface normal directions. Figure 4.2 illustrates (a) the predicted contact stress distribution of a spline tooth and (b) the corresponding tooth grid force distribution to be applied to a tooth of the FE model.

Since Talbot's FE gear tooth segment model [25] was initially created for gear teeth, some additional changes needed to be made so that the model would work for spline teeth. The main modification was that loading at the gear mesh was limited to a small number of teeth. For low contact ratio spur gear pairs, for instance, only one or two 


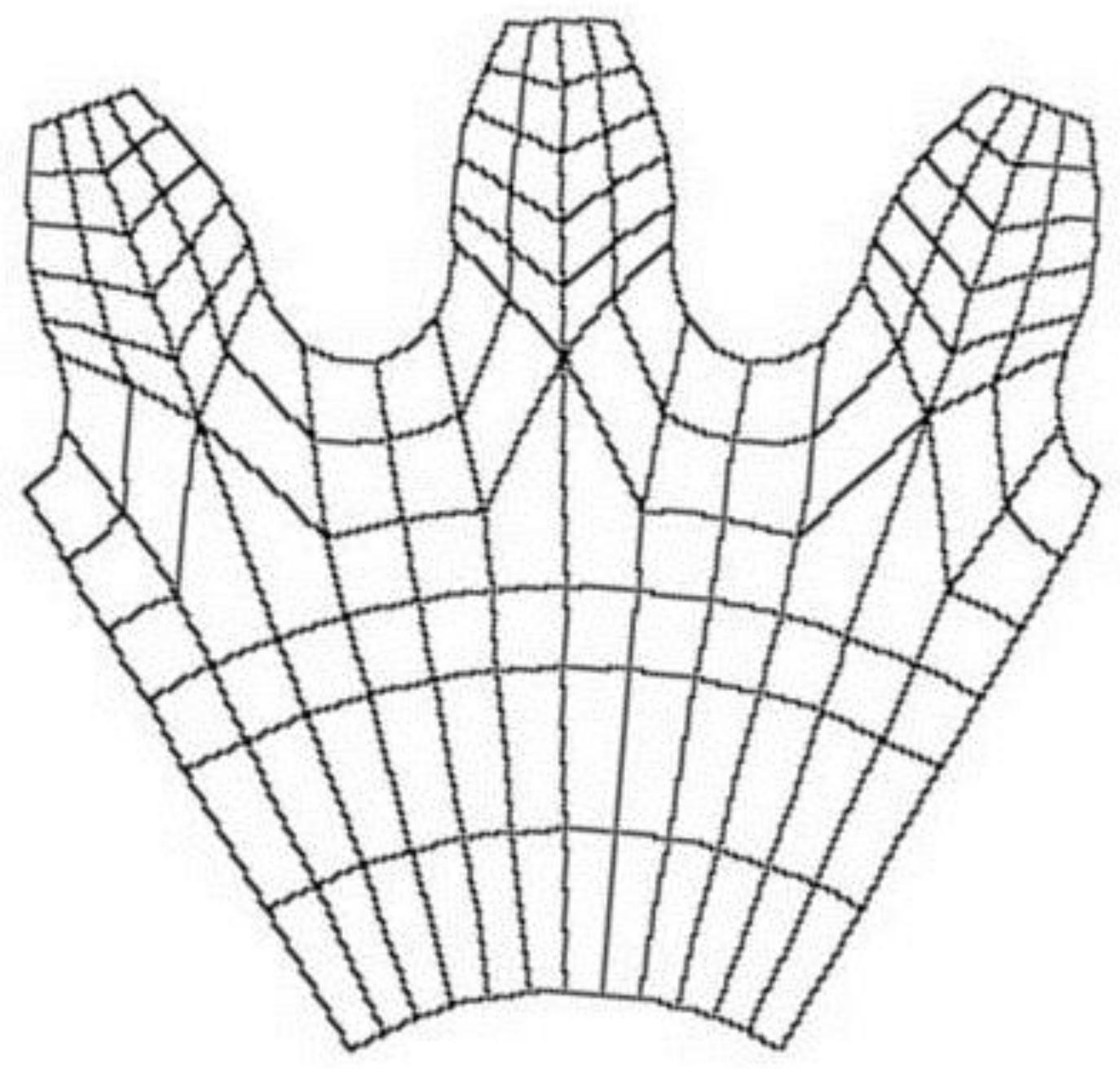

Figure 4.1: Finite element model mesh of the external spline segment. 

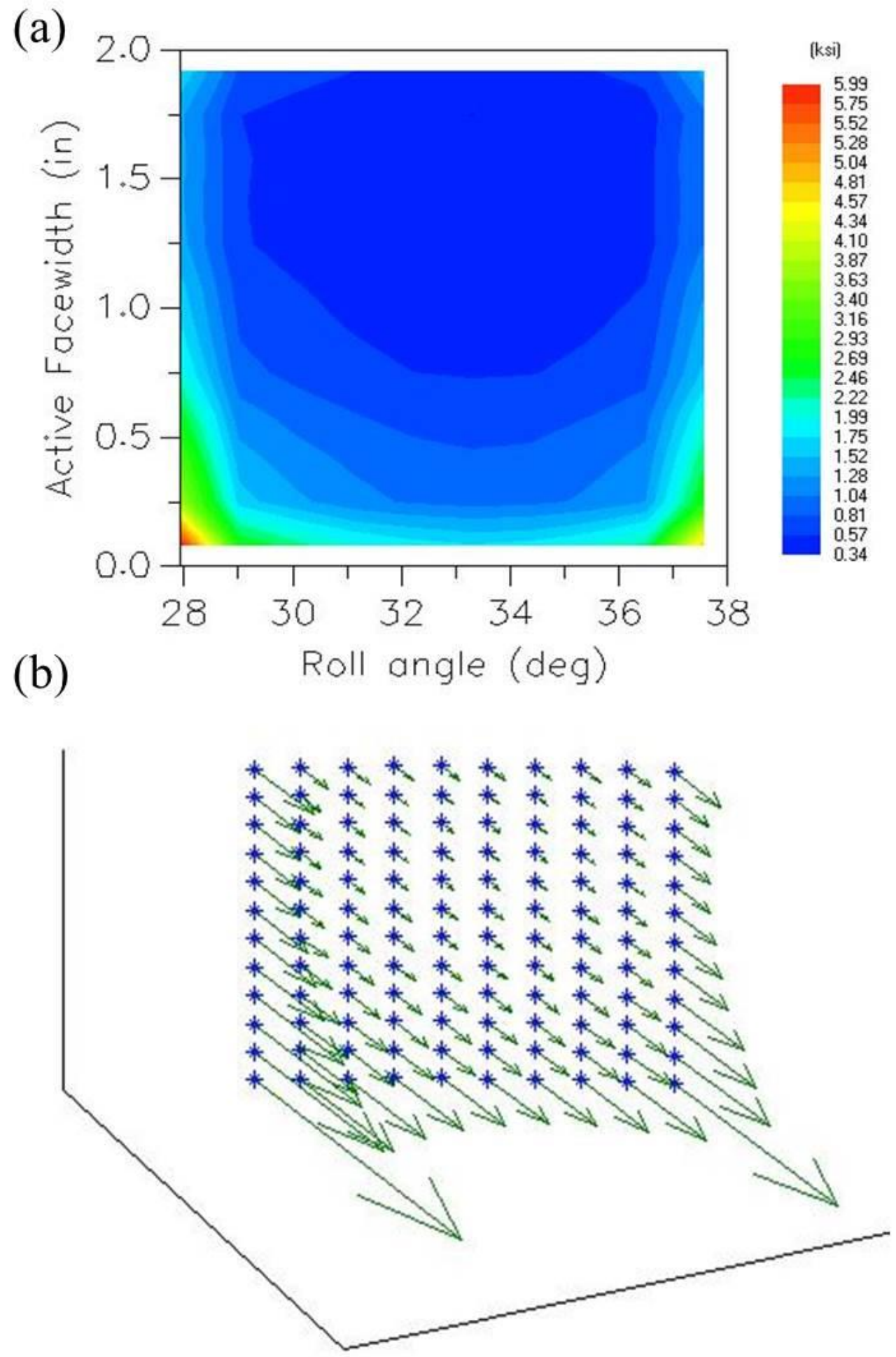

Figure 4.2: (a) Contact stress distribution and (b) corresponding grid cell force distribution on a spline tooth as predicted by Hong et al. [10]. 
consecutive teeth were loaded at a given time. For splines, however, all of the teeth may potentially be carrying load at any given instant. As such, in order to compute the root stress of each spline tooth, one would, ideally, develop an FE model of the entire external spline and apply loads to all teeth simultaneously. While feasible, this method was not adopted in order to minimize the computational effort. With the assumption that the load acting on one tooth has negligible influence on the root stress of other teeth, each tooth load distribution was applied individually to the central tooth of the 3-tooth segment, shown in Figure 4.1. The process was repeated for each spline tooth.

Two primary outputs are obtained from the FE splined joint root stress predictions. One output is the root stress distribution for every tooth of a splined joint. Although the stress takes place along the curved surfaces of spline teeth, it is mapped to contour plots. Figure 4.3 illustrates the mapping of both the contact stress calculated from the model of Hong et al. [10] as well as the root stress predicted using the FE-based splined joint model. The second output is to simulate a surface strain gauge by choosing a specific virtual gauge location in the root of a splined joint. The result is a plot of the stress at the location of the strain gauge, as a function of rotational position.

Figure 4.4 illustrates (a) the contact stress, (b) the tensile root stress, and (c) the compressive root stress of each tooth of the splined joint of Table 2.1 under spur gear loading at $600 \mathrm{Nm}$. As evident in the figure, the root stress is dependent on the contact stress since it is the only loading mechanism in the FE model. For instance, tooth 1 (with the highest contact stress) is also subject to the largest magnitudes of both tensile and 


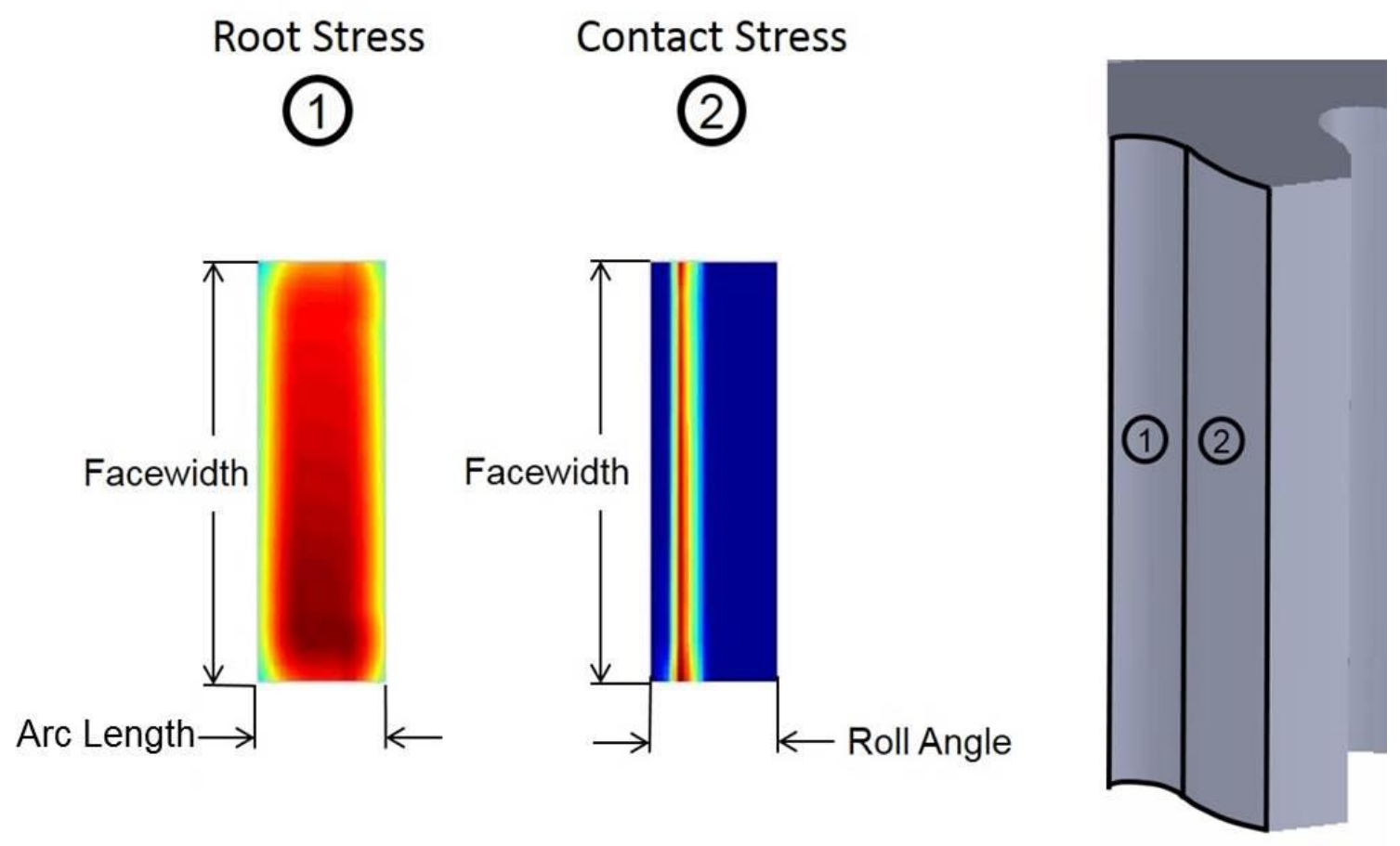

Figure 4.3: Mapping of the root and contact stress on a spline tooth. 
(a)
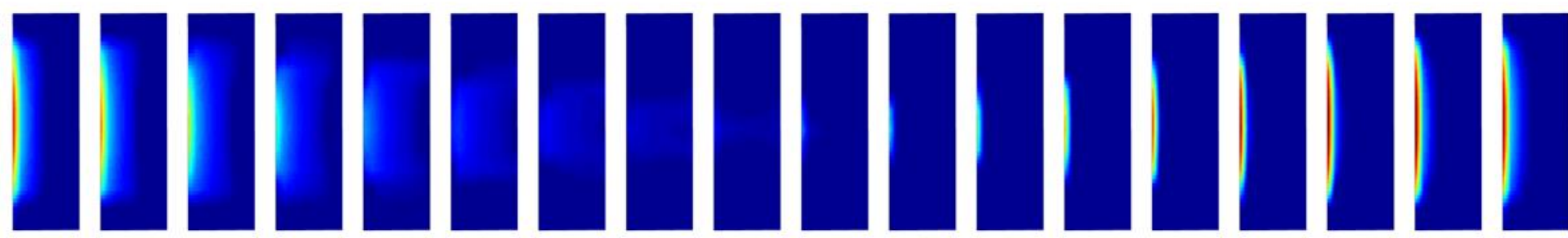

[MPa]

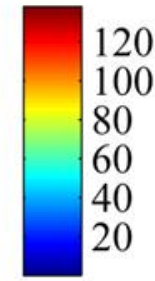

(b)
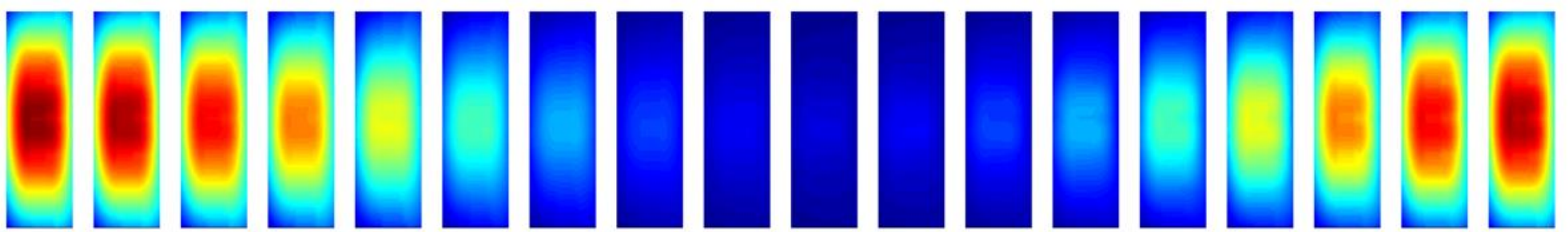

[MPa]

(c)
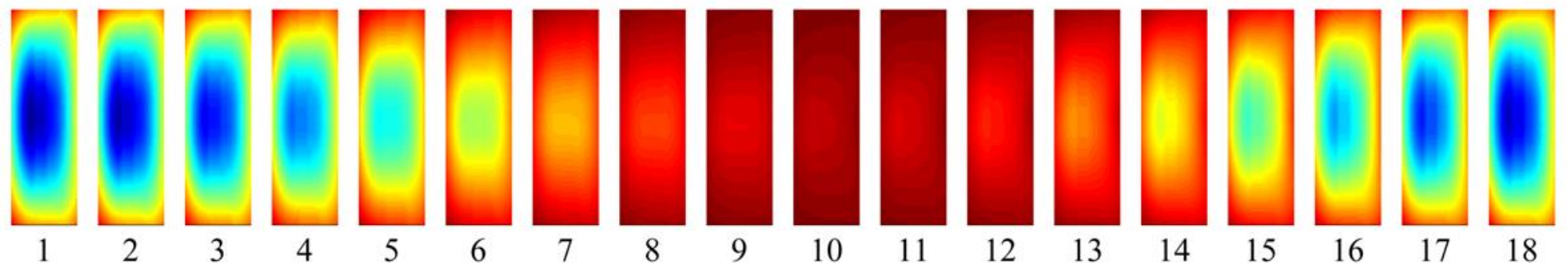

$[\mathrm{MPa}]$

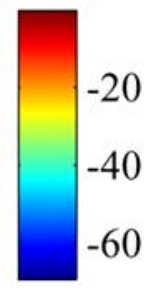

Figure 4.4: Predicted (a) contact stress, (b) tensile root stress, and (c) compressive root stress of each tooth of the splined joint of Table 2.1 under spur gear loading at $600 \mathrm{Nm}$. 
compressive root stress. On the other hand, tooth 10 has almost no contact load and, therefore, it also has almost no root stress. One may also note that, on all spline teeth which have contact stress, the stress is centered on the face width of the spline tooth, resulting in a root stress that is also centered in the root of the spline tooth.

Figure 4.5 shows the contact and root stress contours of the same splined joint under helical gear loading at $600 \mathrm{Nm}$. The qualitative correspondence of the contact and root stress distributions along the spline teeth is evident. The face width location of the contact stress distribution of a tooth dictates the distribution of the tooth's root stress in the same direction.

The second output obtained from the FE splined joint root stress predictions is the time histories at virtual gauge locations (at specific radii and face width positions) along the root of the spline tooth. Figure 4.6 and Figure 4.7 show the predicted tensile root stress for the five gauges, as defined in Figure 2.11, as a function of rotational position, for spur and helical gear loading at $600 \mathrm{Nm}$, respectively. The trends for both the spur and helical gear loading cases described in Chapter 3 are evident in these figures.

\subsection{Validation of FE Splined Joint Root Stress Predictions}

The second task identified in this chapter is the direct validation of the FE splined joint root stress model. This is necessary for two reasons. First of all, as shown in Chapter 3 and reported theoretically by Hong et al. [11], even for small index error magnitudes, 
(a)
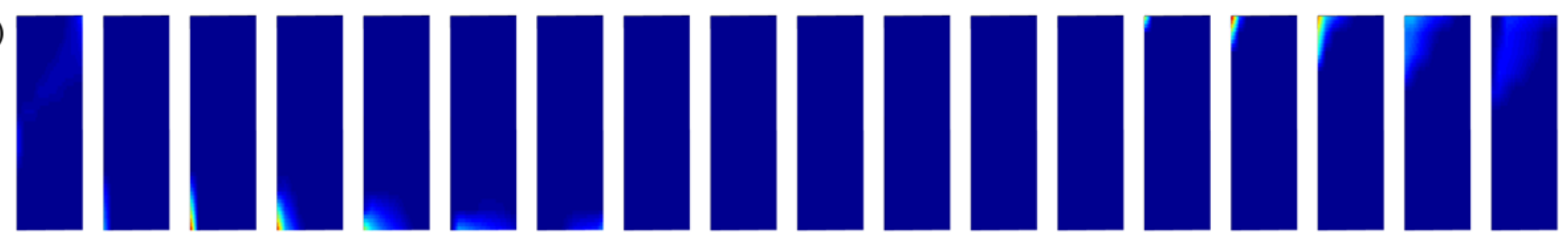

(b)
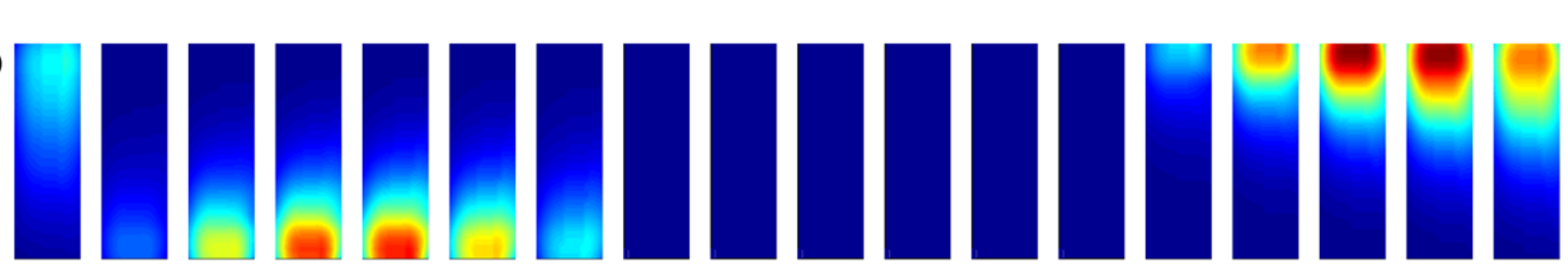

[MPa]

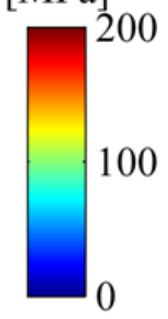

(c)
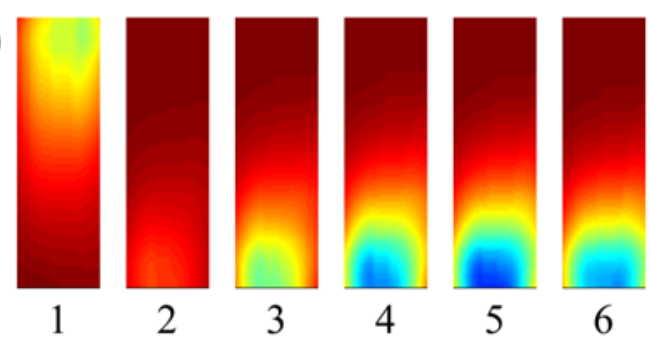

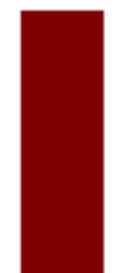

8

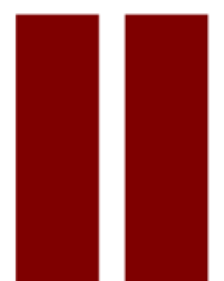

$\begin{array}{lll}10 & 11 & 12\end{array}$

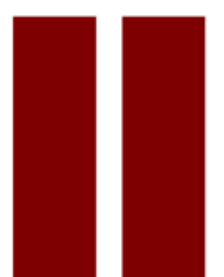

$13 \quad 14$

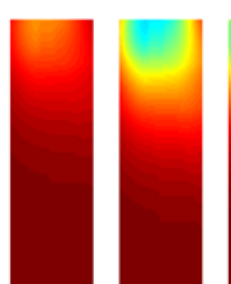

15

Tooth Number

Figure 4.5: Predicted (a) contact stress, (b) tensile root stress, and (c) compressive root stress of each tooth of the splined joint of Table 2.1 under helical gear loading at $600 \mathrm{Nm}$. 


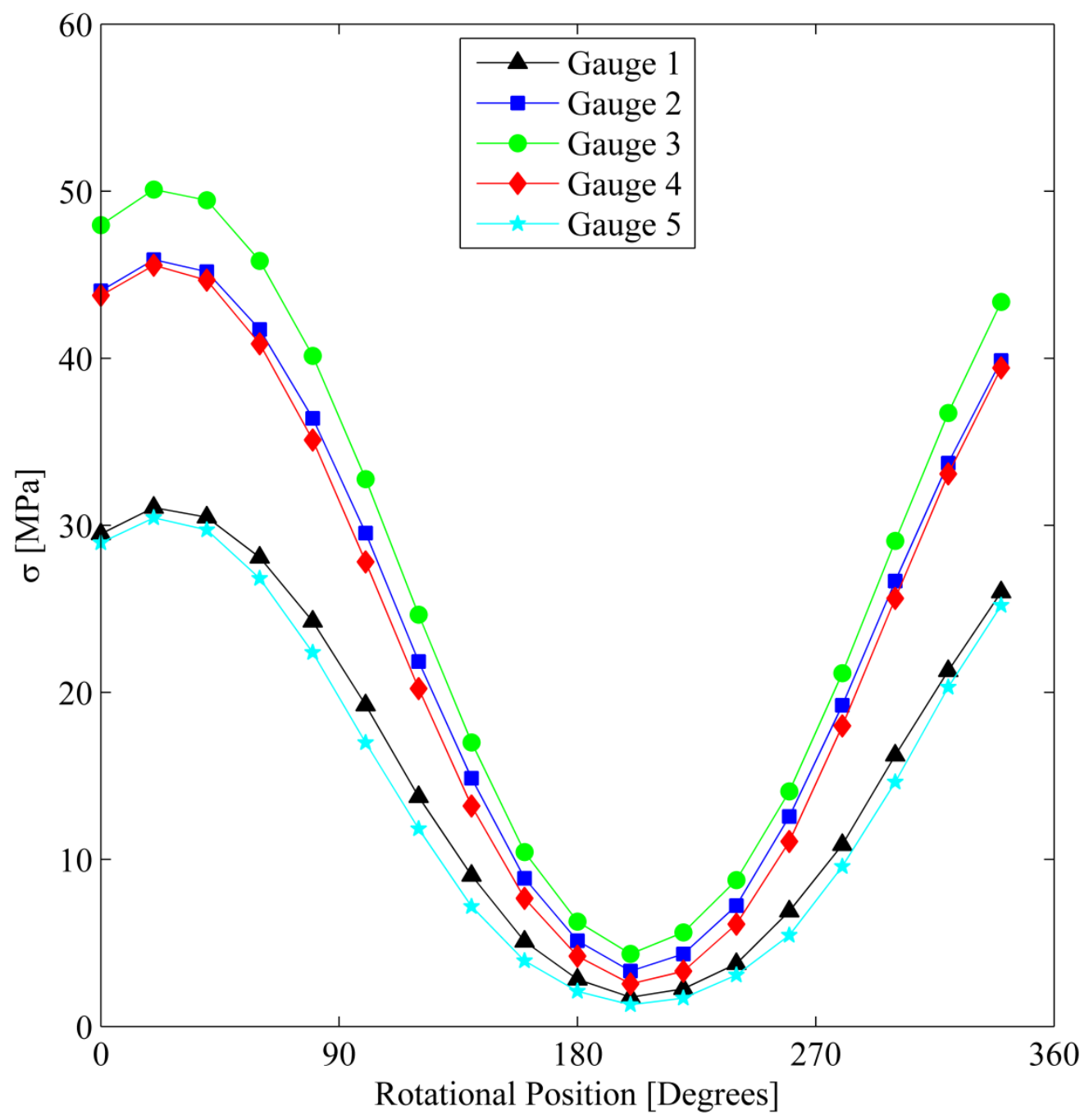

Figure 4.6: Predicted tensile root stress as a function of rotational position for 5 gauges on the face width of a spline tooth as shown in Figure 2.11. Spur gear loading at $600 \mathrm{Nm}$. 


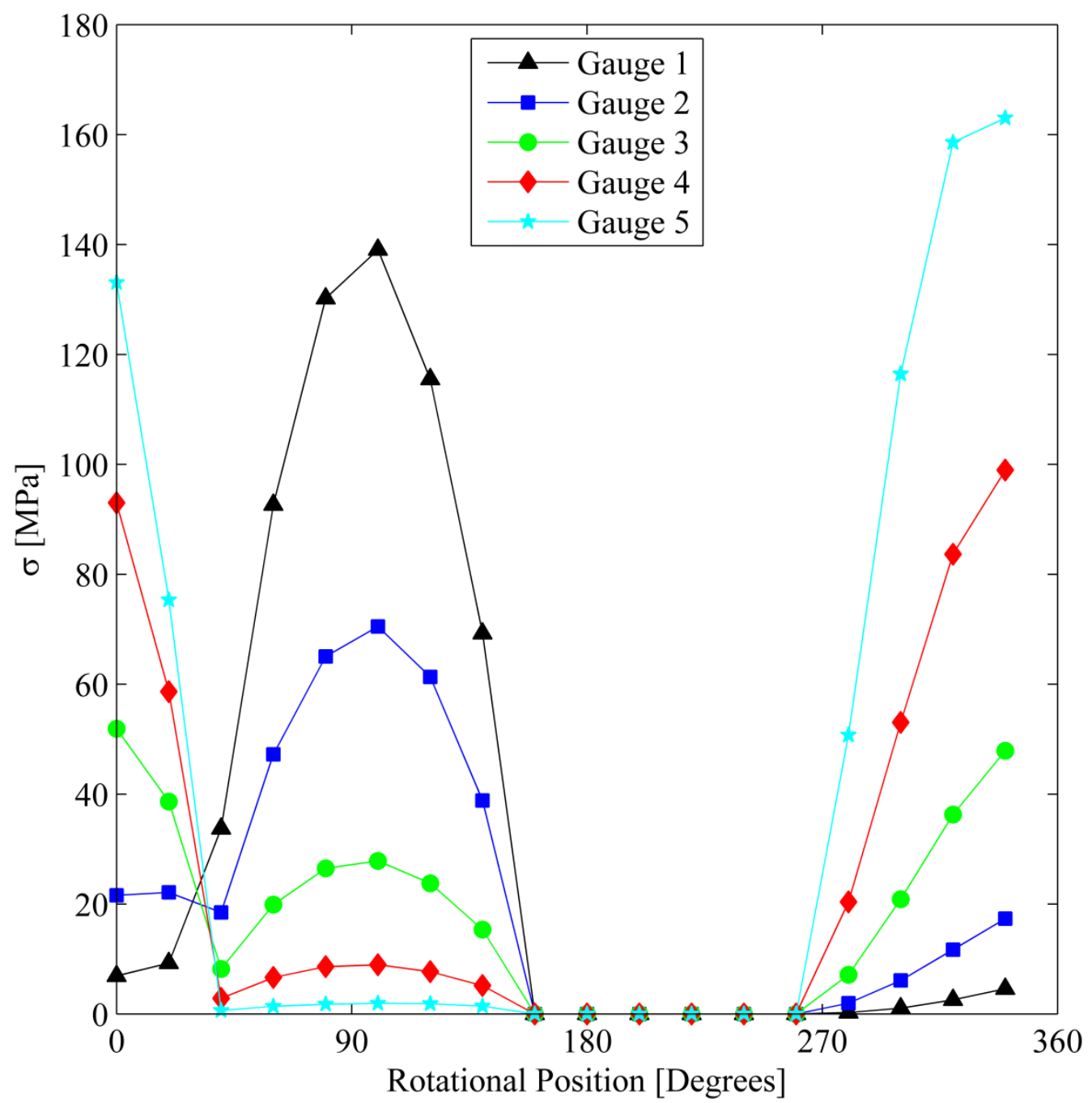

Figure 4.7: Predicted tensile root stress as a function of rotational position for 5 gauges on the face width of a spline tooth as shown in Figure 2.11. Helical gear loading at 600 $\mathrm{Nm}$. 
index errors impact the resultant tooth-to-tooth load sharing. Secondly, there may be gauge position errors, deviations from intended locations, that would result in sizable differences in root stress, since the stress gradient along the root fillet is rather steep. With these two uncertainties, using spur and helical gear loading conditions is not a plausible way of verifying the FE model.

With this consideration, a set of experiments were performed. By loading a single spline tooth at a specified face width location, with a reaction block with a shim (as described in Chapter 2 and shown in Figure 2.6), one is able to measure the root stress of a spline tooth due to a point load applied to that tooth. This point load procedure has two primary advantages. First, predictions of a point load, created by applying drastic tooth modifications to the spline in the model, would provide a direct indication of the accuracy of the FE model without the effect of index errors. Figure 4.8 illustrates (a) the contact stress point load and (b) the corresponding root stress distribution. Second, repeating this procedure for different gauged teeth indicates any tooth-to-tooth gauge position errors.

The virtual gauge tool was not used to validate the FE splined joint root stress predictions. In the model, gauges are placed at specific radii and face width positions. Since it is nearly impossible to determine the exact gauge placement on an actual spline, and since the gauge measures strain representative of the area it occupies (approximately $1 \mathrm{~mm}$ by $1 \mathrm{~mm}$ ), the contour plots were used instead of the virtual gauge tool. 
(a)

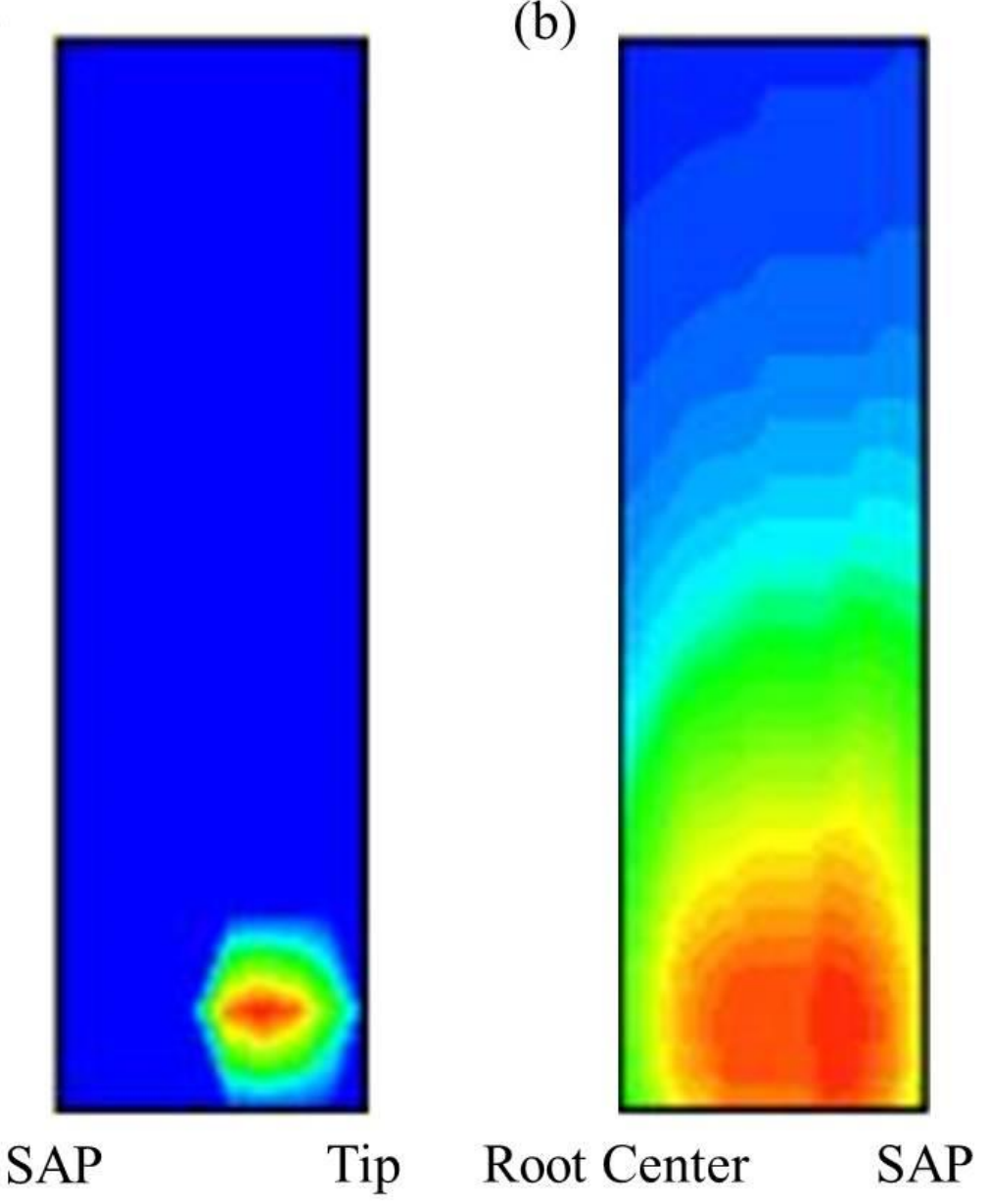

Figure 4.8: (a) Contact stress point load on a single tooth obtained by applying unrealistic tooth modifications, and (b) corresponding root stress prediction. 
Assuming that the exact center of the gauge is at the location specified, maximum and minimum values of the predicted root stress, within the $1 \mathrm{~mm}^{2}$ area of the actual gauge, were extracted to form a band of predictions. Figure 4.9 shows a typical root stress contour plot, with five $1 \mathrm{~mm}^{2}$ boxes representing gauge areas, from which the maximum and minimum values are extracted to create the upper and lower bounds for predictions.

Figure 4.10 shows the single-tooth loading experimental results obtained by point loading teeth 3 and 4 . Here, the point load is moved from the face width location of gauge 1 in Figure 4.10(a) all the way to the face width location of gauge 5 in Figure 4.10(e). The torque applied to the external spline through the loading flange was $16.2 \mathrm{Nm}$ (the force applied by the moment arm with no additional weight). Also plotted in these figures is the range of predictions, assuming that the center of each gauge is at the desired position. Two clear and significant observations may be made from this figure:

(i) The measurements from the gauges on teeth 3 and 4 are in very good agreement and indicate that the gauge placement errors are minimal. The maximum deviations for gauges 1 to 5 on teeth 3 and 4 are 1.7, 0.6, 1.8, 3.9, and 5.9 $\mathrm{MPa}$, respectively; this is relatively small, about 5, 3, 11, 20 and $18 \%$ of the mean value at each specific gauge location.

(ii) The measurements from the gauges on teeth 3 and 4 are mostly within the band of predictions. This indicates that the predictions of the FE-based root stress model are indeed accurate. 


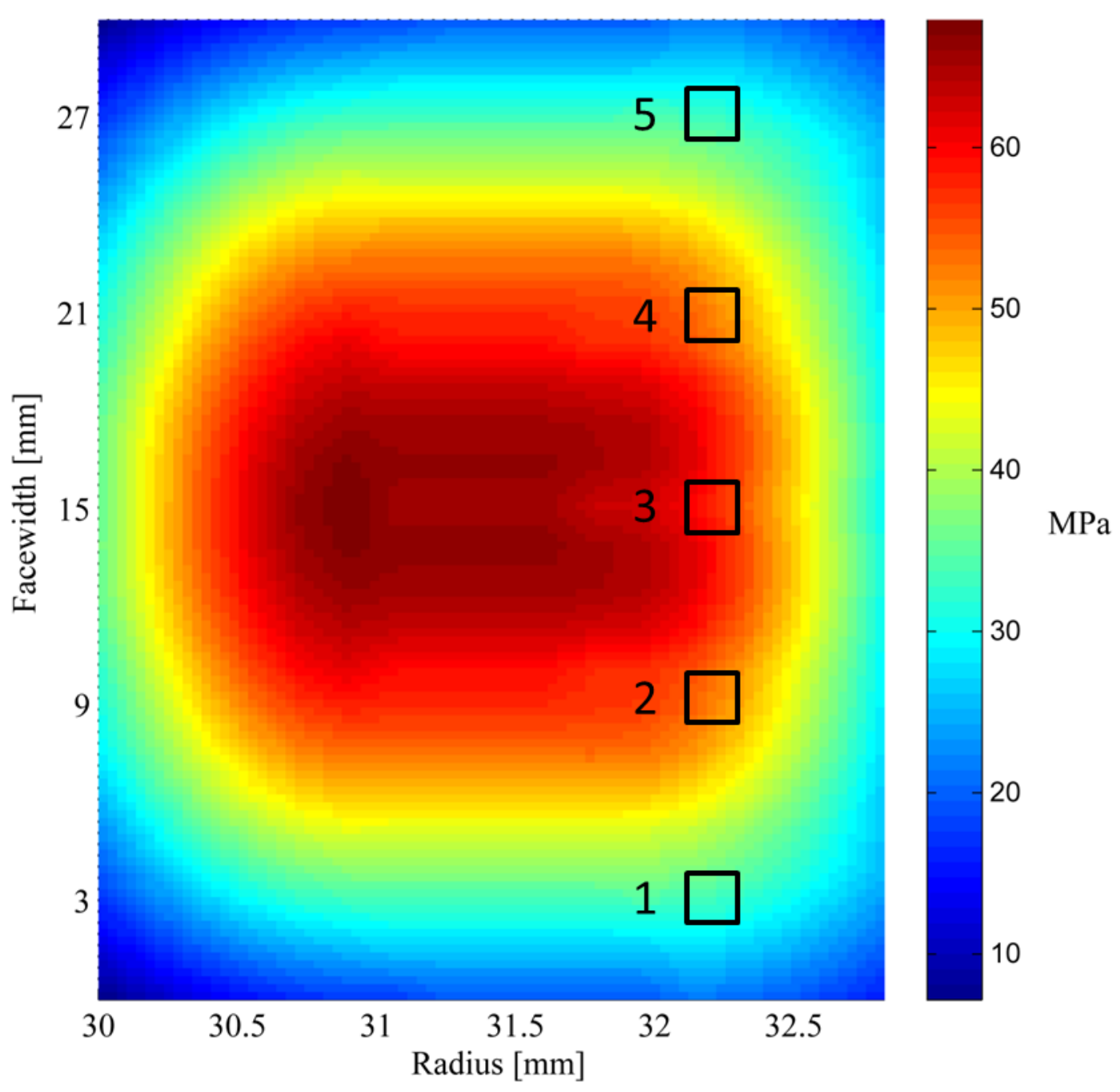

Figure 4.9: Predicted contour plot of root stress for a single tooth of the splined joint along with the gauge locations within which the upper and lower bounds of predictions were extracted. 


\begin{tabular}{|c|c|c|c|c|}
\hline$\Delta$ & $\begin{array}{l}\text { Tooth } 3 \\
\text { Measurement }\end{array}$ & $\begin{array}{ll}\text { - } & \text { Tooth } 4 \\
& \text { Measurement }\end{array}$ & $\begin{array}{l}\text { Maximum } \\
\text { Prediction }\end{array}$ & $\begin{array}{l}\text { Minimum } \\
\text { Prediction }\end{array}$ \\
\hline
\end{tabular}

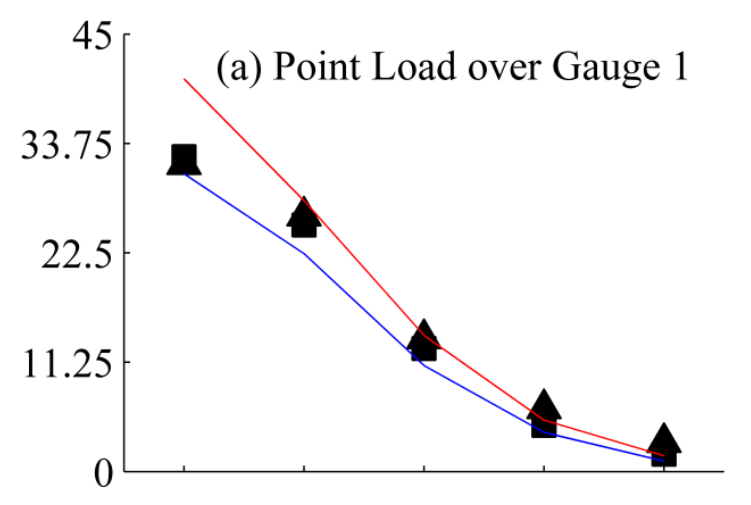

(b) Point Load over Gauge 2
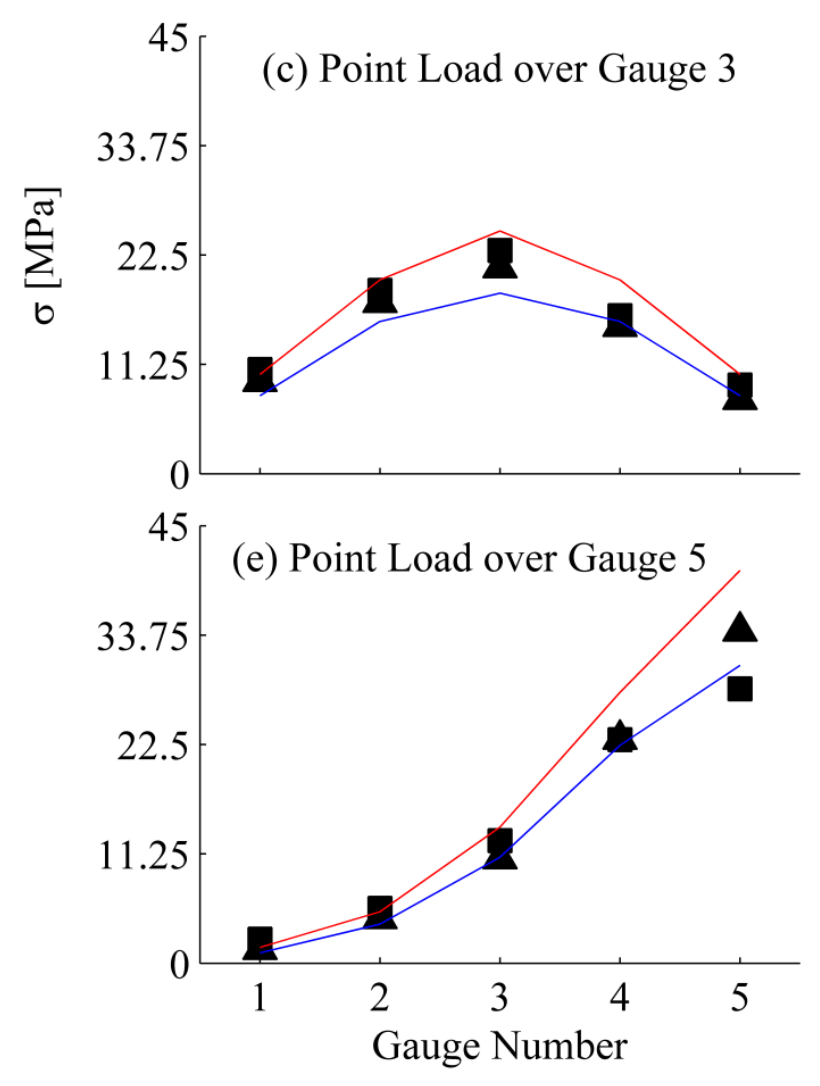

(d) Point Load over Gauge 4

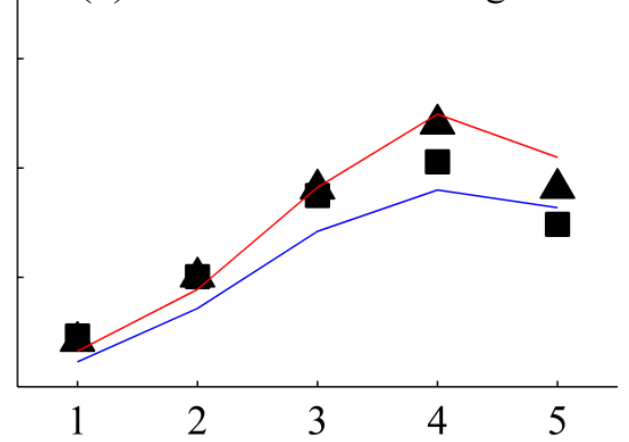

Gauge Number

Figure 4.10: Comparison of single-tooth point load measurements on teeth 3 and 4 when the point load is at the location of (a) gauge 1 through (e) gauge 5 to the predictions of the FE splined joint root stress model. Applied torque is $16.2 \mathrm{Nm}$. 


\subsection{Comparison of FE Splined Joint Root Stress Predictions to Experimental Results}

One of the primary objectives of this thesis was to assess the accuracy of the clearance-fit spline model of Hong et al. [10]. The formulation of this model was the basis for Hong et al.'s other studies [1, 11, 12], which significantly expanded the boundaries of spline load distribution modeling. As such, any reasonable correlation of this clearance-fit spline model to experiments would inject confidence into the use of the model as well as the models which expand upon it.

The experimental results from test \#1 of Table 2.3 for the spur gear loading case and test \#3 for the helical gear loading case will be taken as example tests for comparison. The experimental results for both of these cases were presented, in full, in Chapter 3. Here, data for comparisons will be presented only for the lowest $(150 \mathrm{Nm})$ and the highest $(600 \mathrm{Nm})$ applied load levels for tooth 3 . The stress values from model predictions, created using a "perfect" splined joint without index errors, will be presented within ranges in order to capture the variation within the area occupied by each gauge.

Figure 4.11 compares experimental results for tooth 3 of test \#1 to predictions for spur gear loading at $150 \mathrm{Nm}$; Figure 4.12 does the same at $600 \mathrm{Nm}$. As evident from both of the figures, the general trends presented for both the experimental data and the simulation agree reasonably well. The experimental results and upper bound of the predictions for an applied load of $600 \mathrm{Nm}$ are presented in Figure 4.13 in threedimensional space. The $x$ and $y$ axes represent face width and rotational position, and the 


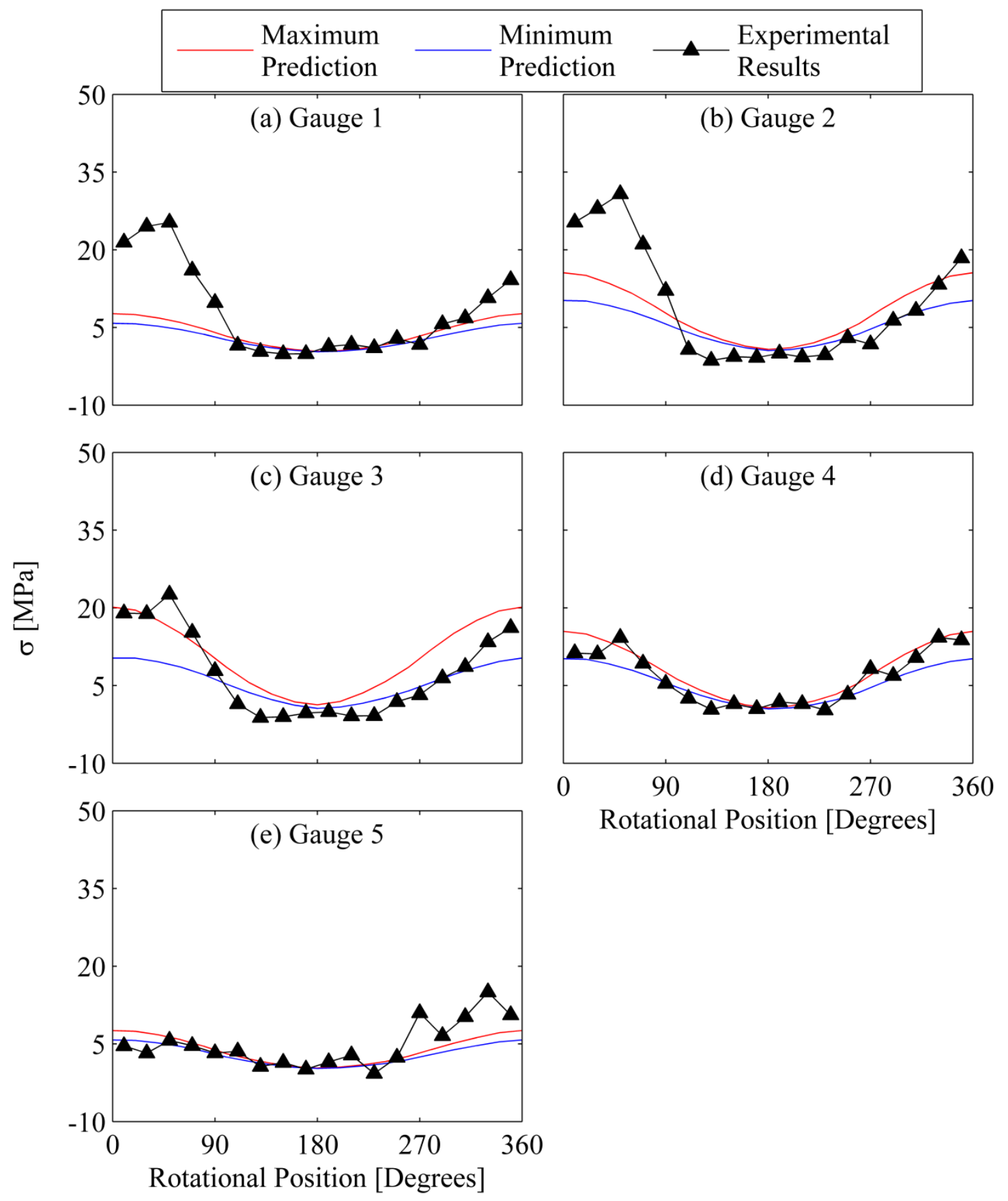

Figure 4.11: Comparison of experimental results from tooth 3 of test \#1 in Table 2.3 to predictions under spur gear loading at $150 \mathrm{Nm}$. 

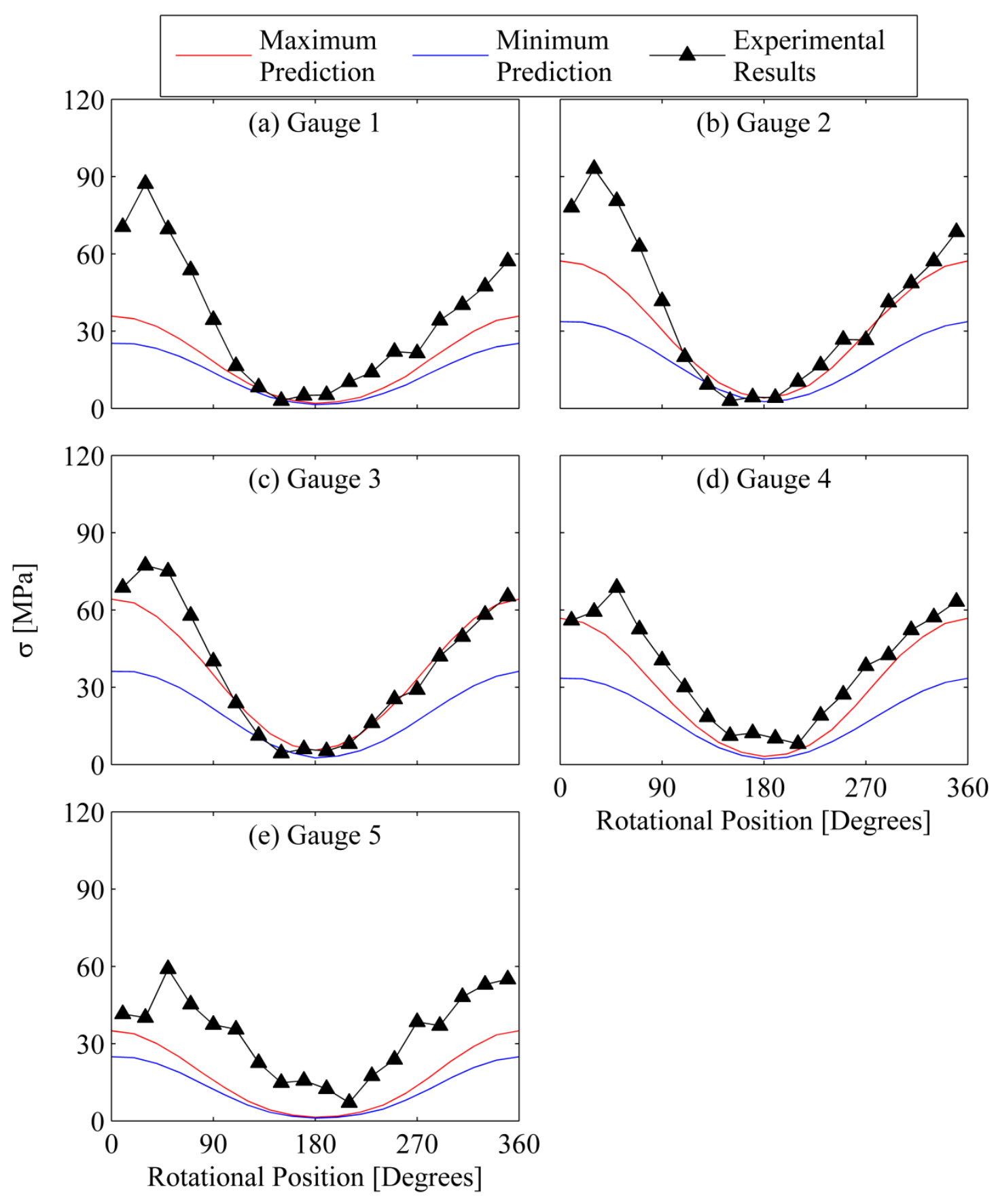

Figure 4.12: Comparison of experimental results from tooth 3 of test \#1 in Table 2.3 to predictions under spur gear loading at $600 \mathrm{Nm}$. 
(a)

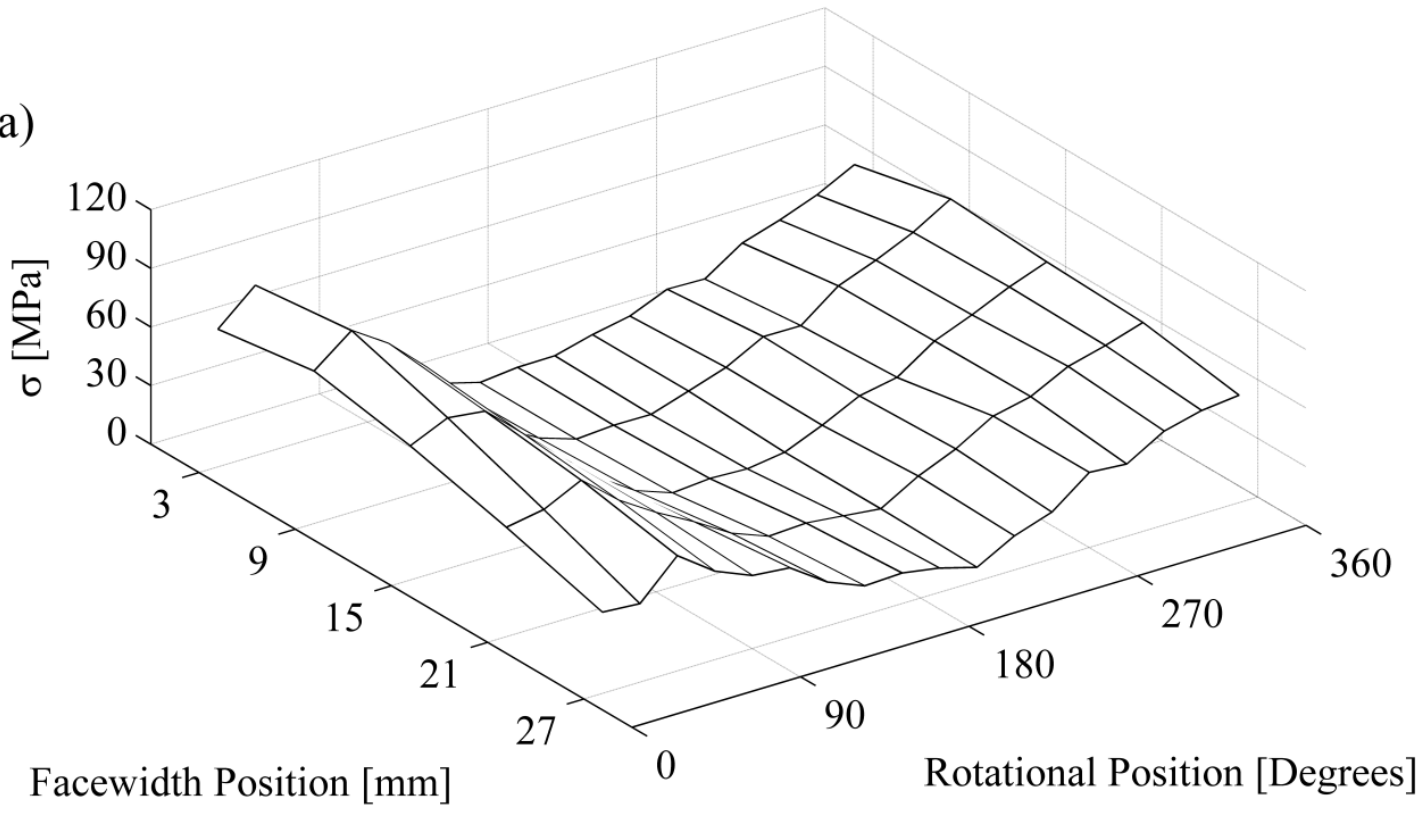

(b)

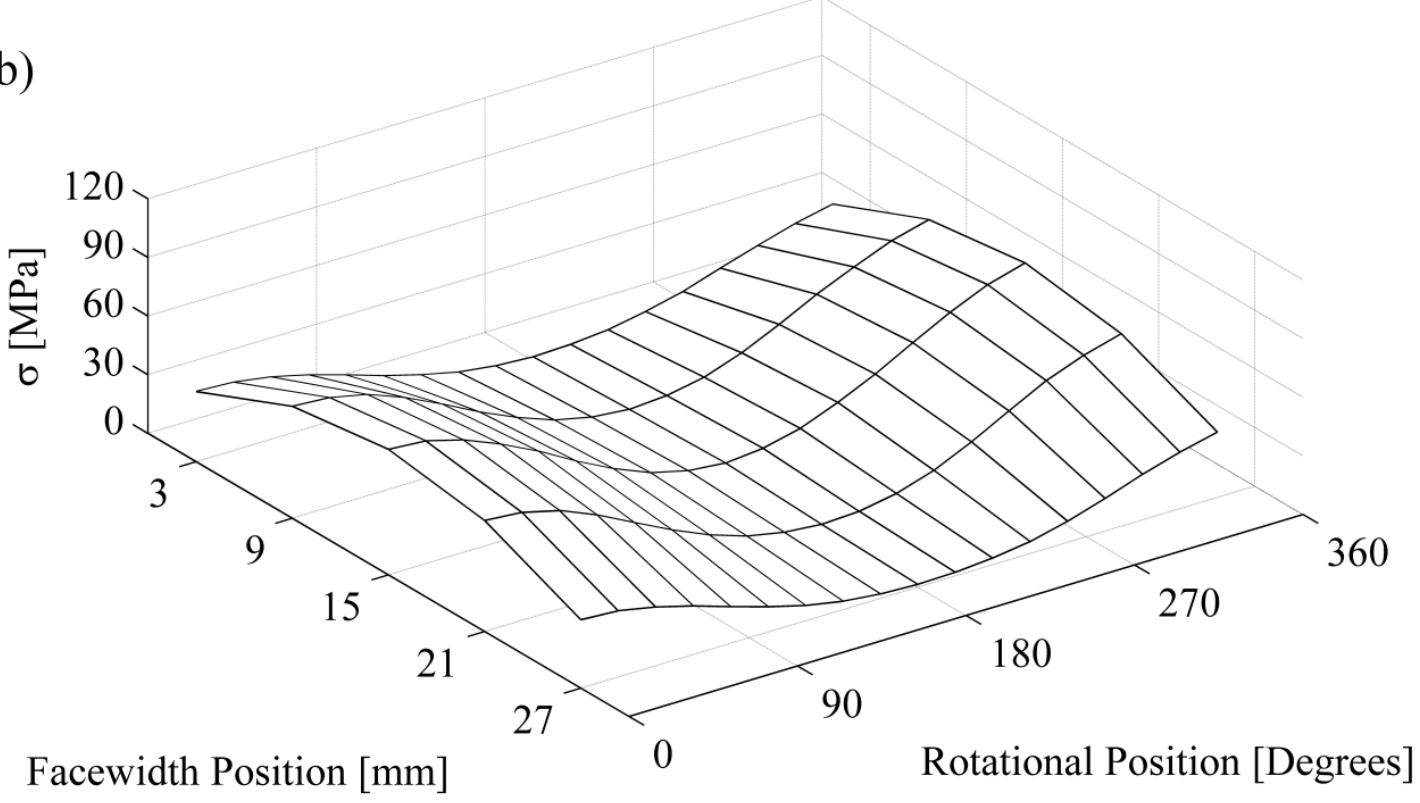

Figure 4.13: Three dimensional representation of the variation of the root stress with respect to rotational and axial positions for (a) the experimental results and (b) the maximum prediction. Spur gear loading at $600 \mathrm{Nm}$. 
vertical $z$ axis represents the root stress. As seen in this figure, the qualitative agreement is strong in terms of sensitivity to each position parameter. The largest difference between the upper bound and experimental results, in Figure 4.12 at $600 \mathrm{Nm}$, is $55 \mathrm{MPa}$ for gauge 1. This is compared to Figure 4.11 at $150 \mathrm{Nm}$. There, the largest difference between the upper bound and experimental data is about $20 \mathrm{MPa}$, again for gauge 1, and the majority of the experimental data falls between the upper and lower bounds obtained by the predictions.

Figure 4.14 and Figure 4.15 compare experimental results for tooth 3 of test \#3 for helical gear loading to the model predictions. Similar to the results for spur gear loading, the general trends presented for both the experimental data and the simulation agree well. For spur gear loading, the biggest discrepancy between the model and the experimental data was the magnitude of stress. For helical gear loading, the magnitude of stress agrees more closely, but there appears to be a slight phase shift. It seems that the point of maximum stress for the experimental results, for all of the gauges, occurs at a rotational position about $20^{\circ}$ earlier when compared to the simulation. However, in general, the quantitative agreement observed in Figure 4.14 and Figure 4.15 appears to be better than in Figure 4.11 and Figure 4.12 for spur gear loading, potentially because the splined joint with the internally splined helical gear has smaller index errors. The threedimensional plot of Figure 4.16 further demonstrates the effectiveness of the model in capturing the variation along the circumferential and axial directions of the root. 

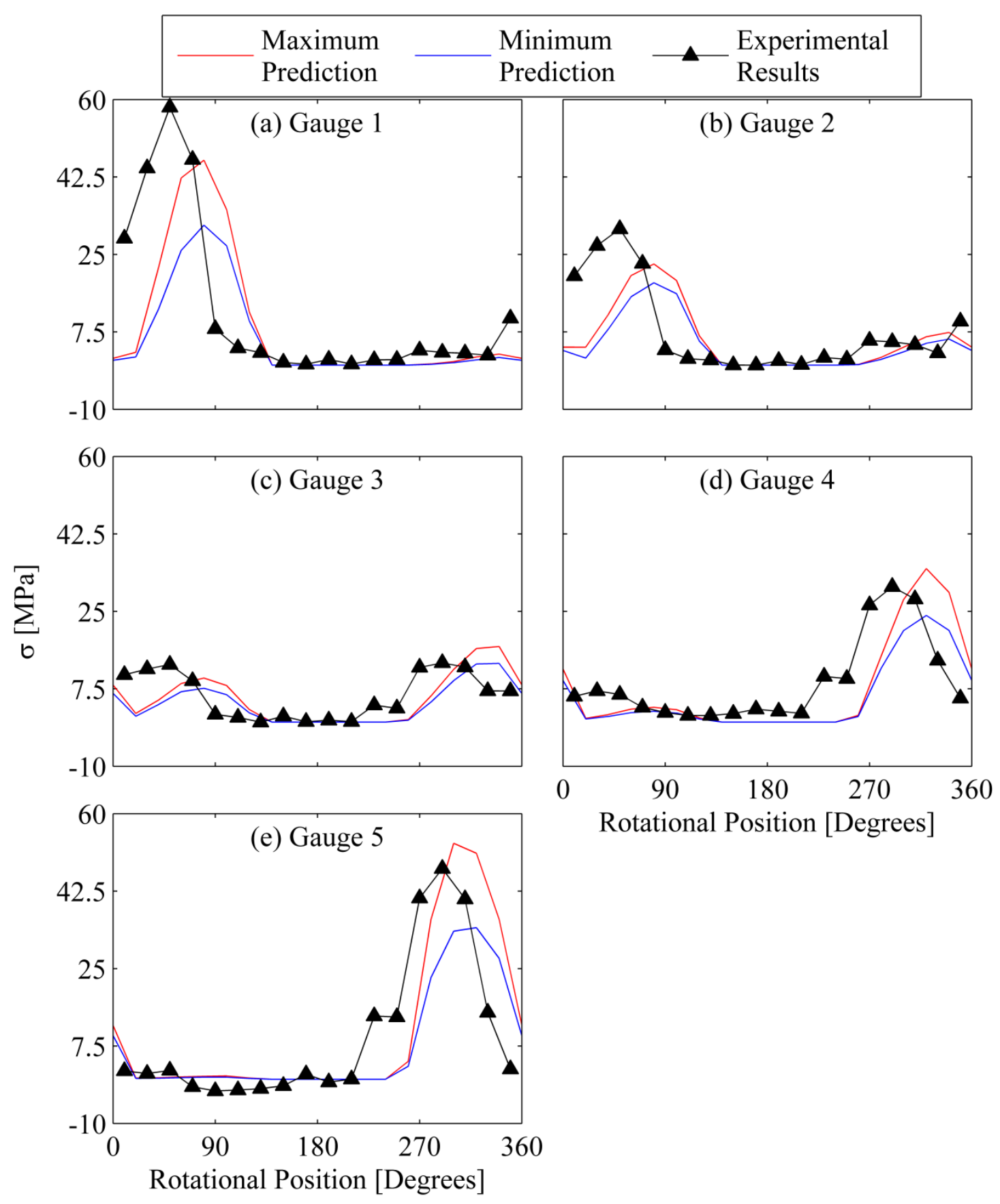

Figure 4.14: Comparison of experimental results from tooth 3 of test \#3 in Table 2.3 to predictions under helical gear loading at $150 \mathrm{Nm}$. 

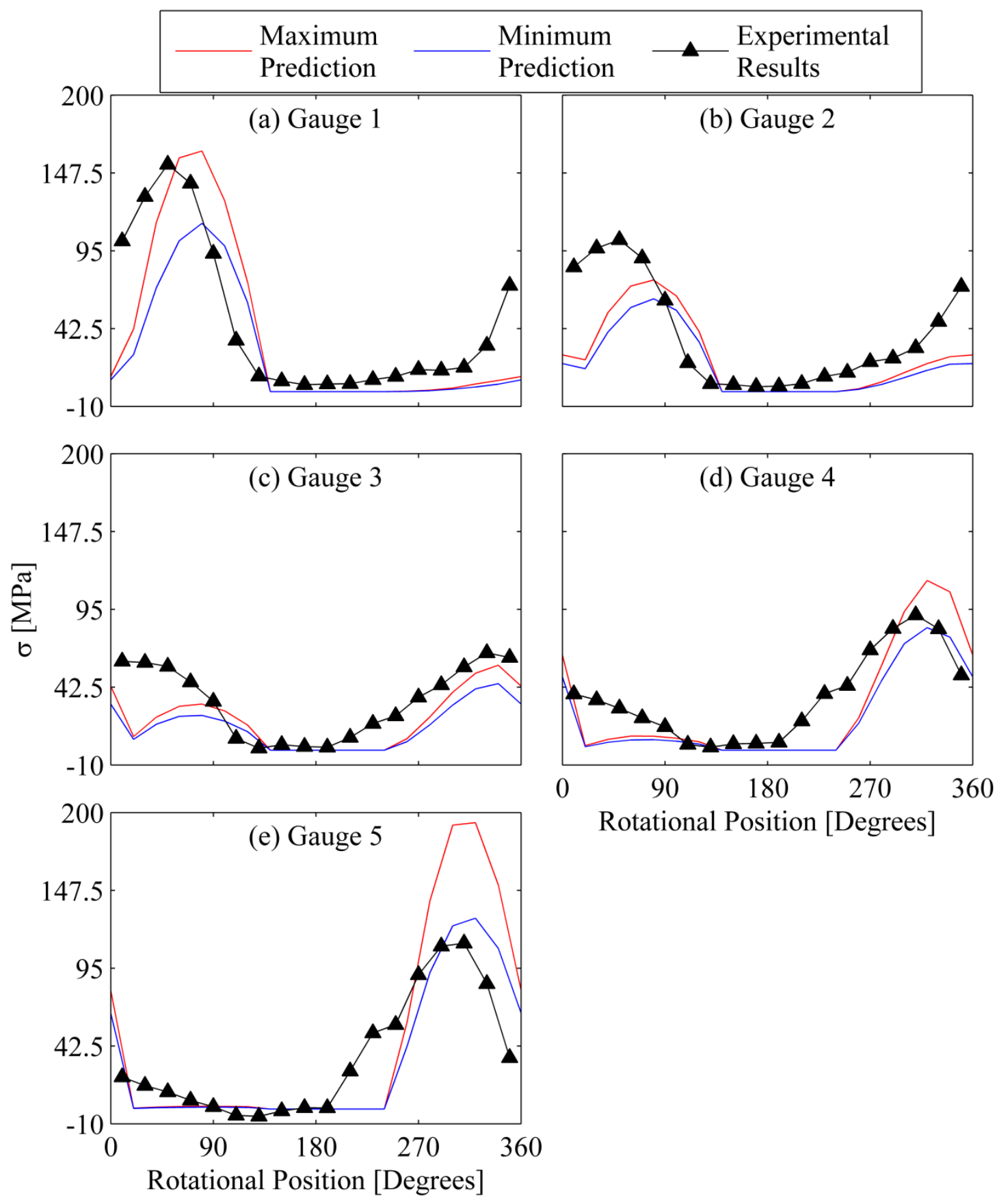

Figure 4.15: Comparison of experimental results from tooth 3 of test \#3 in Table 2.3 to predictions under helical gear loading at $600 \mathrm{Nm}$. 

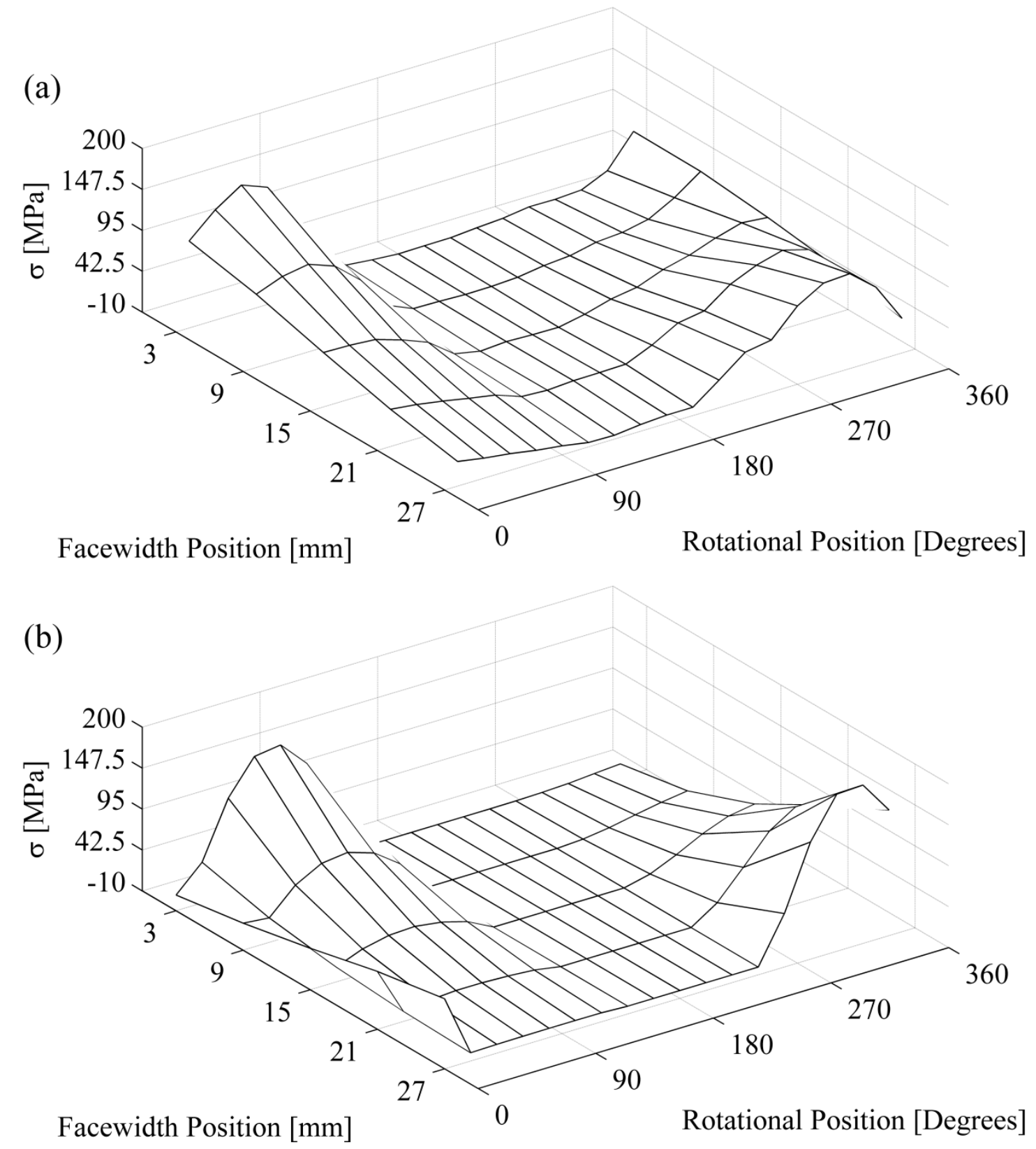

Figure 4.16: Three dimensional representation of the variation of the root stress with respect to rotational and axial positions for (a) the experimental results and (b) the maximum prediction. Helical gear loading at $600 \mathrm{Nm}$. 


\subsection{Discussion of Results}

It is clear from the comparisons presented in the previous section that there are discrepancies between the experimental results and the model, in spite of the fact that they do agree in a qualitative sense. Differences may be attributed to several factors. First, there may be a number of unavoidable variations of the test specimens and within the experimental setup that are not captured by the model. For instance, while the intent was to minimize, and, if possible, to eliminate index errors of tested splines, tests with different index error configurations (see Figure 2.10) using the same spline reveal differences. Although the model is able to include index errors, CMM measurements were not repeatable. As such, the simulations were representative of the baseline behavior of the splined joints, but not simulations of exact conditions. Other physical discrepancies, such as small amounts of shaft misalignment or very small differences between the profile and/or lead shape on different teeth of either the gear or the spline, could also affect the experimental results when compared to the simulation.

Another set of reasons for the discrepancy between the predictions and the measurements may stem from the assumptions employed by the model [10]. The model was developed to require minimal computational effort, so various simplifications were employed. For instance, since the internal and external components of a splined joint are coaxial and have conformal teeth, the model assumed negligible friction between engaged spline tooth pairs. The model also accounted for deflection associated with the spline teeth while any other compliances of spline blanks were ignored. Finally, contact 
forces on one tooth were assumed to induce no elastic deformation on adjacent spline teeth, except for torsional effects.

In spite of the discrepancies, the experimental results agree with the predictions. Specifically:

(i) The FE-based splined joint root stress prediction module is able to calculate the results of single-tooth point load experiments accurately.

(ii) The cyclic nature of a spline tooth's root stress, which varies with the rotational position and is caused by asymmetric loading of the gear mesh, is predicted by the model. In addition, under helical gear loading, the model also predicts the axial variation of the root stress due to the overturning moment.

(iii) Overall, the predicted and measured stress amplitudes agree reasonably well. In some cases, the agreement is exceptional and in other cases, sizable differences are noted. Perhaps this is due to index errors of the splined joint.

(iv) The model and experiments agree on the rotational positions where maximum and minimum values of root stress take place.

In view of the above observations, it can be stated with confidence that the model of Hong et al. [10] effectively captures the nature and magnitude of stress for the load distribution of clearance-fit splined joints under spur and helical gear loading conditions. 


\section{CHAPTER 5}

\section{CONCLUSION}

\subsection{Thesis Summary}

This study intended to establish an experimental database of splined joints subject to gear loading conditions. The results were expected to reveal unique load distribution features of splined joints, while also providing a means to validate the state-of-the art clearance-fit splined joint model created by Hong et al. [10].

Since there was no test setup suitable for the experimental investigation, the first task of this study was to design and fabricate a dedicated test setup with the features necessary to test splined joints under various gear loading conditions. The design and fabrication of the test articles (the gears, the splined joints, and any other necessary components), the instrumentation of the external spline, and the setup of the data acquisition system, all had to be completed before an extensive test matrix could be implemented and the database could be formed. The database created consisted of spline 
root stress data for spur gear and helical gear loading conditions as a function of both circumferential and face width positions. In order to demonstrate the consistency of the experimental data, a repeatability study was performed. Additionally, an attempt was made to quantify the effect of index errors on splined joints under spur and helical gear loading conditions.

Next, the validity of the model created by Hong et al. [10] for clearance-fit splined joints was assessed. This model was chosen to be assessed for three main reasons. First, it was able to capture the impact of loading type on load distributions of splined joints, whereas most other spline models in the literature dealt solely with pure torsion loading. Second, this model was shown to be computationally efficient since it solved the spline contact problem in a fraction of a minute by employing an analytical formulation and a multi-step discretization scheme. While desirable for computational efficiency, the semianalytical nature of the model introduced assumptions that made the model require extensive validation. Third, and most importantly, the formulation of this model was the basis for other studies by Hong et al. [1, 11, 12], which significantly expanded the boundaries of spline load distribution modeling. For instance, the stress matrix formulation for splined joints [12] opens avenues towards including spline compliance in gearbox dynamics models. Likewise, the extension of the model to study the influence of index errors [11] makes it feasible, for the first time, to link manufacturing errors to the resultant stress and stiffness, bridging the gap between designing and manufacturing splined joints. All of these related benefits are possible only if the underlying model formulation proposed in Reference [10] is accurate. 
Realizing that the model of Hong et al. [10] was not able to predict root stress, which is the primary output of the experiments, an intermediate modeling task of adding a root stress prediction module to the model of Hong et al. was included as part of this study. The FE template developed by Talbot [25] for gears was adapted to a segment of an external spline and the force distribution, obtained from contact loads predicted by Hong et al. [10], were applied. The experimental data was compared to root stress predictions for multiple load levels under both spur and helical gear loading conditions in order to assess the accuracy of the model.

\subsection{Major Conclusions}

The experimental data generated in this study is significant because it clearly shows the influence of both spur and helical gear loading on the overall load distribution of a splined joint. Specifically, this data illustrates how the stress is dependent on both the location along the face width and the rotational position of the spline tooth relative to the gear mesh. The major conclusions drawn from the experimental results are:

(i) The experimental data collected is repeatable using the same test setup, testing conditions, and test specimens. As such, the behavior presented represents the true behavior of splines.

(ii) For both spur and helical gear loading conditions, the higher the load applied to the splined joint, the higher the stress on the spline teeth. However, the 
stiffening of the splined joint causes a nonlinear relationship between the applied torque and the resultant stress.

(iii) For both spur and helical gear loading, higher magnitudes of stress are experienced at locations near the edge of the face width of the splined joint, closer to the side where the load was applied.

(iv) For spur gear loading, the lead crown moves the location of maximum stress away from the edge where the load is applied. This effect is diminished significantly for helical gear loading due to the overturning moment.

In terms of the model correlation aspects of this study, aside from the fact that the experimental results and predictions follow the same general trends and agree relatively well quantitatively, the following may be concluded more specifically:

(i) The FE-based splined joint root stress prediction module is able to calculate the results of single-tooth point load experiments accurately.

(ii) The cyclic nature of a spline tooth's root stress, which varies with the rotational position and is caused by asymmetric loading of the gear mesh, is predicted by the model. In addition, under helical gear loading, the model also predicts the axial variation of the root stress due to the overturning moment.

(iii) Overall, the predicted and measured stress amplitudes agree reasonably well. In some cases, the agreement is exceptional and in other cases, sizable differences are noted. Perhaps this is due to index errors of the splined joint. 
(iv) The model and experiments agree on the rotational positions where maximum and minimum values of root stress take place.

Based on the conclusions for the validation portion of this study, it can be stated with confidence that the model of Hong et al. [10] effectively captures the nature and magnitude of stress for the load distribution of clearance-fit splined joints under spur and helical gear loading conditions.

\subsection{Recommendations for Future Work}

Although this study presents new results with respect to the experimental conclusions about the behavior of splined joints and the validation of the clearance-fit splined joint model of Hong et al. [10], it is certainly not all inclusive. Further experimental and modeling efforts regarding the load distribution of splined joints could be very broad and extensive. Some of the following topics which would be beneficial extensions to the research presented here are:

- Experimental studies that describe the changes in the load distribution of splined joints due to various effects such as

○ intentional index errors within the splined joint,

○ major-fit and minor diameter-fit splines,

○ backside contact of splines,

$\circ$ misalignment of the splined joints, and 
○ index errors and misalignments of the gear pair loading the splined joint.

- Experimental studies that use measurement techniques (other than pressure films which introduce index errors) to obtain the contact stress of a splined joint.

- Any of the aforementioned experimental studies, including the testing completed in this study, under dynamic conditions.

- Modeling and experimental validation of models that predict the impact of splined joints on gear dynamic behavior.

- Extensions of spline load distribution models to predict main failure modes of splines such as tooth breakage, wear, and fretting. 


\section{REFERENCES}

[1] Hong, J., Talbot, D., Kahraman, A., 2015, “A Generalized Semi-Analytical Load Distribution Model for Clearance-fit, Major-fit, Minor-Fit, and Mismatched Splines,” published online, Journal of Mechanical Engineering Science, DOI: $10.1177 / 0954406215603741$

[2] Tjernberg, A., 2001, "Load Distribution and Pitch Errors in A Spline Coupling," Materials and Design, 22, 259-266.

[3] Barsoum, I., Khan, F., Barsoum, Z., 2014, "Analysis of Torsional Strength of Hardened Splined Shafts," Materials and Design, 54, 130-136.

[4] Barrot, A., Paredes, M., Sartor, M., 2005, “An Assistance Tool for Spline Coupling Design," Advances in Integrated Design and Manufacturing in Mechanical Engineering, 329-342.

[5] Cura, F., Mura, A., 2014, "Analysis of a Load Application Point in Spline Coupling Teeth,” Zhejiang Univ-Sci A (Appl 302 Phys \& Eng), 15(4), 302-308. 
[6] Adey, R. A., Baynham, J., Taylor, J. W., 2000, “Development of Analysis Tools for Spline Couplings," Proc Instn Mech Engrs, Part G, Journal of Aerospace Engineering, 214, 347-357.

[7] Hong, J., Talbot, D., Kahraman, A., 2014, "Load Distribution Analysis of Clearance-fit Spline Joints Using Finite Elements," Mechanism and Machine Theory, 74, 42-57.

[8] Barrot, A., Paredes, M., Sartor, M., 2006, "Determining Both Radial Pressure Distribution and Torsional Stiffness of Involute Spline Couplings," Journal of Mechanical Engineering Science, 220, 1727-1738.

[9] Wink, C. H., Nakandakar, M., 2014, "Influence of Gear Loads on Spline Couplings," Power Transmission Engineering, February, 42-49.

[10] Hong, J., Talbot, D., Kahraman, A., 2014, “A Semi-Analytical Load Distribution Model for Side-fit Involute Splines," Mechanisms and Machine Theory, 76, 39-55

[11] Hong, J., Talbot, D., Kahraman, A., 2015, "Effects of Tooth Indexing Errors on Load Distribution and Tooth Load Sharing of Splines under Combined Loading Conditions", Journal of Mechanical Design, 137(3), 032601.

[12] Hong, J., Talbot, D., Kahraman, A., 2016, “A Stiffness Formulation for Spline Joints," Journal of Mechanical Design, 138(4), 043301.

[13] Weatherford, W. D., Valtierra, M. L., Ku, P. M., 1966, "Experimental Study of 
Spline Wear and Lubrication Effects," ASLE Transactions, 9, 171-178.

[14] Ku, P. M., Valtierra, M. L., 1975, "Spline Wear-Effects of Design and Lubrication,” Journal of Engineering for Industry, November, 1257-1263.

[15] Brown, H. W., 1979, “A Reliable Spline Coupling,” Journal of Engineering for Industry, 101, 421-426.

[16] Wavish, P. M., Houghton, D., Ding, J., Leen, S.B., Williams, E. J., McColl, I. R., 2009, “A Multiaxial Fretting Fatigue Test for Spline Coupling Contact,” Fatigue and Fracture of Engineering Materials and Structures, 32, 325-345.

[17] Ratsimba, C. H. H., McColl, I. R., Williams, E. J., Leen, S. B., Soh, H. P., 2004, "Measurement, Analysis and Prediction of Fretting Wear Damage in a Representative Aeroengine Spline Coupling,” Wear, 257, 1193-1206.

[18] Cura, F., Mura, A., 2013, "Experimental Procedure for the Evaluation of Tooth Stiffness in Spline Coupling Including Angular Misalignment,” Mechanical Systems and Signal Processing, 40, 545-555.

[19] Cuffaro, V., Cura., F., Mura, A., 2012, "Analysis of the Pressure Distribution in Spline Couplings," Proc. IMechE., Part C: J. Mechanical Engineering Science, 226(12), 2852-2859. 
[20] Pardhi D.G., Khamankar S.D., 2014, "Stress Analysis of Spline Shaft Using Finite Element Method and Its Experimental Verification by Photo Elasticity," Int. J. Mech. Eng. \& Rob. Res, 3, 451-458.

[21] Hotait, M., Kahraman A., 2013, "Experiments on the Relationship between the Dynamic Transmission Error and the Dynamic Stress Factor of Spur Gear Pairs,” Mechanisms and Machine Theory, 70, 116-128.

[22] Hotait, M., Kahraman, A., 2008, "Experiments on Root Stresses of Helical Gears with Lead Crown and Misalignments," Journal of Mechanical Design, 130, 074502.

[23] Houser, D. R., Seireg, A., 1970, “An Experimental Investigation of Dynamic Factors in Spur and Helical Gears,” Journal of Engineering for Industry, 495-503.

[24] Handschuh, M. J., Kahraman A., Milliren, M.R., 2014, "Impact of Tooth Spacing Errors on the Root Stresses of Spur Gear Pairs," Journal of Mechanical Design, 136, 061010.

[25] Talbot, D., 2007, "Finite Element Analysis of Geared Shaft Assemblies and ThinRimmed Gears," MS Thesis, The Ohio State University, Columbus, OH.

[26] Blankenship, G. W., Kahraman, A., 1995, "Steady State Forced Response of a Mechanical Oscillator with Combined Parametric Excitation and Clearance Type Nonlinearity," Journal of Sound and Vibration, 185, 743-765. 
[27] Kubur, M., Kahraman, A., Zini, D., Kienzle, K., 2004, "Dynamic Analysis of a Multi-shaft Helical Gear Transmission by Finite Elements: Model and Experiment," Journal of Vibrations and Acoustics, 126, 398-406.

[28] National Instruments, 2009, "SCXI-1520 User Manual,” 4-3, 4-5. 


\section{APPENDIX A}

\section{ADDITIONAL FIGURES OF EXPERIMENTAL RESULTS}

Figure A.1 through Figure A.8 show the experimental results of test \#2 and test \#4 of Table 2.3. These figures display the same general trends that are described in Chapter 3 for the spur gear loading and helical gear loading presented in Section 3.3 and Section 3.4 , respectively. 


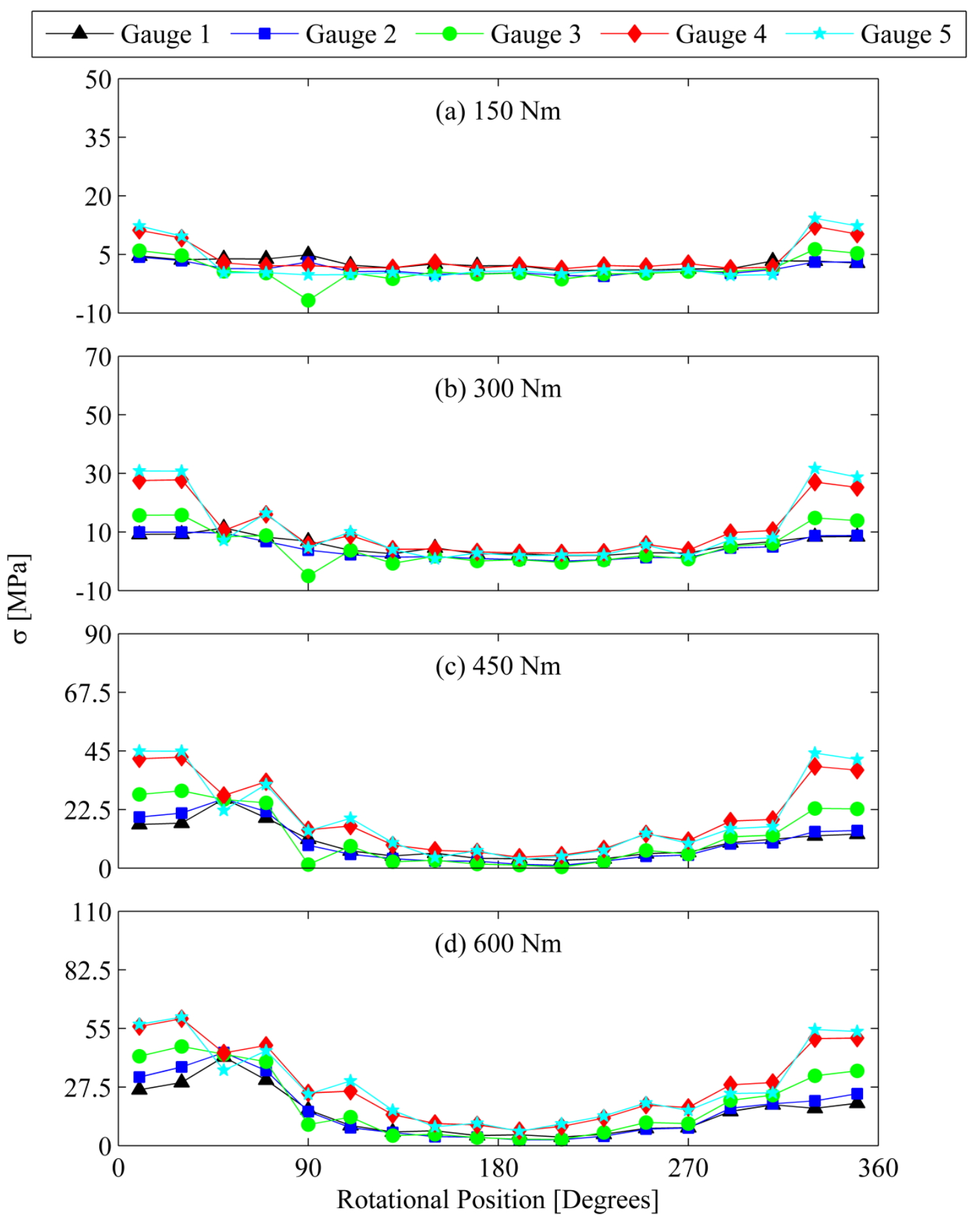

Figure A.1: Root stress of the first instrumented tooth for test \#2 of Table 2.3 under spur gear loading conditions at (a) $150 \mathrm{Nm}$, (b) $300 \mathrm{Nm}$, (c) $450 \mathrm{Nm}$, and (d) $600 \mathrm{Nm}$. 


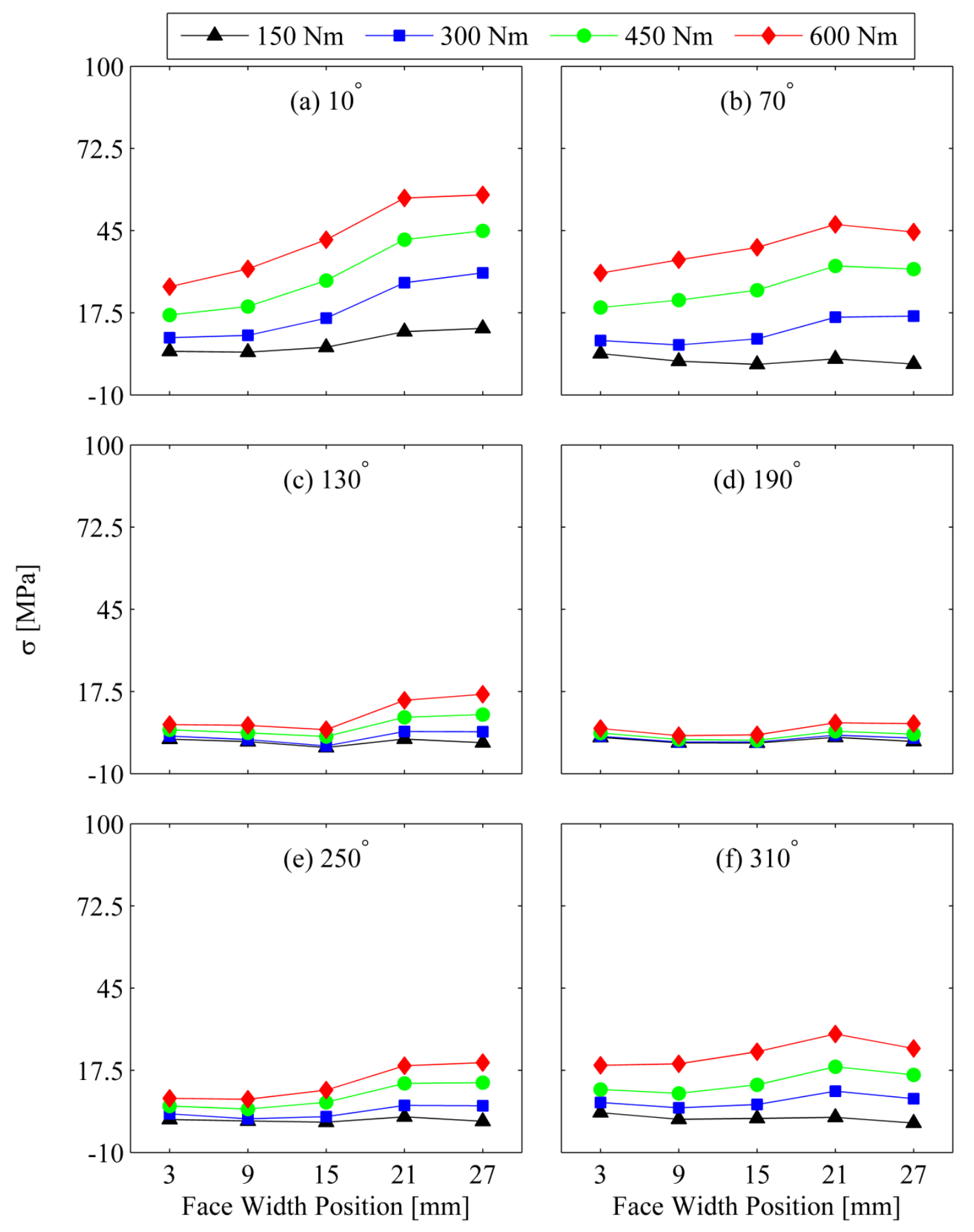

Figure A.2: Root stress of the first instrumented tooth for test \#2 of Table 2.3 under spur gear loading at angular positions of a) $10^{\circ}$, (b) $70^{\circ}$, (c) $130^{\circ}$, (d) $190^{\circ}$, (e) $250^{\circ}$, and (f) $310^{\circ}$. 


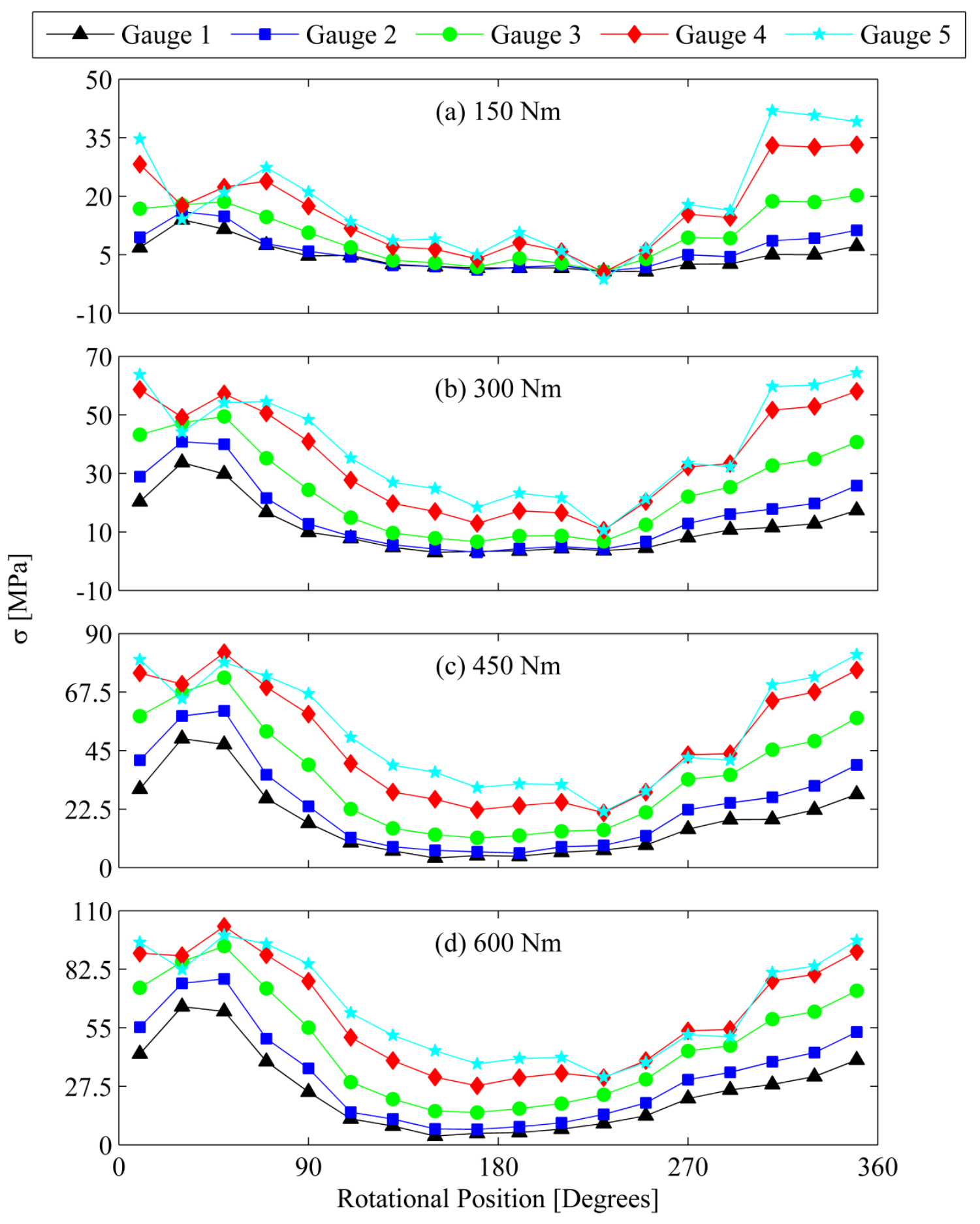

Figure A.3: Root stress of the second instrumented tooth for test \#2 of Table 2.3 under spur gear loading conditions at (a) $150 \mathrm{Nm}$, (b) $300 \mathrm{Nm}$, (c) $450 \mathrm{Nm}$, and (d) $600 \mathrm{Nm}$. 


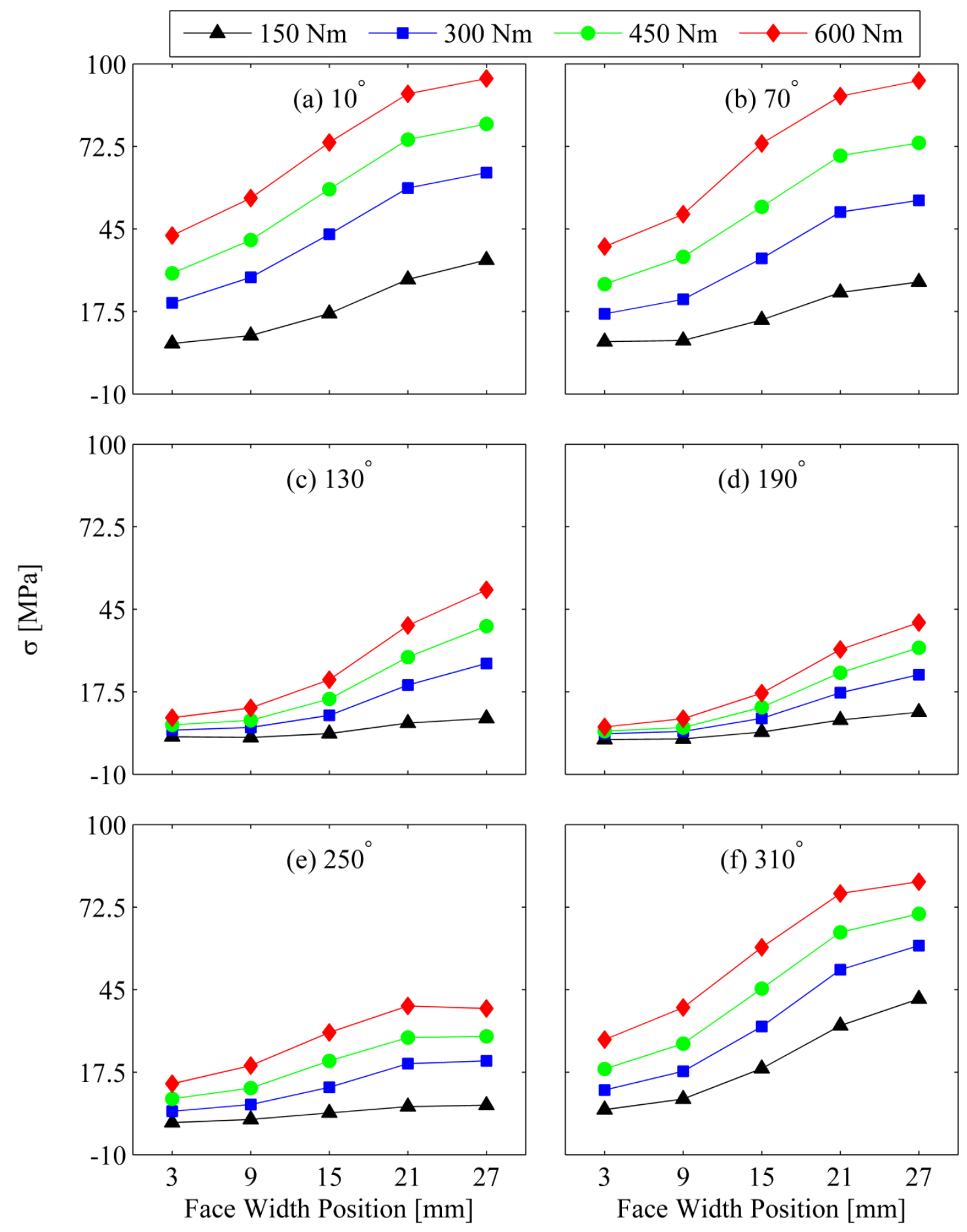

Figure A.4: Root stress of the second instrumented tooth for test \#2 of Table 2.3 under spur gear loading at angular positions of a) $10^{\circ}$, (b) $70^{\circ}$, (c) $130^{\circ}$, (d) $190^{\circ}$, (e) $250^{\circ}$, and (f) $310^{\circ}$. 


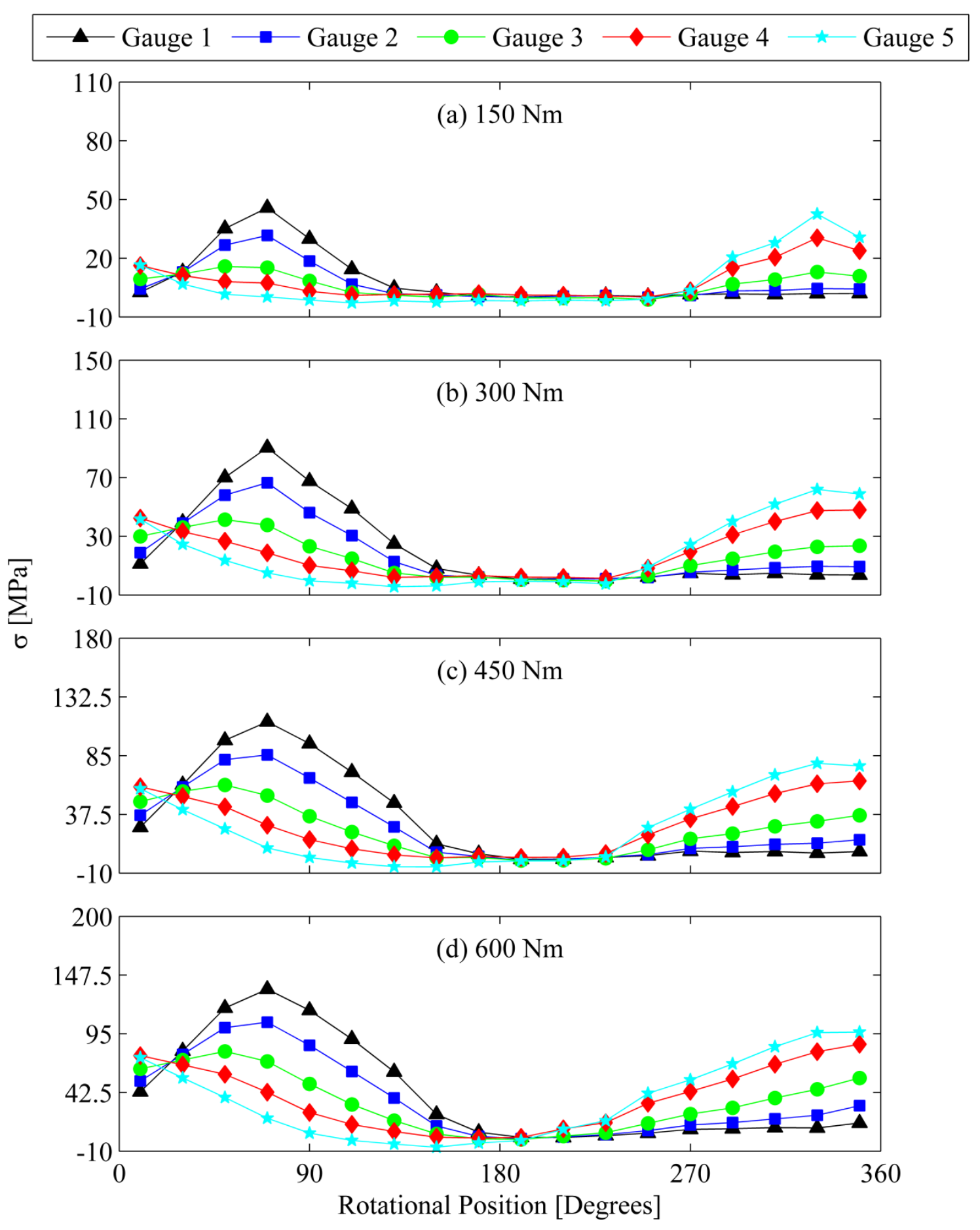

Figure A.5: Root stress of the first instrumented tooth for test \#4 of Table 2.3 under helical gear loading conditions at (a) $150 \mathrm{Nm}$, (b) $300 \mathrm{Nm}$, (c) $450 \mathrm{Nm}$, and (d) $600 \mathrm{Nm}$. 

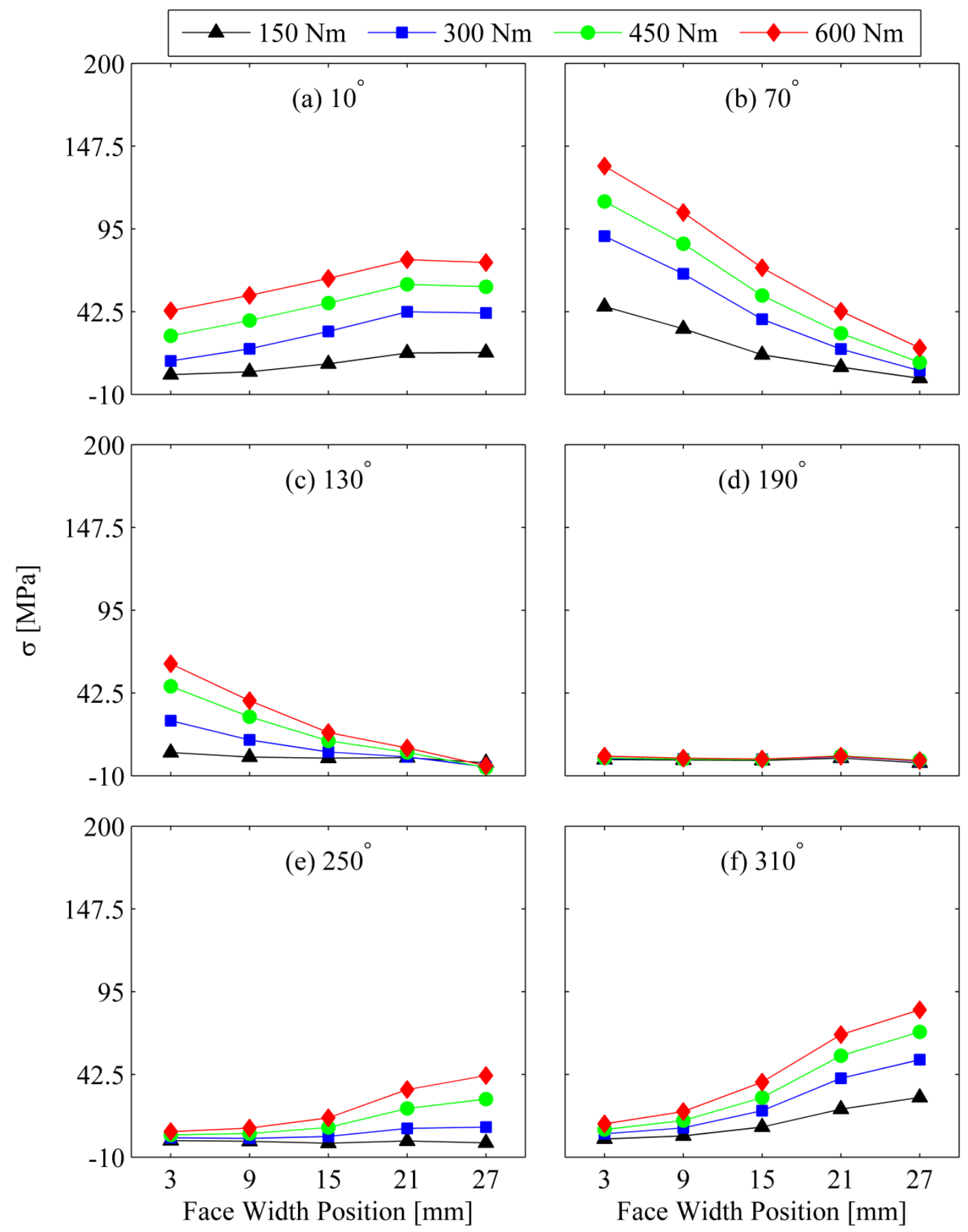

Figure A.6: Root stress of the first instrumented tooth for test \#4 of Table 2.3 under helical gear loading at angular positions of a) $10^{\circ}$, (b) $70^{\circ}$, (c) $130^{\circ}$, (d) $190^{\circ}$, (e) $250^{\circ}$, and (f) $310^{\circ}$. 


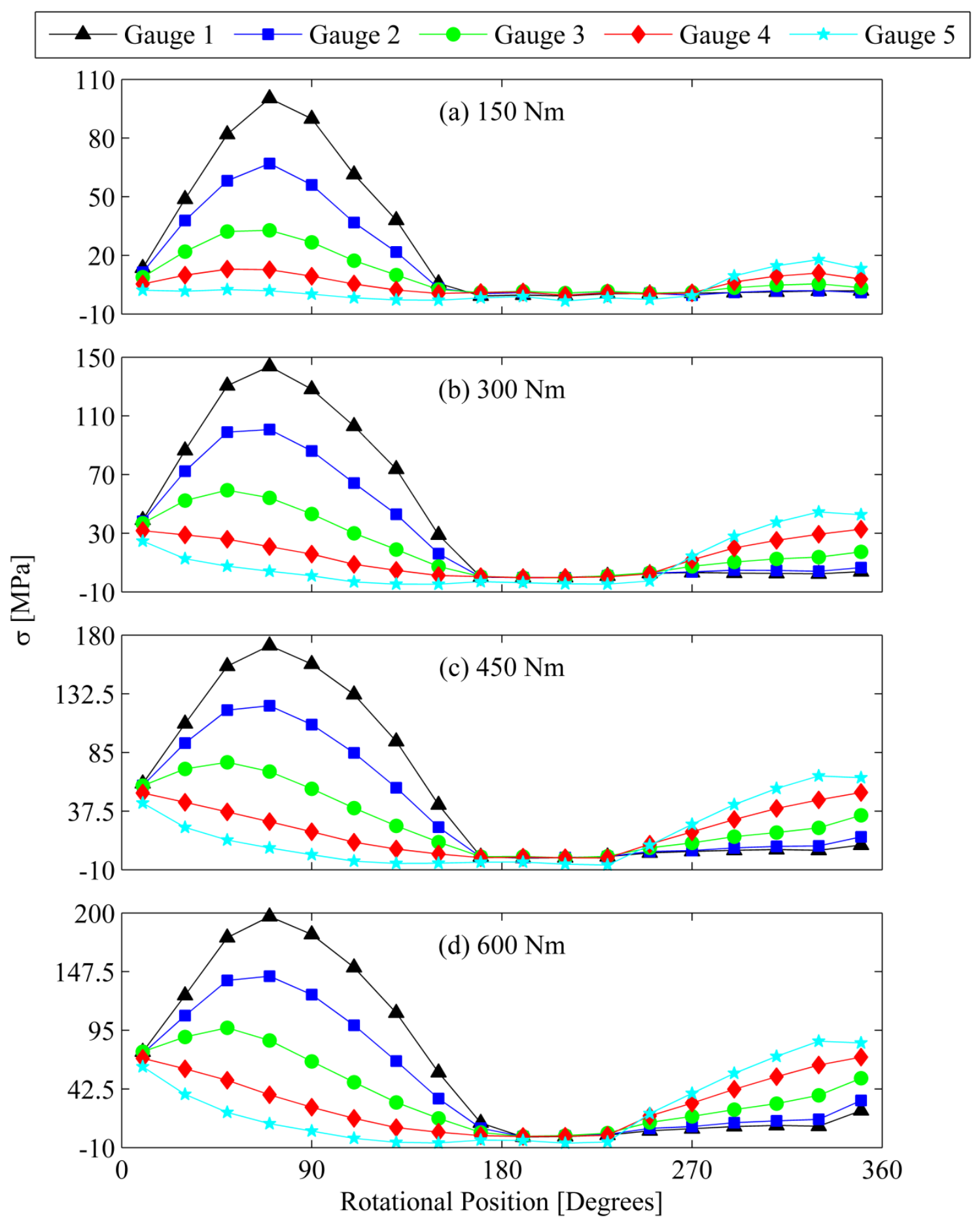

Figure A.7: Root stress of the second instrumented tooth for test \#4 of Table 2.3 under helical gear loading conditions at (a) $150 \mathrm{Nm}$, (b) $300 \mathrm{Nm}$, (c) $450 \mathrm{Nm}$, and (d) $600 \mathrm{Nm}$. 

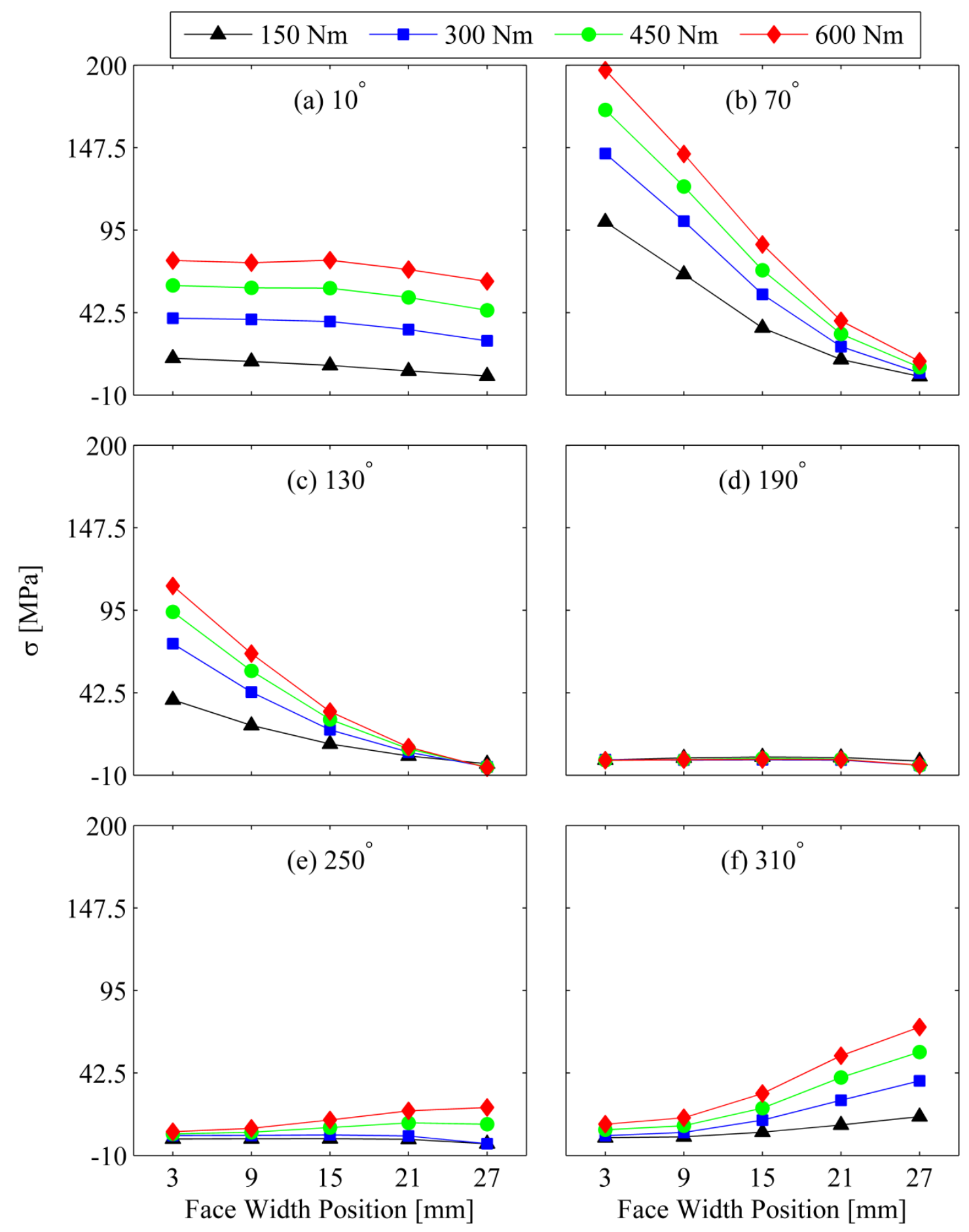

Figure A.8: Root stress of the second instrumented tooth for test \#4 of Table 2.3 under helical gear loading at angular positions of a) $10^{\circ}$, (b) $70^{\circ}$, (c) $130^{\circ}$, (d) $190^{\circ}$, (e) $250^{\circ}$, and (f) $310^{\circ}$. 